

\section{DISCLAIMER}

This report was prepared as an account of work sponsored by an agency of the United States Government. Neither the United States Government nor any agency Thereof, nor any of their employees, makes any warranty, express or implied, or assumes any legal liability or responsibility for the accuracy, completeness, or usefulness of any information, apparatus, product, or process disclosed, or represents that its use would not infringe privately owned rights. Reference herein to any specific commercial product, process, or service by trade name, trademark, manufacturer, or otherwise does not necessarily constitute or imply its endorsement, recommendation, or favoring by the United States Government or any agency thereof. The views and opinions of authors expressed herein do not necessarily state or reflect those of the United States Government or any agency thereof. 


\section{DISCLAIMER}

Portions of this document may be illegible in electronic image products. Images are produced from the best available original document. 


\section{NOTICE}

This report was prepared as an account of work sponsored by the United States Government. Neither the United States nor the United States Atomic Energy Commis. sion, nor any of their employees, nor any of their contractors, subcontractors, or their employees, makes any warranty, express or implied, or assumes any legal liability or responsibility for the accuracy, completeness or usefulness of any information, ap. paratus, product or process disclosed, or represents that its use would not infringe privately owned rights.

Printed in the United States of America

Available from

National Technical Information Service

U.S. Department of Commerce 5285 Port Royal Road

Springfield, Virginia 22161

Price: Printed Copy $\$ \underline{5.45}$; Microfiche $\$ 2.25$ 
HEDL TME 75-39

UC $79 i$

\section{SIMULATION OF COOLANT \\ TRANSPORT AND HEAT \\ EXCHANGE IN PIPE RUNS}

by

H. G. Johnson

May, 1975

This report was prepared as an account of work
sponsored by the United States Government. Neither
the United States nor the United States Energy
Research and Development Administration, nor any of
their employees, nor any of their contractors,
subcontractors, or their employees, makes any
warranty, express or implied, or assumes any legal
liability or responsibility for the accuracy, completeness
or usefulness of any information, apparatus, product or
process disclosed, or represents that its use would not
infringe privately owned rights.

Hanford Engineering Development Laboratory

Operated by the

Westinghouse

A Subsidiary of

Westinghouse Electric

for the United States

Hanford Company

Corporation

Atomic Energy Commission

Contract No. AT[45-1]-2170 
HEDL TME 75-39

UC $79 i$

\title{
SIMULATION OF COOLANT TRANSPORT AND HEAT EXCHANGE IN PIPE RUNS
}

\begin{abstract}
Pipe mus for sodium coolant systems are satisfactorily simulated by simplified models with no more than 24 axial by 3 radial nodes, consisting of coolant, pipe wall and ambient nodal points. Heat losses from the insulated pipe to its surroundings are included by a constant heat transfer resistance from the pipe's outside surface to the ambient. The best accuracy for simplified models is obtained by simulating the $\partial T / \partial X$ derivative by three-point difference approximations. An explicit numerical integration method is used with these simplified models.

The simplified models are checked against detailed 48 axial by 5 or 8 radial node reference models, which use a four-point Adams-Moulton predictorcorrector numerical integration method.

A generalized computer program, which is based on the selected simplified model, has been written for incorporation as a subroutine in reactor/heat transport system simulation codes.
\end{abstract}


LIST OF FIGURES ........................ iv

LIST OF TABLES .................................... vii

INTRODUCTION ........................... 1

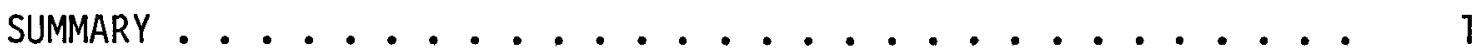

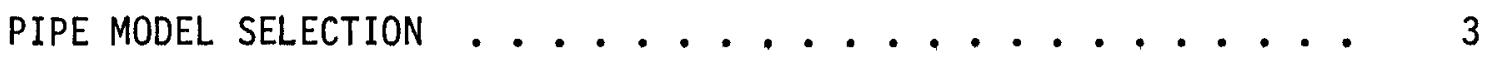

Reference Model for Comparison ............. 3

Rectangular Integration Models .......... 10

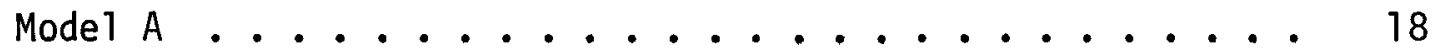

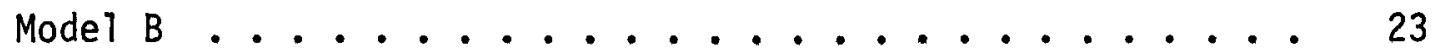

Model C .......................... 24

Additional Verification of Model C . . . . . . . . 24

Model A1 ........................ 37

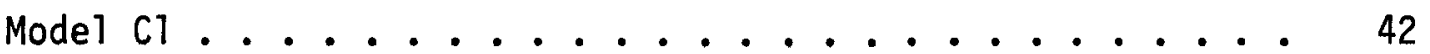

Selection of Simplified Model . . . . . . . . . 42

GENERALIZED PIPE SUBROUTINE . . . . . . . . . . . . 55

Input Data for Program MAIN . . . . . . . . . 57

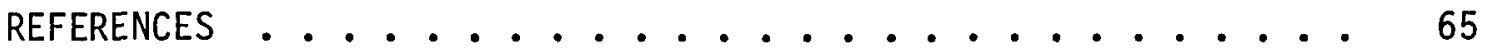

APPENDIX A - PROGRAM LISTING ............... A-1 
1 Coolant Outlet Temperatures. 2, 3, 5 Radial Nodes. Physical Properties and Heat Transfer Based on Average Temperatures. Down Ramps on Coolant Inlet Temperature and Flow. 12 Axial Nodes Used.

2 Model A Sodium Outlet Temperatures. Axial Nodes Varied. Fixed Integration Time Step of 0.1 Seconds. Transient Based on Conditions Set IA, Table 1. Down Ramps in 16 in. $x 450 \mathrm{ft}$ Pipe.

3 Model A Sodium Outlet Temperatures. Axial Nodes Varied. Integration Time Step at 0.99 of Stability Limit. Transient Based on Conditions Set IA, Table 1. Down Ramps in 16 in. $\times 450 \mathrm{ft}$ Pipe.

4 Model B Sodium Outlet Temperatures. Axial Nodes Varied. Integration Time Step at 0.99 of Stability Limit. Transient Based on Conditions Set IA, Table 1. Down Ramps in 16 in. $x 450 \mathrm{ft}$ Pipe.

5 Model C Sodium Outlet Temperatures. Axial Nodes Varied. Combines Features of $A$ and $B$ Models. Transient Based on Conditions Set IA, Table 1. Down Ramps in 16 in. $x$ $450 \mathrm{ft}$ Pipe.

6 Model C Sodium Outlet Temperatures. Axial Nodes Varied. Transient Based on Conditions Set IB, Table 1. Constant Flow Rate of $1600 \mathrm{lb} / \mathrm{sec}$. $200^{\circ} \mathrm{F}$ Inlet Coolant Temperature Down Ramp

7 Model C Sodium Outlet Temperatures. Axial Nodes Varied. Transient Based on Conditions Set IC, Table 1. Down/Up Ramps on Flow Rate. Down/Up Ramps on Inlet Sodium Temperature

8 Model C Sodium Outlet Temperatures. Axial Nodes Varied. Transient Based on Conditions Set ID, Table 1. Inlet Coolant Temperature Ramp of 1000 to $800^{\circ} \mathrm{F}$ from 70 to 110 sec. Flow Ramp of 1600 to $160 \mathrm{lb} / \mathrm{sec}$ from 2 to $27 \mathrm{sec}$.

9 Model C Sodium Outlet Temperatures. Axial Nodes Varied. Transient Based on Conditions Set IE, Table 1. Ramp Inlet Coolant Temperature at $-5^{\circ} / \mathrm{sec}$ from 0 to $40 \mathrm{sec}$. Flow Constant at $160 \mathrm{lb} / \mathrm{sec}$. 
10 Model C Sodium Outlet Temperatures. Axial Nodes Varied. Transient Based on Conditions Set IIA, Table 1. $200^{\circ} \mathrm{F}$ Inlet Coolant Temperature Down Ramp. Flow Ramp of 1600 to $160 \mathrm{~Tb} / \mathrm{sec}$ from 2 to $27 \mathrm{sec}$.

11 Model C Sodium Outlet Temperatures. Axial Nodes Varied. Transient Based on Conditions Set IIB, Table 1. $200^{\circ} \mathrm{F}$ Inlet Coolant Temperature Down Ramp. Constant Flow Rate of $1600 \mathrm{lb} / \mathrm{sec}$.

12 Model C Sodium Outlet Temperatures. Axial Nodes Varied. Transient Based on Conditions Set IIIA, Table 1. $200^{\circ} \mathrm{F}$ Inlet Coolant Temperature Down Ramp. Flow Ramp of 400 to $40 \mathrm{lb} / \mathrm{sec}$ from 2 to $27 \mathrm{sec}$.

13 Model C Sodium Outlet Temperatures. Axial Nodes Varied. Transient Based on Conditions Set IIIB, Table 1. $200^{\circ} \mathrm{F}$ Inlet Coolant Temperature Down Ramp. Flow Constant at $400 \mathrm{lb} / \mathrm{sec}$.

14 Model C Sodium Outlet Temperatures. Axial Nodes Varied. Transient Based on Conditions Set IVA, Table $1.200^{\circ} \mathrm{F}$ Inlet Coolant Temperature Down Ramp. Ramp Flow from 31.6 to $3.16 \mathrm{lb} / \mathrm{sec}$ from 2 to $27 \mathrm{sec}$.

15 Model Al Sodium Outlet Temperatures. Transient Based on Conditions Set IA, Table 1. Inlet Coolant Temperature Ramp of 1000 to $800^{\circ} \mathrm{F}$ from 0 to $10 \mathrm{sec}$. Flow Ramp of 1600 to $160 \mathrm{lb} / \mathrm{sec}$ from 2 to $27 \mathrm{sec}$.

16 Model A1. Use Stability Limit. Sodium Outlet Temperatures. Transient Based on Conditions Set IA, Table 1. Inlet Coolant Temperature Ramp of 1000 to $800^{\circ} \mathrm{F}$ from 0 to 10 sec. Flow Ramp of 1600 to $160 \mathrm{lb} / \mathrm{sec}$ from 2 to $27 \mathrm{sec}$.

17 Model Al with Stability Limits. Sodium Outlet Temperatures. Transient Based on Conditions Set IA, Table 1. Inlet Coolant Temperature Ramp of 1000 to $800^{\circ} \mathrm{F}$ from 0 to 10 sec. Flow Ramp of 1600 to $160 \mathrm{lb} / \mathrm{sec}$ from 2 to $27 \mathrm{sec}$.

18 Model Al with Stability Limits. Sodium Outlet Temperatures. Transient Based on Conditions Set IB, Table 1. Inlet Coolant Temperature Ramp of 1000 to $800^{\circ} \mathrm{F}$ from 0 to 10 sec. Flow Rate Constant at $1600 \mathrm{1b} / \mathrm{sec}$. 
19 Mode1 Al with Stability Limits. Sodium Outlet Temperatures. Transient Based on Conditions Set IC, Table 1. Down/Up Ramps on Inlet Sodium Temperature. Down/Up Ramps on Flow Rate.

20 Mode1 Al with Stability Limits. Sodium Outlet Temperatures. Transient Based on Conditions Set ID, Table 1. 1000 to $800^{\circ} \mathrm{F}$ Temperature Ramp from 70 to $110 \mathrm{sec}$. Flow Ramp of 1600 to $160 \mathrm{lb} / \mathrm{sec}$ from 2 to $27 \mathrm{sec}$.

21 Model Al with Stability Limits. Sodium Outlet Temperatures. Transient Based on Conditions Set IE, Table 1. Inlet Coolant Temperature Ramp of 1000 to $800^{\circ} \mathrm{F}$ from 0 to $40 \mathrm{sec}$. Constant Flow Rate of $160 \mathrm{1b} / \mathrm{sec}$.

22 Mode1 Al with Stability Limits. Sodium Outlet Temperatures. Transient Based on Conditions Set IIA, Table 1. Inlet Coolant Temperature Ramp of 1000 to $800^{\circ} \mathrm{F}$ from 0 to $10 \mathrm{sec}$. Flow Ramp of 1600 to $160 \mathrm{lb} / \mathrm{sec}$ from 2 to $27 \mathrm{sec}$.

23 Mode1 Al with Stability Limits. Sodium Outlet Temperatures. Transient Based on Conditions Set IIB, Table 1. Inlet Coolant Temperature Ramp of 1000 to $800^{\circ} \mathrm{F}$ from 0 to $10 \mathrm{sec}$. Flow Rate Constant at $1600 \mathrm{lb} / \mathrm{sec}$.

24 Model Al with Stability Limits. Sodium Outlet Temperatures. Transient Based on Conditions Set IIIA, Table 1. Inlet Coolant Temperature Ramp of 1000 to $800^{\circ} \mathrm{F}$ from 0 to $10 \mathrm{sec}$. Flow Ramp of 400 to $40 \mathrm{lb} / \mathrm{sec}$ from 2 to $27 \mathrm{sec}$.

25 Model A1 with Stability Limits. Sodium Outlet Temperatures. Transient Based on Conditions Set IIIB, Table 1. InTet Coolant Temperature Ramp of 1000 to $800^{\circ} \mathrm{F}$ from 0 to $10 \mathrm{sec}$. Flow Constant at $400 \mathrm{lb} / \mathrm{sec}$.

26 Model Al with Stability Limits. Sodium Outlet Temperatures. Transient Based on Conditions Set IVA, Table 1. Inlet Coolant Temperature Ramp of 1000 to $800^{\circ} \mathrm{F}$ from 0 to $10 \mathrm{sec}$. Ramp Flow from 31.6 to $3.16 \mathrm{lb} / \mathrm{sec}$ from 2 to $27 \mathrm{sec}$.

27 Model $\mathrm{Cl}$ with Stability Limits. Sodium Outlet Temperatures. Transient Based on Conditions Set IA, Table 1. Inlet Coolant Temperature Ramp of 1000 to $800^{\circ} \mathrm{F}$ from 0 to $10 \mathrm{sec}$. Flow Ramp of 1600 to $160 \mathrm{lb} / \mathrm{sec}$ from 2 to $27 \mathrm{sec}$. 
LIST OF FIGURES (Cont'd.)

Figure

$\underline{\text { Page }}$

29 FORCE Flow Chart

60

30 LEG Flow Chart

60

31 PIPE Flow Chart

61

32 UCOEF Flow Chart

62 


\section{LIST OF TABLES}

Table

$\underline{\text { Page }}$

1 Sets of Conditions Used in Model Development

2 Model A Sodium Outlet Errors with the Integration Time Step Equal to 0.99 of the Limiting Stability Value and for Table 1 Conditions Set IA

3 Model B Sodium Outlet Errors with the Integration Time Step Equal to 0.99 of the Limiting Stability Value and for Table 1 Conditions Set IA

4 Mode1 $C$ Sodium Outlet Errors with Table 1 Conditions Set IA

5 Final Checkout of Model C

6 Model Al Sodium Outlet Temperatures with a Fixed 0.1 Second Integration Time Step and for Table 1 Conditions Set IA

7 Final Checkout of Model Al

8 Key Features of PIPE Subroutine

9 Auxiliary Subroutines and Functions for PIPE 


\section{INTRODUCTION}

A11 reactor system simulation models necessarily must include piping models. During the design stage of a project, it is sometimes acceptable to allow for coolant transport only, disregarding heating/cooling effects entirely. But for analyzing system process performance for normal perturbations and various upset events, it is necessary that heat exchange between the coolant, pipe wall, insulation and surroundings be also accounted for, otherwise significant inaccuracies may occur for process control and plant protection trips which are temperature-dependent.

This study was carried out to develop a simplified pipe model for accurate heat transfer and coolant transport simulation. The developed model could be used to replace the pipe model, which is based on coolant transport only, in an existing reactor/heat transport system program. ${ }^{(4)}$

\section{SUMMARY}

A relatively simple model is developed for simulation of heat transfer and coolant transport for insulated piping runs between components. Satisfactory accuracy is obtained using only 3 radial nodes and no more than 24 axial nodes. Coolant, pipe wall and a constant temperature ambient node are the three radial nodal points. The model uses an explicit numerical integration scheme, with variable time steps depending on 7 imiting values for numerical stability. The $\partial T / \partial X$ derivatives in the coolant heat balance equations are best approximated by a three-point difference formula.

The selected simplified model includes constant heat transfer resistance from the pipe's outer surface to the ambient nodal point, which is at constant temperature with distance, but not necessarily time. The model works equally well with or without a gas gap between the pipe and insulation. For sodium piping systems at high temperatures, the gas gap resistance is unimportant because of the high radiation heat transfer across the gap such that the insulation's inside surface temperature is nearly equal to the pipe's outside surface. On the other hand, for low temperature systems, the gas gap may be treated as having a heat transfer resistance equal to insulation of the same dimensional characteristics. These simplifications are practical because the 
coolant and pipe wall temperatures are quite insensitive to what is happening on the outside of the pipe during transients.

As a rough rule of thumb, the number of axial nodes should be about equal to the coolant transport time at the design flow rate of the coolant in the pipe. Thus, only a few axial nodes are needed for short pipe runs.

The simplified models are checked against a detailed 48 axial by 5 radial node reference model, which uses an implicit, four-point, predictor/corrector numerical integration method. The five radial nodes are coolant, pipe wall, insulation, insulation surface and ambient. This five-node model gives coolant and pipe wall temperatures which agree within $0.5^{\circ} \mathrm{F}$ of corresponding temperatures using a more complex eight-radial node model. The three additional nodes are pipe outside surface, gas gap, and insulation inside surface. Because sodium systems at high temperatures are investigated, the gas gap resistance to heat transfer is neglected in the five radial node reference model.

The outlet coolant temperatures by the selected simplified explicit solution model, for a variety of transients and piping systems, differ from the reference by no more than $5^{\circ} \mathrm{F}$ at any given time; the simplified model's temperatures also lead or lag the reference by no more than five seconds for any given temperature. The selected simplified model is judged to be satisfactory on the basis of these small differences.

The selected simplified model is used in the development of a generalized computer program for simulation of heat transfer and coolant transport. It has been written as a subroutine for incorporation in an overall reactor/heat transport system simulation code. (4) The subroutine is programmed for positive or negative flow rates in any pipe run between components. It is to be used only for insulated pipes, which may or may not contain a gas gap between the pipe and insulation. Pipe runs between components may be divided into as many as four connecting and continuous legs, each with its own ambient temperature and dimensional data. This subdivision of pipe runs provides for good utilization of computer memory, which might otherwise be wasted. 


\section{PIPE MODEL SELECTION}

The objective of this study is to develop a simplified, yet accurate, pipe model for proper simulation of heat exchange and coolant transport. Because of the large number of individual pipe runs between components in the heat transport system, it is essential that the number of axial and radial nodes in any computer model be minimized to avoid an unacceptable burden on the computer's memory locations and to enable realistic computational times.

\section{Reference Model for Comparison}

A prerequisite to model selection is the development of a detailed reference model for comparison purposes. The selected reference model, which includes 48 axial and 5 radial nodes, is set up for an implicit solution of the set of ordinary differential equations using a fourth order Adams-Moulton predictor-corrector routine $^{(1)}$ for numerical integration. Preliminary computer runs were made considering 6, 12, 24, and finally 48 axial nodes, with all other parameters fixed. Significant differences were observed between the 6-, 12- and 24-node models, but the 24-node model was seen to be essentially identical to the one with 48 nodes, which means that 48 axial nodes is certainly sufficient for the reference model. The tolerance on the truncation error is set very small for the reference cases to eliminate numerical errors as far as practicable; the maximum allowable absolute difference between the predicted and corrected temperatures is on 7 y $0.01^{\circ} \mathrm{F}$.

The radial nodal points are coolant, pipe wall, insulation, insulation surface, and ambient.

The basic heat balance equations are given in equations (1) through (4) wherein axial heat conduction and mixing are neglected, and a constant ambient temperature with distance is assumed. The flow rate is constant with distance for the nearly incompressible liquid sodium coolant.

$$
\left(V{ }^{-} \rho C\right)_{C j} \dagger_{c j}=-(W C)_{c j} \frac{\partial T_{C j}}{\partial x}-\left(U A^{-}\right)_{C / p j}\left(T_{c j}-T_{p j}\right)
$$




$$
\begin{gathered}
\left(V^{\circ} \rho C\right)_{p j} \dagger_{p j}=\left(U^{-}\right)_{c / p j}\left(T_{c j}-T_{p j}\right)-\left(U A^{-}\right)_{p / i j}\left(T_{p j}-T_{i j}\right) \\
\left(V^{\circ} \rho C\right)_{i j} \dagger_{i j}=\left(U A^{-}\right)_{p / i j}\left(T_{p j}-T_{i j}\right)-\left(U A^{-}\right)_{i / s j}\left(T_{i j}-T_{s j}\right) \\
0=\left(U A^{-}\right)_{i / s u}\left(T_{i j}-T_{s j}\right)-\left(U A^{-}\right)_{s / a j}\left(T_{s j}-T_{a}\right)
\end{gathered}
$$

where

$$
\begin{aligned}
& A^{-}=\text {unit heat transfer area, sq } \mathrm{ft} / \mathrm{ft} \\
& C=\text { specific heat, Btu/lb- }{ }^{\circ} \mathrm{F} \\
& T=\text { temperature, }{ }^{\circ} \mathrm{F} \\
& U^{-}=\text {overall heat transfer coefficient, Btu/ }\left(\text { sec-sq } \mathrm{ft}-{ }^{\circ} \mathrm{F}\right) \\
& V^{-}=\text {unit volume, cu } \mathrm{ft} / \mathrm{ft} \\
& W=\text { coolant flow } \mathrm{rate}, \mathrm{lb} / \mathrm{sec} \\
& \rho=\text { density, } 1 \mathrm{~b} / \mathrm{cu} \mathrm{ft}
\end{aligned}
$$

and subscripts,

$$
\begin{aligned}
& \mathrm{a}=\text { ambient } \\
& \mathrm{c}=\text { coolant } \\
& \mathrm{c} / \mathrm{p}=\text { coolant to pipe } \\
& \mathrm{j}=\text { insulation } \\
& \mathrm{i} / \mathrm{s}=\text { insulation to surface } \\
& j=\text { axial nodal location } \\
& \mathrm{p}=\text { pipe } \\
& \mathrm{p} / \mathrm{i}=\text { pipe to insulation } \\
& \mathrm{s}=\text { surface } \\
& \mathrm{s} / \mathrm{a}=\text { surface to ambient. }
\end{aligned}
$$

The partial derivative $\partial T_{c} / \partial x$ is approximated by three-point formula alternating between central and backward differences as recommended in reference (2):

for even numbered nodal points,

$$
\frac{\partial T_{c j}}{\partial x}=\frac{T_{c j+1}-T_{c j-1}}{2 \Delta X}
$$


and for odd numbered nodal points,

$$
\frac{\partial T_{c j}}{\partial X}=\frac{3 T_{c j}-4 T_{c j-1}+T_{c j-2}}{2 \Delta X}
$$

where

$$
\Delta X=\text { node length, ft. }
$$

Model convention is that flow is positive in the direction of increasing axial nodal point numbers.

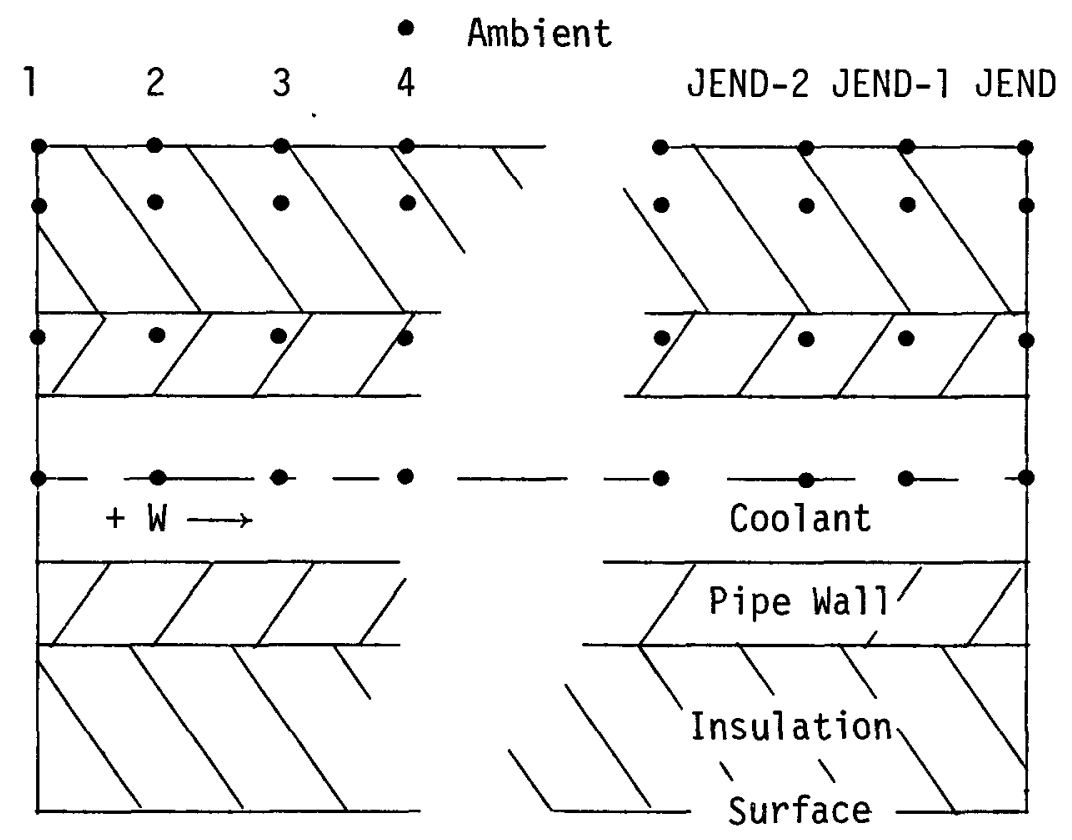

Sketch of Reference Model

An even number of nodes is a requirement in order that the last node, JEND, is odd and therefore consistent with the use of the backward difference formula for uneven-numbered nodal points.

Physical properties and heat transfer coefficients are determined using local temperatures, instead of being based on average axial temperatures. 
A modified Lyon's equation is used for the coolant film coefficient

$$
\begin{aligned}
\mathrm{Nu}_{c} & =5.0+0.025\left(\overline{\Psi P e_{c}}\right)^{0.8} \\
& =\frac{h_{c} D_{i}}{k_{c}}
\end{aligned}
$$

where

$$
\begin{aligned}
\mathrm{Nu}= & \text { Nusselt number } \\
\mathrm{Pe}= & \text { Peclet number } \\
\bar{\Psi}= & \text { average value of ratio of diffusivity for heat transfer } \\
& \text { to diffusivity for momentum transfer } \\
D_{i}= & \text { pipe inside diameter, } \mathrm{ft} \\
\mathrm{h}_{\mathrm{C}}= & \text { film coefficient, } \mathrm{Btu} /\left(\mathrm{sec}-\mathrm{sq} \mathrm{ft}-{ }^{\circ} \mathrm{F}\right) \\
K_{C}= & \text { coolant thermal conductivity, Btu/(sec-ft- } \left.{ }^{\circ} \mathrm{F}\right) .
\end{aligned}
$$

The $\bar{\Psi}$ corrector term is evaluated as a function of Reynolds number by the method of Dwyer. (3)

The overall heat transfer coefficients are as follows:

$$
\begin{gathered}
\frac{1}{U_{c / p}}=\frac{1}{h_{c}}+\frac{D_{i}}{2 K_{p}} \ln \frac{D_{p}}{D_{i}} \\
\frac{1}{U_{p / i}}=\frac{D_{0}}{2 K_{p}} \ln \frac{D_{0}}{D_{p}}+\frac{D_{0}}{2 K_{i}} \ln \frac{D_{i n}}{D_{0}} \\
U_{i / s}=\frac{K_{i}}{D_{s}} \frac{D_{s}}{D_{i n}} \\
U_{s / a}=h_{s c}+h_{s r}
\end{gathered}
$$


where

$$
\begin{aligned}
& D_{i}=\text { pipe inside diameter, } f t \\
& D_{i n}=\text { diameter at centerline of insulation, } \mathrm{ft} \\
& D_{0}=\text { pipe outside diameter, } f t \\
& D_{p}=\text { diameter at centerline of pipe wall, ft } \\
& D_{S}=\text { insulation outside diameter, } \mathrm{ft} \\
& h_{\text {sc }}=\text { convection heat transfer coefficient at insulation } \\
& \text { surface, Btu/ (sec-sq ft- } \left.{ }^{\circ} \mathrm{F}\right) \\
& h_{s r}=\text { equivalent radiation heat transfer coefficient from } \\
& \text { insulation surface, Btu/(sec-sq } \left.\mathrm{ft}-{ }^{\circ} \mathrm{F}\right) \\
& \left.K=\text { thermal conductivity, Btu/(sec-ft- }{ }^{\circ} \mathrm{F}\right)
\end{aligned}
$$

The insulation surface coefficients are temperature dependent:

$$
\begin{gathered}
h_{s c}=0.27\left(T_{s j}-T_{a}\right)^{0.25} \\
h_{s r}=\frac{0.173 \times 10^{-8} \mathcal{J}\left[\left(460+T_{s j}\right)^{4}-\left(460+T_{a}\right)^{4}\right]}{T_{s j}-T_{a}}
\end{gathered}
$$

A value of 0.4236 is used for the overall interchange factor for the two surfaces.

A gas gap may be found between the pipe outside surface and insulation in some installations. The heat accumulation term can be ignored for the gas, and its effect on overall heat transfer allowed for in the overall coefficients. In this case, equations (2) and (3) can be replaced by:

$$
\begin{aligned}
& \left(V^{\circ} \rho C\right)_{p j} \dagger_{p j}=\left(U A^{-}\right)_{C / p j}\left(T_{c j}-T_{p j}\right)-\left(U A^{-}\right){ }_{p / i j}\left(T_{p j}-T_{i j}\right) \\
& \left(V^{-} \rho C\right)_{i j} \dot{\top}_{i j}=\left(U A^{-}\right)_{p / i j}\left(T_{p j}-T_{i j}\right)-\left(U A^{-}\right)_{i / s j}\left(T_{i j}-T_{s j}\right)
\end{aligned}
$$


where

$$
\begin{aligned}
& \left(U A^{-}\right)^{*}{ }_{p / i j}=\frac{D}{N} \\
& D=\left(U A_{p / s_{1}}^{-} U A_{s_{1} / g}^{-} U A_{g / s_{2}}^{-} U A_{s_{2} / i}^{-}+U A_{p / s_{1}}^{-} U A_{s_{1} / s_{2}} U A_{s_{1} / g} U A_{s_{2} / i}^{-}+\right. \\
& \left.U A_{p / s_{1}}^{-} U A_{s_{1} / s_{2}}^{-} U A_{g / s_{2}}^{-} U A_{s_{2} / i}^{-}\right)_{j} \\
& N=\left(U A_{p}^{-} / s_{1} U A_{s_{1} / g}^{-} U A_{s_{1} / s_{2}}^{-}+U A_{p / s_{1}}^{-} U A_{s_{1} / g}^{-} U A_{g / s_{2}}^{-}+\right. \\
& U A_{p / s_{1}}^{-} U A_{s_{1} / g}^{-} U A_{s_{2} / i}^{-}+U A_{p / s}^{-} U A_{g}^{-} s_{s_{2}} U A_{s_{1} / s_{2}}^{-}+ \\
& U A_{p / s_{1}}^{-} U A_{g / s_{2}}^{-} U A_{s_{2} / i}^{-}+U A_{s_{1} / g}^{-} U A_{g / s_{2}}^{-} U A_{s_{2} / i}^{-}+ \\
& \left.U A_{s_{1} / s_{2}}^{-} U A_{s_{1} / g}^{-} U A_{s_{2} / i}^{-}+U A_{s_{1} / s_{2}}^{-} U A_{g / s_{2}}^{-} U A_{s_{2} / i}^{-}\right)_{j}
\end{aligned}
$$

subscripts,

$$
\begin{aligned}
& g=\text { gas gap node } \\
& s_{1}=\text { outside surface of pipe node } \\
& s_{2}=\text { inside surface of insulation node. }
\end{aligned}
$$

The composite UA coefficient of equation (15) results from the series/ parallel heat transfer with radiation across the gap and conduction (or convection) to and from the surfaces to the gas. It is derived, along with equations $(2 A)$ and $(3 A)$, assuming zero heat storage for the surface nodes and gas gap node. Good approximations of the temperature-dependent heat transfer and radiation coefficients can be obtained using the pipe node temperature, thus eliminating the need to compute actual surface and gas temperatures.

A series of computer runs was made to determine the importance of explicitly including the gas gap resistance in the calculational model. It was found that all axial coolant and pipe wall transient temperatures are 
within $0.5^{\circ} \mathrm{F}$ of the values calculated by an eight-radial node model, based on equations (2A) and ( $3 A)$ if a 1 -inch gas gap is assumed to have the same heat transfer resistance as insulation of the same dimensional characteristics. Better agreement results by neglecting the gas gap resistance entirely for the relatively high temperature sodium coolant system. In the latter case, the difference is less than $0.1^{\circ} \mathrm{F}$. It is concluded that a five-radial node model is completely satisfactory as the reference model for pipe systems with or without a gas gap between the pipe and insulation.

Initial exploratory studies were made using the detailed reference model to see what simplifications might be made concerning heat transfer calculations and additional simplifications on the number of radial nodes. These studies were done using the following set of conditions:

- 28-inch OD x 27.25-inch ID x 150-ft long pipe

- Down ramp on sodium inlet temperature from 1000 to $800^{\circ} \mathrm{F}$ from zero to 10 seconds

- Down ramp on coolant flow rate from 1600 to $160 \mathrm{lb} / \mathrm{secona}$ from 2 to 27 seconds

- 4-inch insulation thickness and no gas gap

- $0.075 \mathrm{Btu} /\left(\mathrm{hr}-\mathrm{ft}-{ }^{\circ} \mathrm{F}\right)$ insulation conductivity

- $100^{\circ} \mathrm{F}$ ambient temperature

- 12 axial nodes.

The unimportance of using local physical properties and local heat transfer coefficients is established by comparing a computer run with local conditions used versus a run in which volume average temperatures are used for physical properties and heat transfer. Computer output shows that there is less than a $1^{\circ} \mathrm{F}$ difference between corresponding temperatures at any given time for the two comparative cases. This small difference is judged to be insignificant.

Examination of computer output for these exploratory runs also shows that the insulation and insulation surface temperatures are quite insensitive to what is happening inside the pipes, at least for the first six minutes of the transient: the runs were stopped at that time. It suggests that the initial steady-state insulation temperature could be used as a constant temperature heat sink throughout the transient, or that the heat transfer resistance from 
the pipe wall surface to the ambient could be kept constant throughout the transient at the initial steady-state value. The latter assumption is preferable because it probably can be applied with reasonably good accuracy even for long transients and for cases in which the coolant temperature decays to values below the initial insulation temperature. The difference in transient results is insignificant between the two assumptions for the conditions of the exploratory computer runs.

A three-radial node model of coolant, pipe wall, and constant insulation is checked against a detailed twelve-axial, five-radial node model with the results shown in Figure 1. Also shown is the result of a still further possible simplification of lumping coolant and pipe wall together (i.e., combining equations (1) and (2) by assuming the same temperature exists for coolant and pipe wal1); this produces a two-radial node model including a constant insulation node temperature. As shown in Figure 1, the two-node model is inadequate, but the three-node model is very satisfactory, being in nearly perfect agreement with the detailed five-radial node model.

The suggested simplifications on the use of average properties and heat transfer coefficients and three radial nodes are included in the development of the rectangular integration model to be used in the heat transport system (HTS) simulation.

The inadequacy of a pure transport delay model is also shown in Figure 1. A transport delay model may be satisfactory for simulations directed toward component design in that the rate of temperature change may be conservatively high, but it is an inadequate model when system process performance is to be determined.

Rectangular Integration Models

The pipe models developed here are to be incorporated in a reactor/HTS FFTF model which will make extensive use of the LMFBR Demonstration Plant Simulation Model (DEMO), which is described in reference (4). The explicit rectangular integration method for pipe simulation is selected because it is the method used in the DEMO computer program for the other components. An important consideration in this pipe model development is that the main part 
FIG. 1. COOLANT OUTLET TEMPERATURES. 2, 3,5 RAOIPL NOCES

PHYSICAL PROPS. AND HEAT TRANSFER BASED ON PIVG. TEMPERATURES.

DOWN RAMPS ON COOLANT INLET TEMPERATURE PND FLOW.

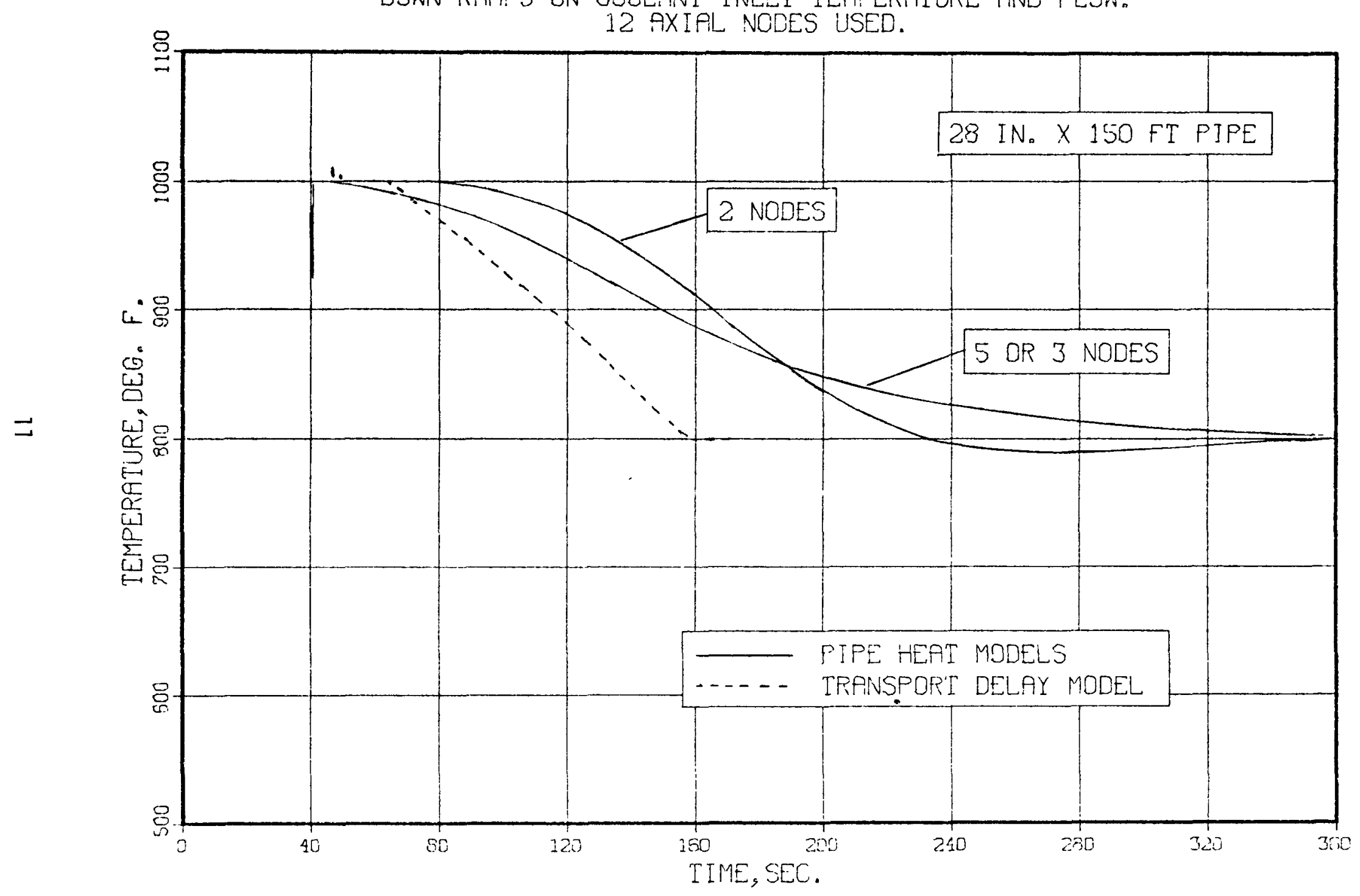


of the reactor/HTS simulation will be operating with a relatively small, fixed integration time step as compared to a much larger allowable time step for pipe calculations. Hence, in order to minimize computer run times, the pipe models are developed to use a time step for each pipe leg in the HTS model different than that used for other components or processes, and including other pipe legs.

The previously suggested simplifications are used whenever they can be justified. Thus, to start with, the rectangular integration models are arranged for three radial nodes, including a fixed sink temperature node in both time and distance and physical properties and heat transfer coefficients are based on volume average coolant and pipe wall temperatures. The preliminary exploratory computer runs using the reference mode1 show that the insulation, pipe wall, and coolant temperatures are nearly constant with distance for the heavily insulated pipes and for a wide range of flow rates. These early runs also show that there is less than a $1^{\circ} \mathrm{F}$ temperature difference between the coolant and pipe wall at steady-state conditions. As a result, for simplicity, initial conditions are set up for all coolant and pipe wall node temperatures equal to the inlet coolant temperature, and the corresponding insulation and surface temperatures are calculated accordingly using the heat transfer equations (10) through (14).

The criteria for acceptance of any simplified model is on the degree of comparison to the 48 axial by 5 radial node reference model with its use of local temperatures for physical properties and heat transfer coefficients at each nodal point. Two things must be satisfied before the simplified model is judged to be satisfactory.

1. The coolant temperature difference at any point in time between corresponding points is less than about $5^{\circ} \mathrm{F}$. This tolerance is consistent with the accuracy of actual temperature measurements of sodium coolant in HTS pipes at the temperature levels of interest here. The measurement error is about twice the tolerance (i.e., about $10^{\circ} \mathrm{F}$ ).

2. The simplified model's outlet sodium temperature must not lead or lag the reference model's temperature by more than about 5 seconds. 
This is especially important at the start of the transients in order to get good initial representation of coolant transport time.

Finite difference forms of equations (1) through (4) are arranged as shown below using an explicit formulation on a model with the coolant nodes staggered relative to the pipe wall nodes (see sketch below), and for a constant heat transfer resistance from the pipe wall outside surface to the ambient. It is necessary to assume a zero heat storage term for the insulation in the development of the three radial node model. Equation (16) includes a two-point difference approximation of the $\partial T / \partial X$ derivative.

$$
\begin{aligned}
& \frac{\left(V_{p} C\right)_{c}}{\Delta t}\left[\frac{\left(T_{c j}-T_{c j}\right)+\left(T_{c j-1}-T_{c j-1}\right)}{2}\right]= \\
& -W C_{c}\left[\frac{\left(T_{c j}^{\prime}-T_{c j-1}^{\prime}\right)+\left(T_{c j}-T_{c j-1}\right)}{2}\right] \\
& -\frac{(U A) c / p}{2}\left\{\left[\frac{T_{j}+T_{c j-1}^{\prime}}{2}-T_{p j}\right]+\left[\frac{T_{c j}+T_{c j-1}}{2}-T_{p j}\right]\right\} \\
& \frac{\left(V_{p} C\right)_{p}}{\Delta t}\left[\frac{\left(T_{p j}-T_{p j}\right)+\left(T_{p j-1}-T_{p j-1}\right)}{2}\right]= \\
& \frac{(U A)_{c / p}}{2}\left\{\left[\frac{T_{c j}+T_{c j-1}^{j}}{2}-T_{p j}\right]+\left[\frac{T_{c j}+T_{c j-1}}{2}-T_{p j}\right]\right\} \\
& -(U A)_{p / i}\left[\frac{\left(T_{p j}^{\prime}-T_{i j}^{\prime}\right)+\left(T_{p j}-T_{i j}\right)}{2}\right]
\end{aligned}
$$




$$
\begin{aligned}
& (U A)_{p / i}\left[\frac{\left(T_{p j}-T_{i j}\right)+\left(T_{p j}-T_{i j}\right)}{2}\right]= \\
& (U A)_{i / s}\left[\frac{\left(T_{i j}-T_{s j}^{\prime}\right)+\left(T_{i j}-T_{s j}\right)}{2}\right] \\
& (U A)_{i / s}\left[\frac{\left(T_{i j}-T_{s j}\right)+\left(T_{i j}-T_{s j}\right)}{2}\right]= \\
& \text { (UA) } s / a\left[\frac{\left(T_{s j}-T_{a}^{j}\right)+\left(T_{s j}-T_{a}\right)}{2}\right]
\end{aligned}
$$

where

$$
\begin{aligned}
t & =\text { time seconds } \\
V & =\text { volume per node, } \mathrm{cu} \mathrm{ft} \\
\Delta t & =\text { integration time step, seconds }
\end{aligned}
$$

and prime denotes values at new time $t+\Delta t$ while unprimed values are at time $t$. other terms are as defined before.

- Ambient Node

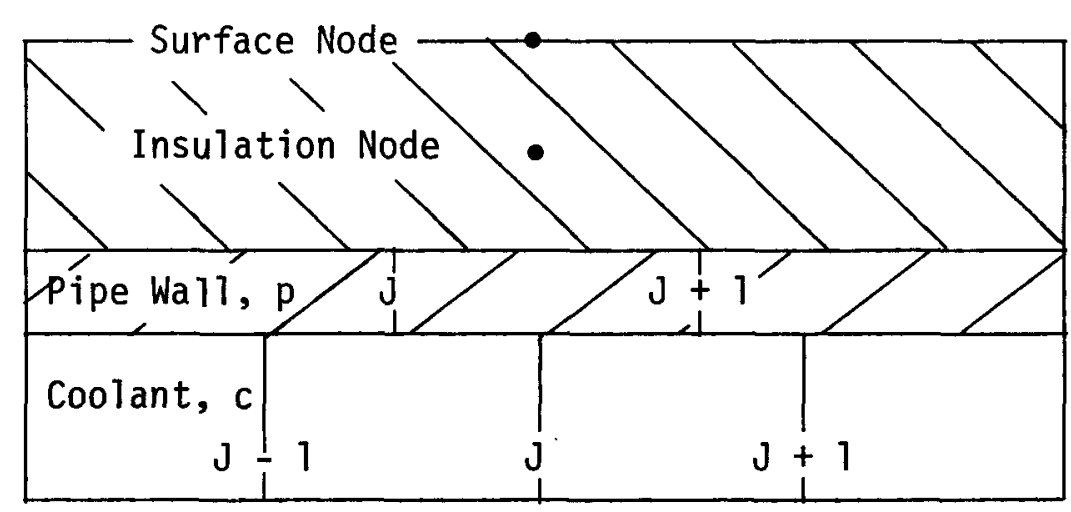

Sketch of Staggered Node Model 
By assuming that temperature gradients at time $t$ and $t+\Delta t$ are the same (a good approximation as $\Delta t \rightarrow 0$ ), it then follows that,

$$
\begin{gathered}
T_{c j}^{\prime}-T_{c j-1}^{\prime} \approx T_{c j}-T_{c j-1} \\
\frac{T_{c j}^{\prime}+T_{c j-1}^{\prime}}{2}-T_{p j}^{j} \approx \frac{T_{c j}+T_{c j-1}}{2}-T_{p j} \\
T_{p j}^{\prime}-T_{i j} \approx T_{p j}-T_{i j} \\
T_{i j}-T_{s j} \approx T_{i j}-T_{s j}
\end{gathered}
$$

and

$$
T_{s j}-T_{a} \approx T_{s j}-T_{a}
$$

Putting Equations (20) through (24) into Equations (16) through (19) and treating (20)-(24) as equalities, results in a set of equations which enables an explicit determination of temperatures at time $t+\Delta t$ :

$$
\begin{gathered}
\frac{\left(V_{p C}\right)_{c}}{\Delta t}\left[T_{c j}^{\prime}-T_{c j}\right]=-W_{c}\left[T_{c j}-T_{c j-1}\right]-(U A)_{c / p}\left[\frac{T_{c j}+T_{c j-1}}{2}-T_{p j}\right] \\
\frac{\left(V_{p C}\right)_{p}}{\Delta t}\left[T_{p j}-T_{p j}\right]=(U A)_{c / p}\left[\frac{T_{c j}+T_{c j-1}}{2}-T_{p j}\right]-(U A)_{p / i}\left[T_{p j}-T_{i j}\right] \\
0=(U A)_{p / i}\left[T_{p j}-T_{i j}\right]-(U A)_{i / s}\left[T_{i j}-T_{s j}\right] \\
0=(U A)_{i / s}\left[T_{i j}-T_{s j}\right]-(U A)_{s / a}\left[T_{s j}-T_{a}\right]
\end{gathered}
$$


give:

$T_{s j}$ and $T_{i j}$ are eliminated by substitution of (27) and (28) into (26) to

$$
\frac{\left(V_{p} C\right)_{p}}{\Delta t}\left[T_{p j}^{\prime}-T_{p j}\right]=(U A)_{c / p}\left[\frac{T_{c j}+T_{c j-1}}{2}-T_{p j}\right]-(U A)_{p / a}\left[T_{p j}-T_{a}\right]
$$

where

$$
(U A)_{p / a}=\frac{(U A)_{p / i}(U A)_{i / s}(U A)_{s / a}}{(U A)_{p / i}(U A)_{i / s}+(U A)_{p / i}(U A)_{s / a}+(U A)_{i / s}(U A)_{s / a}}
$$

Rearranging Equations (25) and (29) yields,

$$
\begin{gathered}
T_{c j}=\left[1-\frac{W c_{c}^{\Delta t}}{\left(V_{\rho} C\right)_{c}}-\frac{(U A) c / p^{\Delta t}}{2\left(V_{\rho} C\right)_{c}}\right] T_{c j}+\left[\frac{W C c^{\Delta t}}{\left(V_{\rho} C\right)_{c}}-\frac{(U A)_{c / p}^{\Delta t}}{2\left(V_{\rho} C\right)_{c}}\right] T_{c j-1} \\
+\frac{(U A)_{c / p} \Delta t}{\left(V_{\rho} C\right)_{c}} T_{p j}
\end{gathered}
$$

and

$$
\begin{gathered}
T_{p j}^{\prime}=\left[1-\frac{(U A)_{c / p} \Delta t}{\left(V_{\rho} C\right)_{p}}-\frac{(U A)_{p / a} \Delta t}{\left(V_{p} C\right)_{p}}\right] T_{p j}+\frac{(U A)_{c / p} \Delta t}{2\left(V_{\rho} C\right)_{p}}\left[T_{c j}+T_{c j-1}\right] \\
+\frac{(U A)_{p / a} \Delta t}{\left(V_{p} C\right)_{p}} T_{a}
\end{gathered}
$$

Equations (31) and (32) are used in the explicit solution for the case of constant heat transfer resistance from the pipe's outside surface to the ambient.

An equation similar to (32) results if a constant insulation temperature is assumed. For this case,

$$
T_{p j}^{\prime}=\left[1-\frac{(U A)_{c / p} \Delta t}{(V \rho C)_{p}}-\frac{(U A)_{p / i} \Delta t}{(V \rho C)_{p}}\right] T_{p j}+\frac{(U A)_{c / p} \Delta t}{2\left(V_{p} C\right)_{p}}\left[T_{c j}+T_{c j-1}\right]
$$




$$
+\frac{(U A)_{p / i}{ }^{\Delta t}}{(V \rho C)_{p}} T_{i}
$$

Thus, Equations (31 and (33) would be used in the explicit solution for the assumption of constant insulation temperature.

For numerical stability it is necessary that the temperature coefficients in Equations (31), (32), and (33) are never negative. The coefficient for $T_{c j}$ in Equation (31) will be equal to or greater than zero if,

$$
\Delta t=\frac{\left(V_{\rho} C\right)_{c}}{W C_{c}+(U A)_{c / p} / 2}
$$

The $T_{c j-1}$ coefficient can only be positive or zero if,

$$
W C_{c}>(U A)_{c / p} / 2
$$

It is unlikely that $(U A)_{C /} / 2$ will exceed $W_{C}$, but if it should happen, the computer program is coded to set $(U A)_{c p}=2 W C_{c}$.

The $T_{p j}$ coefficient in Equations (32) and (33) will be equal to or greater than zero if, in Equation (32),

$$
\Delta t=\frac{(V \rho C)_{p}}{(U A)_{c / p}+(U A)_{p / a}}
$$

or, for Equation (33),

$$
\Delta t=\frac{\left(V_{\rho} C\right)_{p}}{(U A)_{c / p}+(U A)_{p / i}}
$$

The inequalities of Equations (34), (35), and (36) or (37) are continuously checked in all of the pipe heat models using the rectangular integration method to make certain the time step is small enough for stability. 
About 100 different cases were run in the course of the model development work based on Equations (16) through (37). The number of axial nodes was varied from as few as 6 to as many as 624 for the sets of conditions given in Table 1. Most work was done using Condition IA for the $16 \mathrm{in}$. by $450 \mathrm{ft}$ long pipe, which appeared to be the most difficult configuration to simulate because of its long transport time. Once a satisfactory model was found for this particular situation, the selected model was then checked for the other sets of conditions. The pipe sizes and lengths are typical of those found in the FFTF's HTS.

Model A

Model $A$ is the name given the model which programs Equations (31) and (33) and uses inequalities (34), (35), and (37). Model A was first tried with a fixed small time step, which is much smaller than the limiting values for stability. Of course, stable solutions result, but accuracy is poor unless a large number of axial nodes are specified. Results of a series of computer runs are shown in Figure 2. The maximum temperature error at any given time is about $16^{\circ} \mathrm{F}$ for the 12 axial node Model $\mathrm{A}, 12^{\circ} \mathrm{F}$ for 24 nodes, $5^{\circ} \mathrm{F}$ for 48 nodes, and $3^{\circ} \mathrm{F}$ for 96 nodes. The Model $\mathrm{A}$ pipe end temperatures lead the reference case by from 15 to about 40 seconds at the start of the transient. The conclusion concerning Model A with a fixed small integration time step is that it cannot meet the selection criteria untess a very large number of axial nodes (over 96) are used. Results could be improved if the lead time could be reduced.

An explanation of the stated errors and curves drawn in Figure 2 and all subsequent figures of computer results is needed. The curves are drawn by hand by overlaying the computer's Calcomp plots from the several separate runs on to these report figures. Thus, the curves of this report are not exact duplicates of the computer output. The quoted errors are determined from the actual computer output though. Hence, a reader may not get the same errors if he scales these report figures.

Cases were rerun using Model $A$ except this time the integration time step was allowed to vary as determined by inequalities (34) and (37). To assure a stable solution, the right-hand sides of the inequalities are 
TABLE 1

SETS OF CONDITIONS USED IN MODEL DEVELOPMENT

\begin{tabular}{|c|c|c|c|c|c|c|c|c|c|c|}
\hline & & & & & Conditi & ons Set & & & & \\
\hline Parameter & IA & IB & IC & ID & IE & IIA & IIB & IIIA & IIIB & IVA \\
\hline PIpe 00 , in. & 16. & 16. & 16. & 16. & 16. & 28. & 28. & 8.625 & 8.625 & 3.5 \\
\hline ID, in. & 15.25 & 15.25 & 15.25 & 15.25 & 15.25 & 27.25 & 27.25 & 7.981 & 7.981 & 3.068 \\
\hline Length, ft & 450 & 450. & 450. & 450 & 450 & 150. & 150. & 75. & 75 & 150 \\
\hline $\begin{array}{l}\text { Insulation Thickness, } \\
\text { in. }\end{array}$ & 4. & 4. & 4. & 4. & 4. & 4. & 4. & 4. & 4. & 4. \\
\hline $\begin{array}{l}\text { Insulation Conductivity, } \\
\left.\text { Btu/(hr-ft- }{ }^{\circ} \mathrm{F}\right)\end{array}$ & .075 & .075 & .075 & .075 & .075 & .075 & .075 & .075 & .075 & .075 \\
\hline Inlet Coolant Temperature & $(1 A)$ & $(7 A)$ & (1B) & (IC) & (1D) & $(1 A)$ & $(1 \mathrm{~A})$ & $(1 A)$ & $(1 A)$ & $(1 A)$ \\
\hline Coolant Flow Rate, $1 \mathrm{~b} / \mathrm{sec}$. & $(2 A)$ & $\begin{array}{c}\text { Constant } \\
1600\end{array}$ & $(2 B)$ & $(2 A)$ & $\begin{array}{c}\text { Constant } \\
160\end{array}$ & $(2 A)$ & $\begin{array}{l}\text { Constant } \\
1600\end{array}$ & $(2 C)$ & $\begin{array}{l}\text { Constant } \\
400\end{array}$ & $(2 D)$ \\
\hline
\end{tabular}

Inlet Coolant Ramps:

(1A) Ramp, 1000 to $800^{\circ} \mathrm{F}$ between 0 and $10 \mathrm{sec}$.

(1B) Ramp, 1000 to $800^{\circ} \mathrm{F}$ between 0 and $10 \mathrm{sec}$, hold at 800 for. 90 secs., ramp to 1000 between 100 and 150 sec.

(1C) Delayed Ramp, 1000 to $800^{\circ} \mathrm{F}$ between 70 and $110 \mathrm{sec}$.

(1D) Ramp, 1000 to $800^{\circ} \mathrm{F}$ between 0 and $40 \mathrm{sec}$

(2A) Ramp, 1600 to $160 \mathrm{lb} / \mathrm{sec}$. between 2 and $27 \mathrm{sec}$.

2B) Ramp, 1600 to $160 \mathrm{lb} / \mathrm{sec}$. between 2 and $27 \mathrm{sec}$, hold at 160 for 73 secs., ramp to 1600 between 100 and 110 sec.

2C) Ramp, 400 to $40 \mathrm{lb} / \mathrm{sec}$. between 2 and $27 \mathrm{sec}$.

(2D) Ramp, 31.6 to $3.16 \mathrm{lb} / \mathrm{sec}$. between 2 and $27 \mathrm{sec}$. 
FIG. 2. MODEL A SODIUM OUTLET TEMPERATURES. AXIAL NODES VARIED.

FIXED INTEGRATION TIME STEP OF .1 SECONDS. TRANSIENT BASED DN CONDITIDNS SET IA, TABLE 1. DOWN RAMPS IN 16 IN. $X 450$ FT PIPE.

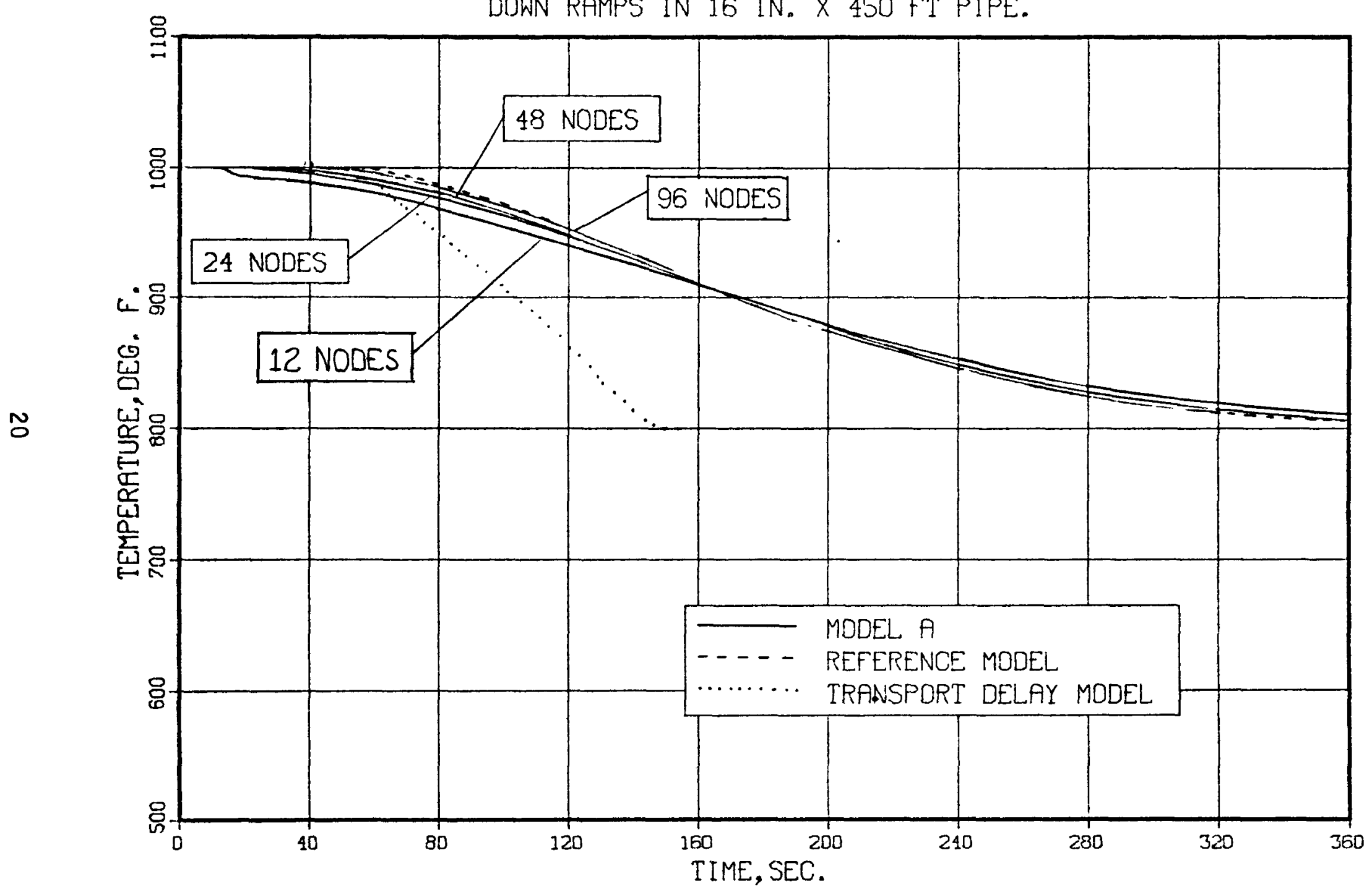


multiplied by 0.99 before selecting the minimum of the two possible calculated time steps:

$$
\tau 2=\frac{.99\left(V_{p} C\right)_{c}}{W C_{c}+(U A)_{c / p} / 2}
$$

Tl from Equation (36) is,

$$
\tau \tau=\frac{.99\left(V_{p} C\right)_{p}}{(U A)_{c / p}+(U A)_{p / a}}
$$

Il from Equation (37) is,

$$
\begin{aligned}
\tau l & =\frac{.99\left(V_{\rho} C\right)_{p}}{(U A)_{c / p}+(U A)_{p / i}} \\
\Delta t & =\operatorname{MINIMUM}(\tau 1, \tau 2)
\end{aligned}
$$

The results of this series of runs are tabulated in Table 2 are are shown in Figure 3 for the 12, 24, and 48 axial node cases.

\section{TABLE 2}

MODEL A SODIUM OUTLET ERRORS WITH THE INTEGRATION TIME STEP EQUAL TO 0.99 OF THE LIMITING STABILITY VALUE AND FOR TABLE 1 CONDITIONS SET IA

Number of
Axial Nodes

12
24
48
96
210
624

Maximum Lead Time Error (Model A Leads the Reference), seconds

As before, the model meets the selection criteria only for a large number of axial nodes. The 624 axial node case, which agrees perfectly with the reference detail model, helps to substantiate the credibility of the reference model because good results should be expected for such an enormous number of axial nodes. 
FIG. 3. MODEL A SODIUM OUTLET TEMPERATURES. AXIAL NODES VARIED. INTEGRATION TIME STEP AT .99 OF STABILITY LIMIT. TRANSIENT BASED ON CONDITIONS SET IA, TABLE 1.

DOWN RAMPS IN 16 IN. $X 450$ FT PIPE.

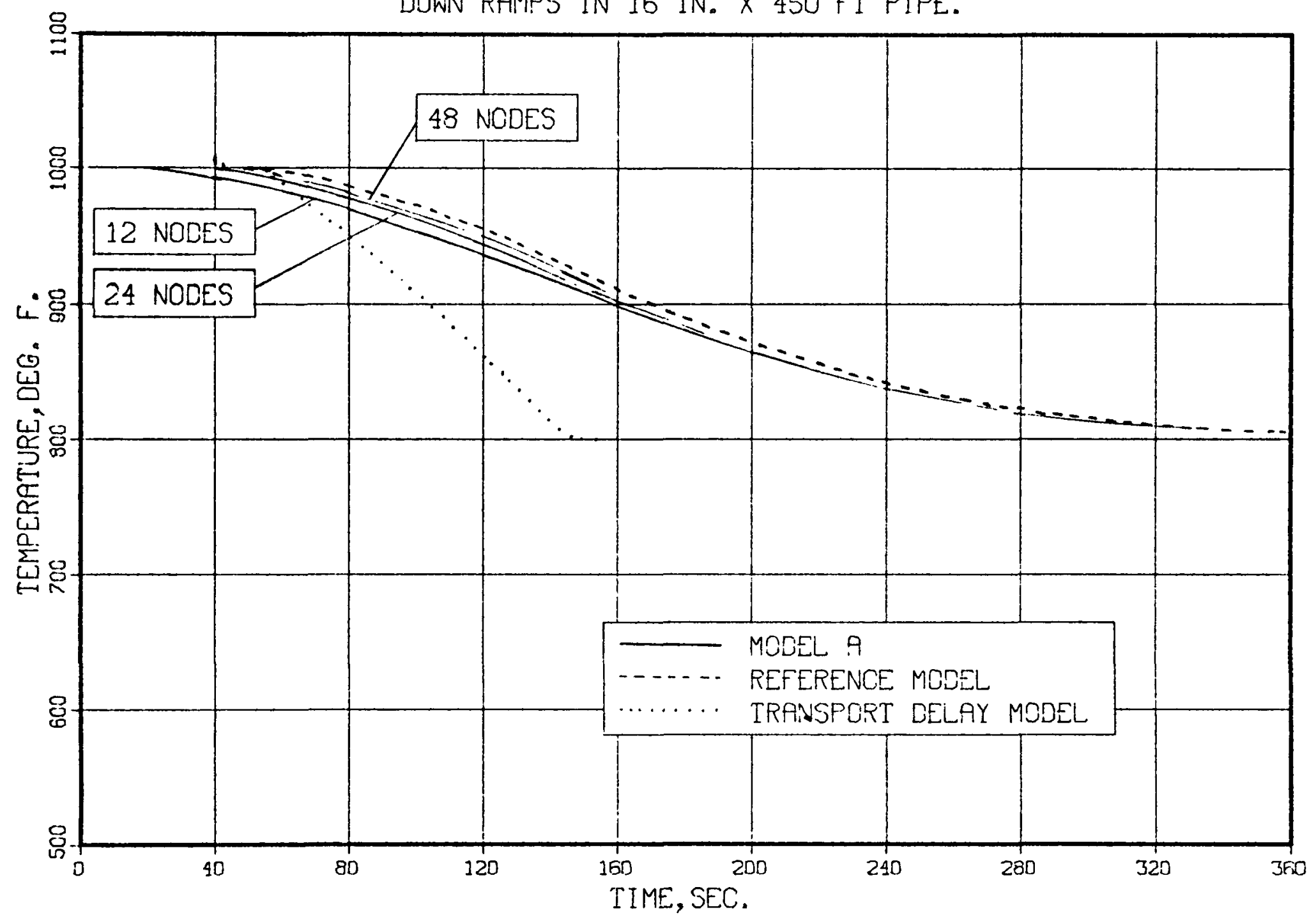


Mode $1 \mathrm{~B}$

The lead time problem with Model A could possibly be eliminated by performing the temperature integrations only as each node is refilled with incoming coolant. Model $B$ does just that by integrating the flow rate and comparing it to the volume of a single node. The volumes of all nodes are equal. The volume integration is only approximate in that the incoming coolant flow rate is only known at the start of the time span of the temperature integration. Thus, the approximate time to fill a node is determined directly by:

$$
\Delta t=\frac{v_{\text {node }}}{W / \bar{\rho}}
$$

where

$$
\begin{aligned}
\Delta t= & \text { node refill time, seconds } \\
V_{\text {node }}= & \text { coolant node volume, cu ft } \\
W= & \text { coolant flow rate at the start of the node refilling } \\
& \text { process, } 1 \mathrm{~b} / \mathrm{sec} \\
\bar{\rho}= & \text { average coolant density based on volume average pipe leg } \\
& \text { temperature at the start of the node refilling process, } \\
& 1 \mathrm{~b} / \mathrm{cu} \mathrm{ft} .
\end{aligned}
$$

The concept of a constant heat transfer resistance from the pipe's outside surface to the ambient is used with Model B; therefore, the numerical integrations by Equations (31), (32), (35), (38), (39), and (40) are performed at the $\Delta t$ time intervals.

Results are given in Table 3 for several axial node cases and the results are shown in Figure 4 for the 12, 24, and 48 node cases.

It is apparent that Model $B$ overcorrects the Model A lead time problem. The fact that Model A leads while Model $B$ lags suggests that a combination of the two models might give a model which can meet the selection criteria with a reasonably few number of axial nodes. 
TABLE 3

MODEL B SODIUM OUTLET ERRORS WITH THE INTEGRATION TIME STEP EQUAL TO 0.99 OF THE LIMITING STABILITY VALUE AND FOR TABLE 1 CONDITIONS SET IA

Number of Maximum Temperature Axial Nodes

12

24

48

96

210
Error, ${ }^{\circ} \mathrm{F}$

20

11

7

5

3
Maximum Lag Time Error

(Model B Lags the Reference), seconds

\section{Mode1 C}

Model $C$ is a combination of the $A$ and $B$ models. Model $B$ is used until the entire pipe leg is once refilled with coolant after the temperature transient starts; Model $A$ is used thereafter.

Results are tabulated in Table 4 and shown in Figure 5 for 6,12 , and 24 axial nodes. The model selection criteria is met, for this particular set of conditions, with 24 nodes.

TABLE 4

MODEL C SODIUM OUTLET ERRORS WITH TABLE 1 CONDITIONS SET IA

Number of

Axial Nodes

6

12

24
Maximum Temperature Error, ${ }^{\circ} \mathrm{F}$
Maximum Lead Time Error (Mode] C Leads the Reference), seconds

\section{0}

10

5
30

10

5

Additional Verification of Model $C$

Several additional computer runs were made with Model $C$ to check out $i$ ts performance for a variety of alternative conditions, as listed in Table 1. A reference case, using the detailed 48 axial $\times 5$ radial node, implicit solution model, was run for each set of conditions. Results are tabulated in Table 5 and are shown in Figures 6 through 14. 
FIG. 4. MODEL 8 SODIUM OUTLET TEMPERATURES. AXIAL NCDES VARIED. INTEGRATION TIME STEF AT 99 CF STADILITY LIMIT. TRPAVSIENT BASED ON CONDITIONS SET IA, TABLE 1.

DOWN RPMPS IN 16 IN. $X 450$ FT PTPL.

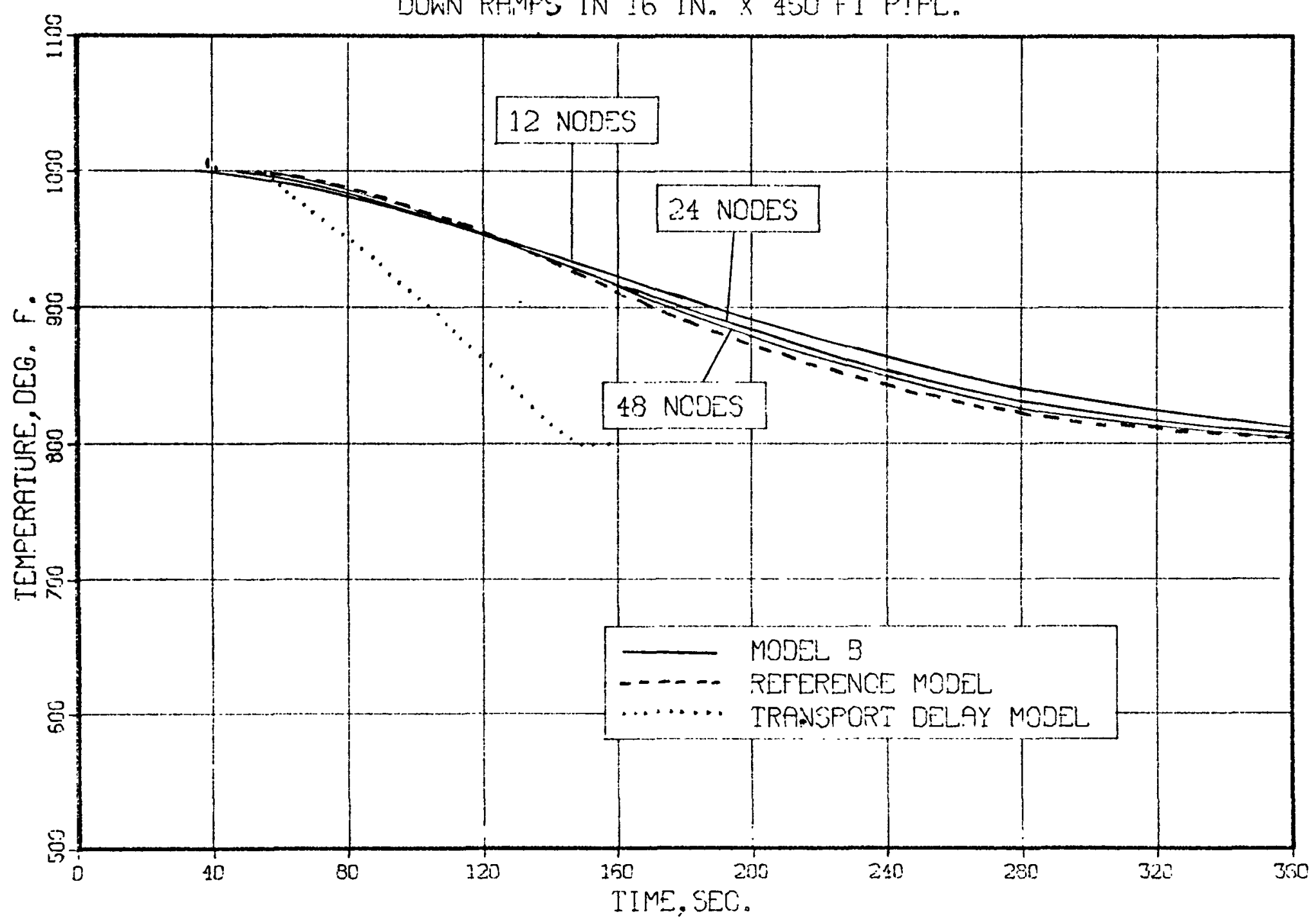


FIG. 5. MODEL $C$ SODIUM OUTLET TEMPERATURES. AXIAL NODES VARIED. COMBINES FEATURES OF A AND B MODELS. TRANSIENT BASED ON CONDITIONS SET IA, TABLE 1.

DOWN RAMPS IN 16 IN. $X 450$ FT PIPE.

No

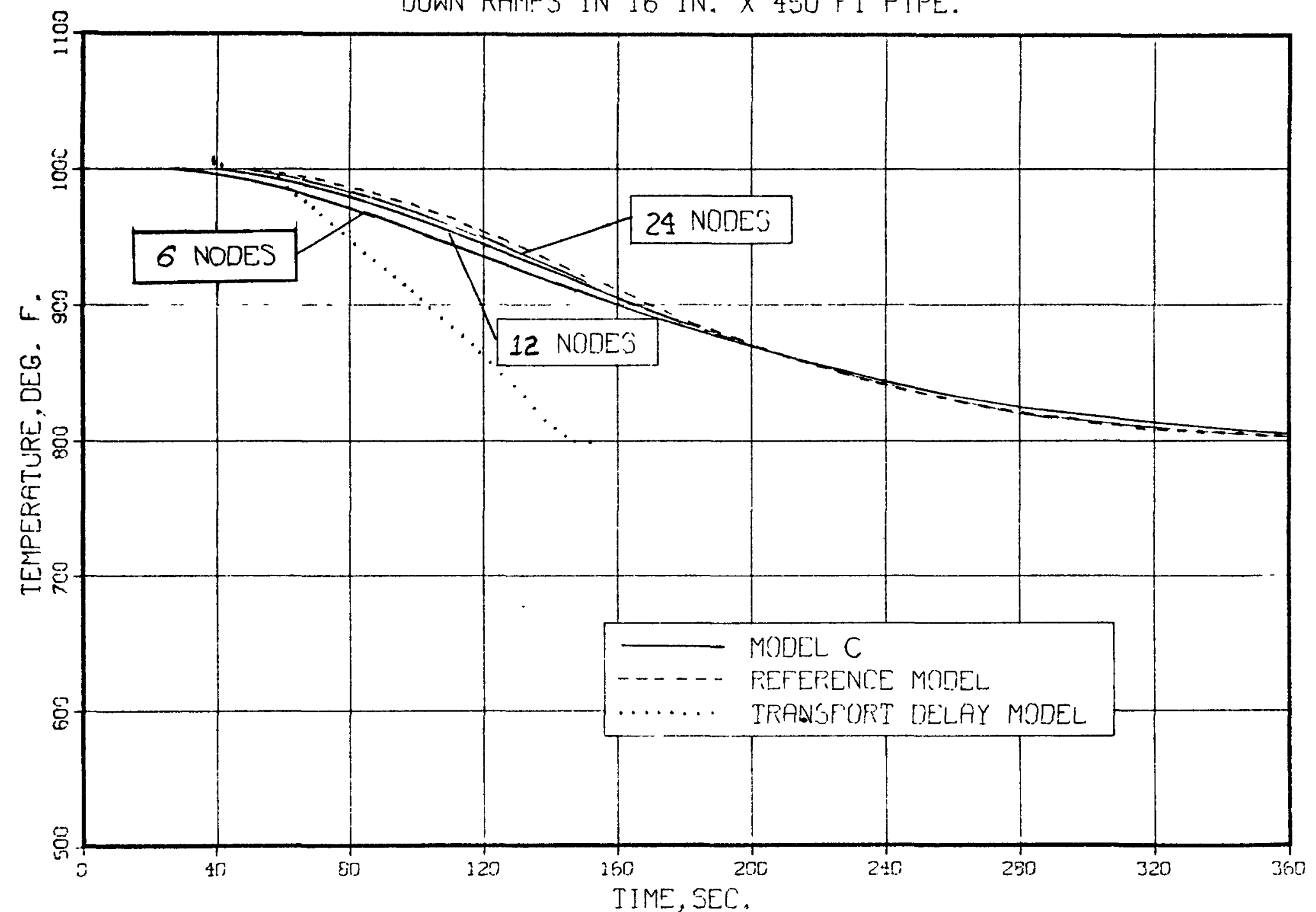


TABLE 5

FINAL CHECKOUT OF MODEL C

\begin{tabular}{|c|c|c|c|c|c|c|}
\hline \multirow{2}{*}{$\begin{array}{c}\text { Conditions Set } \\
\text { As Defined } \\
\text { In Table I } \\
\end{array}$} & \multirow{2}{*}{$\begin{array}{r}\text { Pipe Size } \\
\text { OD } \times \text { Length } \\
\end{array}$} & \multirow{2}{*}{$\begin{array}{c}\text { Forcing Ramps } \\
T=\text { Temperature } \\
F=\text { Flow } \\
\text { (See Table 1) } \\
\end{array}$} & \multirow{2}{*}{$\begin{array}{c}\begin{array}{c}\text { Number } \\
\text { Axial Nodes }\end{array} \\
\end{array}$} & \multicolumn{2}{|c|}{$\begin{array}{l}\text { Maximum Outlet Coolant Errors } \\
\text { Relative to Reference Case }\end{array}$} & \multirow{2}{*}{$\begin{array}{c}\text { Initial } \\
\text { Steady State } \\
\text { Transport Time, } \\
\text { seconds } \\
\end{array}$} \\
\hline & & & & Temperature, ${ }^{\circ} \mathrm{F}$ & Lead or Lag Time, seconds & \\
\hline IA & $16^{\prime \prime} \times 450^{\prime}$ & T\&F down & $\begin{array}{r}6 \\
12 \\
24\end{array}$ & $\begin{array}{r}20 \\
10 \\
5\end{array}$ & $\begin{array}{r}30 \text { (lead) } \\
10 \text { (lead) } \\
5 \text { (lead) }\end{array}$ & 18 \\
\hline IB & $16^{\prime \prime} \times 450^{\prime}$ & $\begin{array}{l}T \text { down; } \\
F \text { constant } \theta \\
1600 \mathrm{ib} / \mathrm{sec}\end{array}$ & $\begin{array}{r}6 \\
12 \\
24\end{array}$ & $\begin{array}{r}14 \\
9 \\
5\end{array}$ & $\begin{array}{l}3(\mathrm{lag}) \\
2(\mathrm{lag}) \\
1 \\
\text { lag }\end{array}$ & 18 \\
\hline IC & $16^{\prime \prime} \times 450^{\prime}$ & $\begin{array}{l}\text { T\&F down, } \\
\text { then back to } \\
\text { initial }\end{array}$ & $\begin{array}{r}6 \\
12 \\
24\end{array}$ & $\begin{array}{r}16 \\
10 \\
4\end{array}$ & $\begin{array}{r}25 \text { (lead) } \\
15 \text { (lead } \\
5 \text { (lead) }\end{array}$ & 18 \\
\hline ID & $16^{\prime \prime} \times 450^{\prime}$ & $\begin{array}{l}\text { T\&F down; } \\
\text { T ramp delayed }\end{array}$ & $\begin{array}{r}6 \\
12 \\
24\end{array}$ & $\begin{array}{r}22 \\
10 \\
3\end{array}$ & $\begin{array}{r}50 \text { (lead) } \\
20 \text { (lead) } \\
5 \text { (lead) }\end{array}$ & 18 \\
\hline IE & $16^{\prime \prime} \times 450^{\prime}$ & $\begin{array}{l}T \text { down; } \\
\mathrm{F} \text { constant } \mathrm{a} \\
160 \mathrm{lb} / \mathrm{sec}\end{array}$ & $\begin{array}{r}6 \\
12 \\
24 \\
96 \\
192\end{array}$ & $\begin{array}{r}72 \\
40 \\
22 \\
7 \\
2\end{array}$ & $\begin{array}{r}100(\mathrm{lag}) \\
50(\mathrm{lag}) \\
16(\mathrm{lag}) \\
5(\mathrm{lag}) \\
2(\mathrm{lag})\end{array}$ & 180 \\
\hline IIA & $28^{\prime \prime} \times 150^{\prime}$ & T\&F down & $\begin{array}{r}6 \\
12 \\
24\end{array}$ & $\begin{array}{r}40 \\
20 \\
8\end{array}$ & $\begin{array}{r}35 \text { (lead) } \\
15 \text { (lead) } \\
8 \text { (lead) }\end{array}$ & 19 \\
\hline IIB & $28^{\prime \prime} \times 150^{\prime}$ & $\begin{array}{l}T \text { down; } \\
\mathrm{F} \text { constant } \mathrm{e} \\
1600 \mathrm{ib} / \mathrm{sec}\end{array}$ & $\begin{array}{r}6 \\
12 \\
24\end{array}$ & $\begin{array}{l}8 \\
7 \\
5\end{array}$ & $\begin{array}{l}3(\mathrm{lag}) \\
3(\mathrm{lag}) \\
2(\mathrm{lag})\end{array}$ & 19 \\
\hline IIIA & $8^{\prime \prime} \times 75^{\prime}$ & T\&F down & $\begin{array}{r}6 \\
12 \\
24\end{array}$ & $\begin{array}{l}5 \\
1 \\
0\end{array}$ & $\begin{array}{l}2 \\
1 \\
0\end{array}\left(\begin{array}{l}\mathrm{lag} \\
\mathrm{lag}\end{array}\right)$ & 3 \\
\hline IIIB & $8^{\prime \prime} \times 75^{\prime}$ & $\begin{array}{l}T \text { down; } \\
F \text { constant } a \\
400 \mathrm{~b} / \mathrm{sec}\end{array}$ & $\begin{array}{r}6 \\
12 \\
24\end{array}$ & $\begin{array}{l}0 \\
0 \\
0\end{array}$ & $\begin{array}{l}0 \\
0 \\
0\end{array}$ & 3 \\
\hline IVA & $3^{\prime \prime} \times 150^{\prime}$ & T\&F down & $\begin{array}{r}6 \\
12 \\
24\end{array}$ & $\begin{array}{r}15 \\
5 \\
0\end{array}$ & $\begin{array}{l}40(\mathrm{lag}) \\
8(\mathrm{lag}) \\
0\end{array}$ & 13 \\
\hline
\end{tabular}


FIG. 6. MODEL C SODIUM OLTLET TEMPERATLRES. AXIAL NDDES VARIED. TRANSIENT BASED ON CONDITIONS SET IB, TRBLE 1. CONSTANT FLOW RATE OF 1600 LB/SEC.

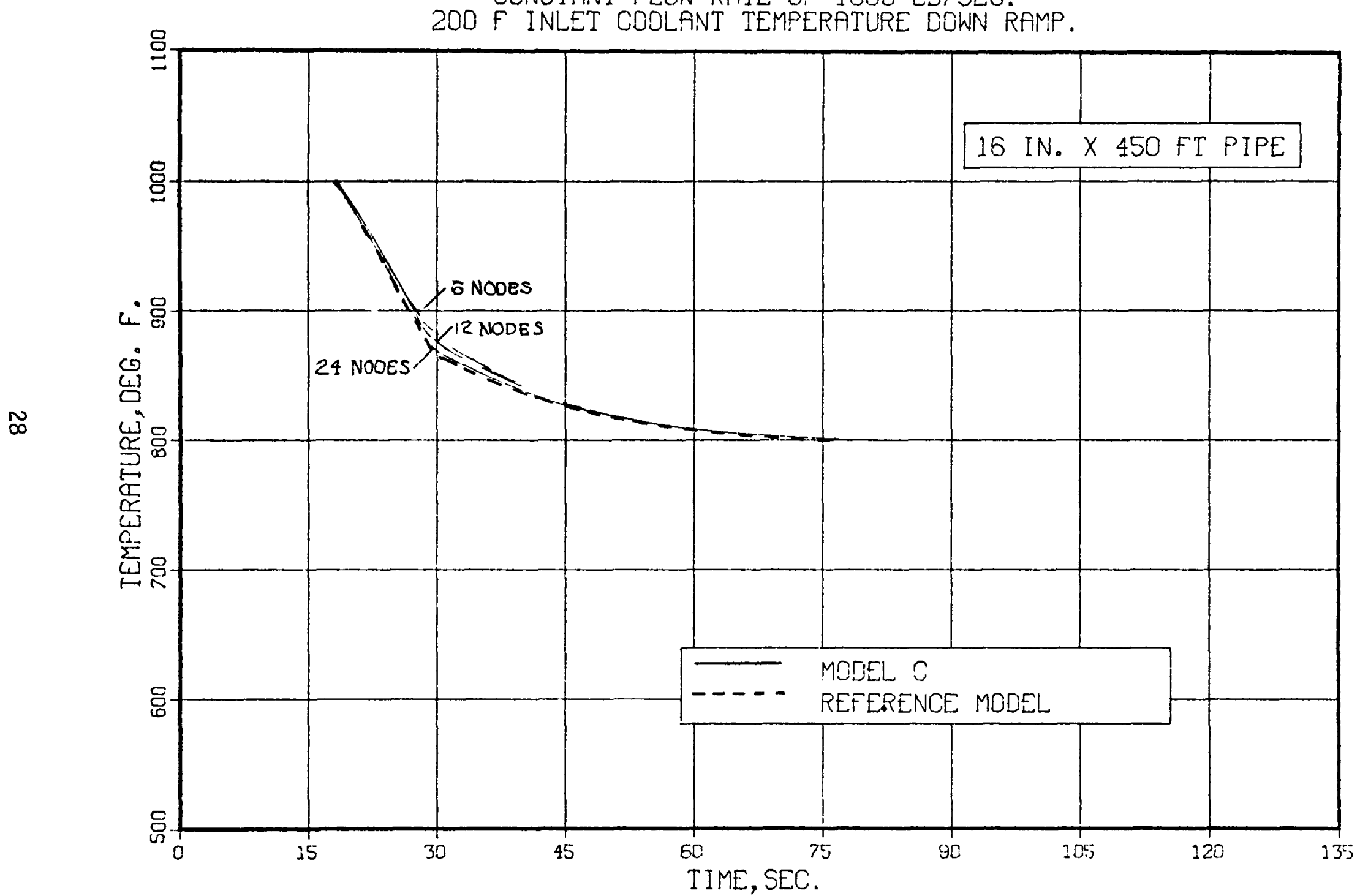


FIG. 7. MODEL C SODILM OUTLET TEMPERATLRES. FXIAL NODES VARIED. 'TRANSIENT BASED ON CONDITIONS SET IC, TABLE 1. DOWN LLP RAMPS ON FLOW RATE.

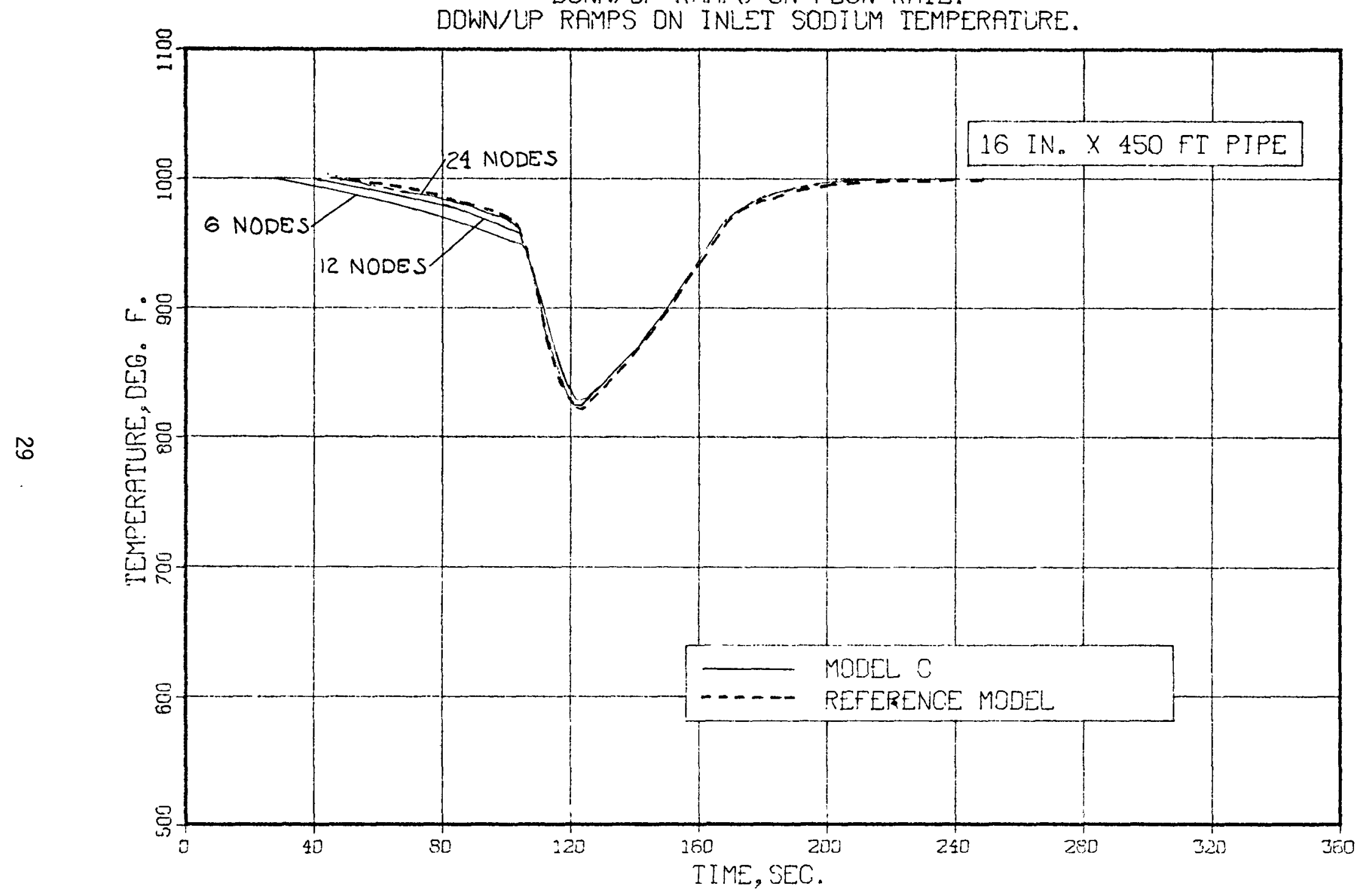


FIG. 8. MODEL C SODIUM OUTLET TEMPERATURES. AXIAL NODES VARIED. TRANSIENT BASED ON CONDITIONS SET ID, TAELE 1.

INLET COOLFNT TEMP. RAMP OF 1000 TO 800 DEG F FRDM $70 T 0110$ SEC

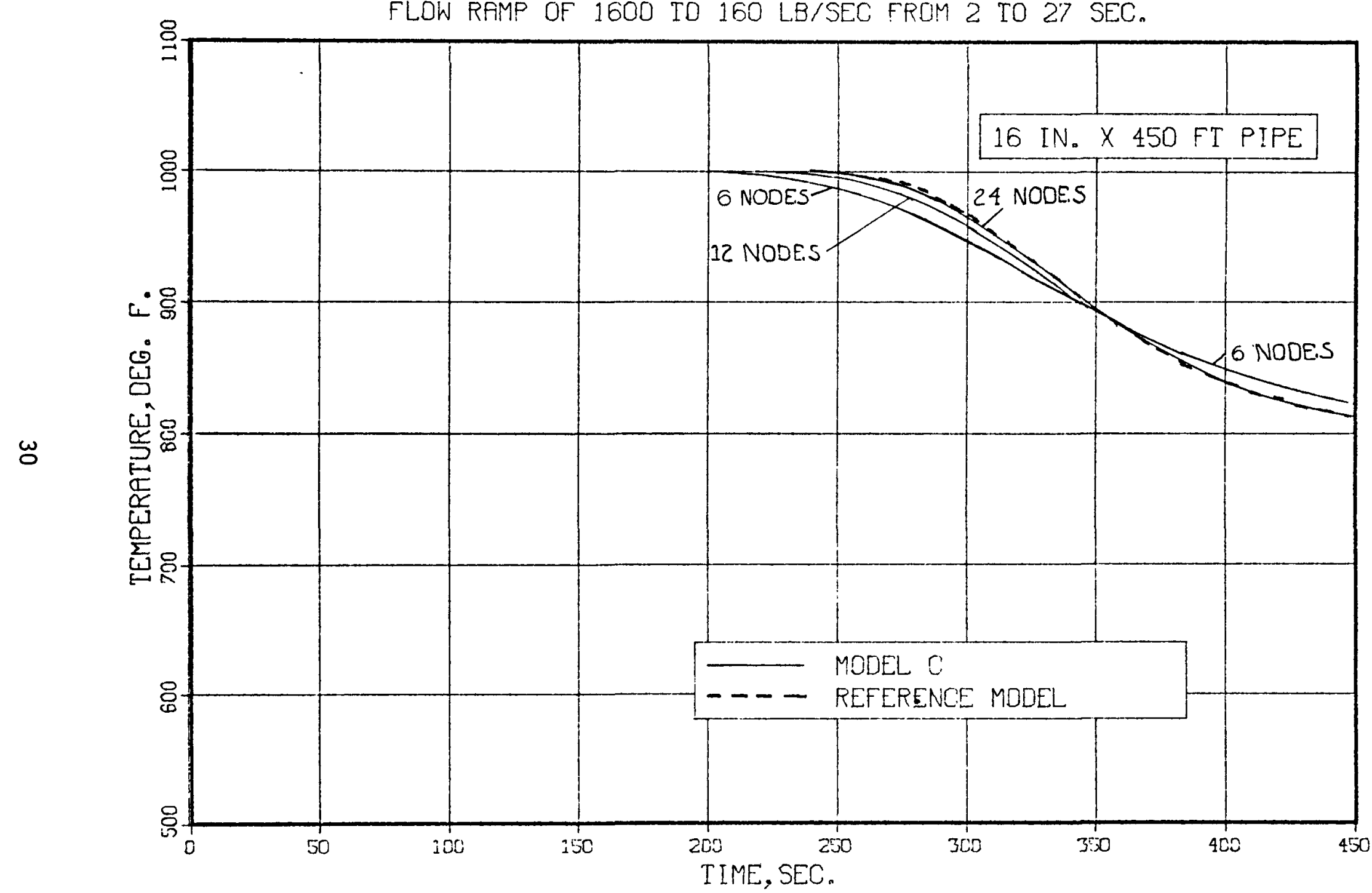


FIG. 9. MODEL C SODIUM OUTLET TEMPERATLRES. AXIAL NODES VARIED. TRANSIENT BASED ON CONDITIONS SET IE, TABLE 1.
RAMP INLET COOLANT TEMPERATURE AT -5 DEG./SEC FROM O TO 40 SEC FLOW CCNSTANT AT 150 LB/SEC.

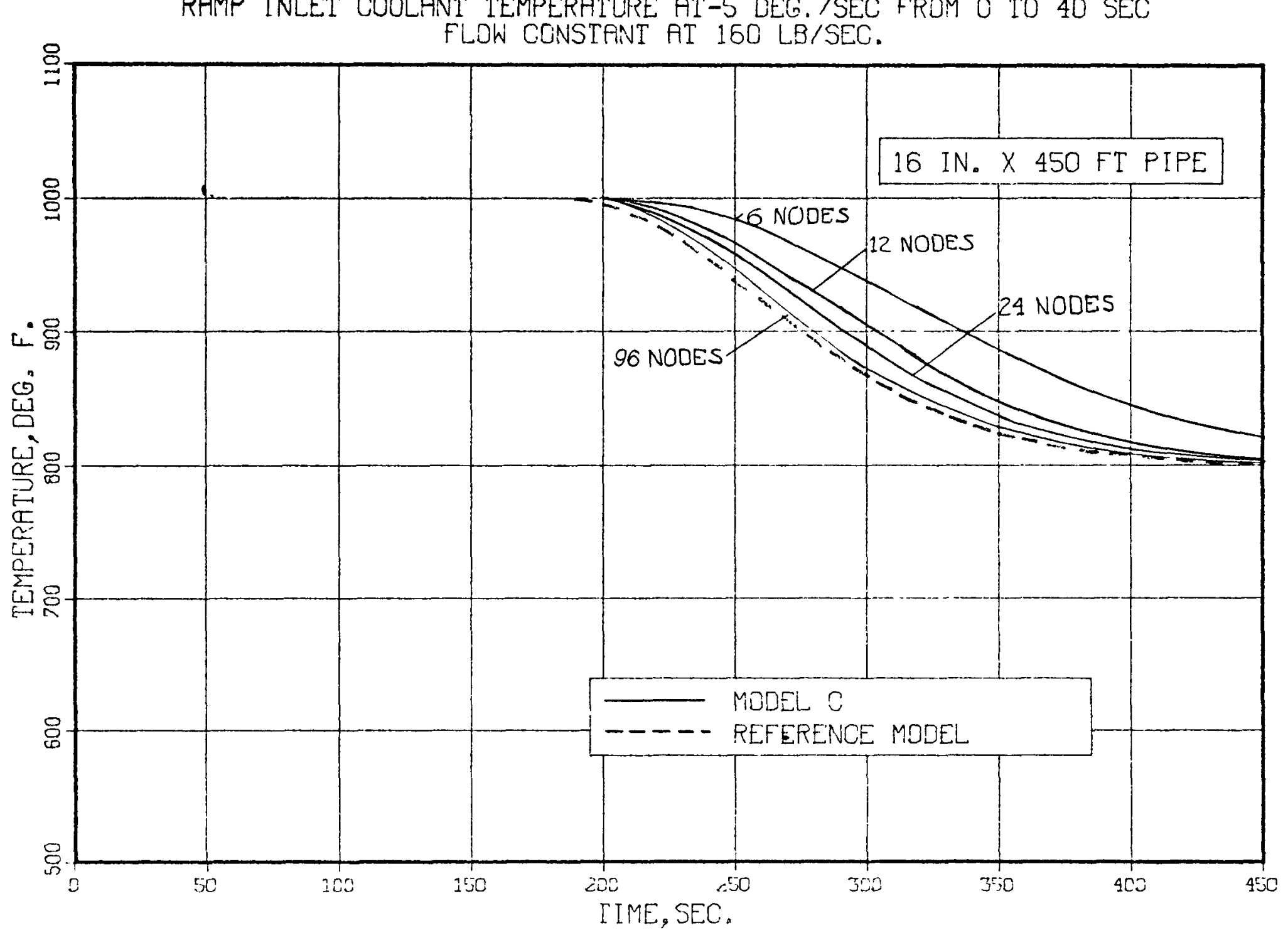


FIG. 10. MODEL C SODIUM OUTLET TEMPERATURES. AXIAL NODES VARIED TRANSIENT BASED ON CONDITIONS SET IIA, TABLE $\hat{\imath}$.

$200 \mathrm{~F}$ INLET COOLANT TEMPERATURE DOWN RAMP.

FLOW RAMP OF 1600 TO 160 LB/SEC FROM 2 TO 27 SEC.

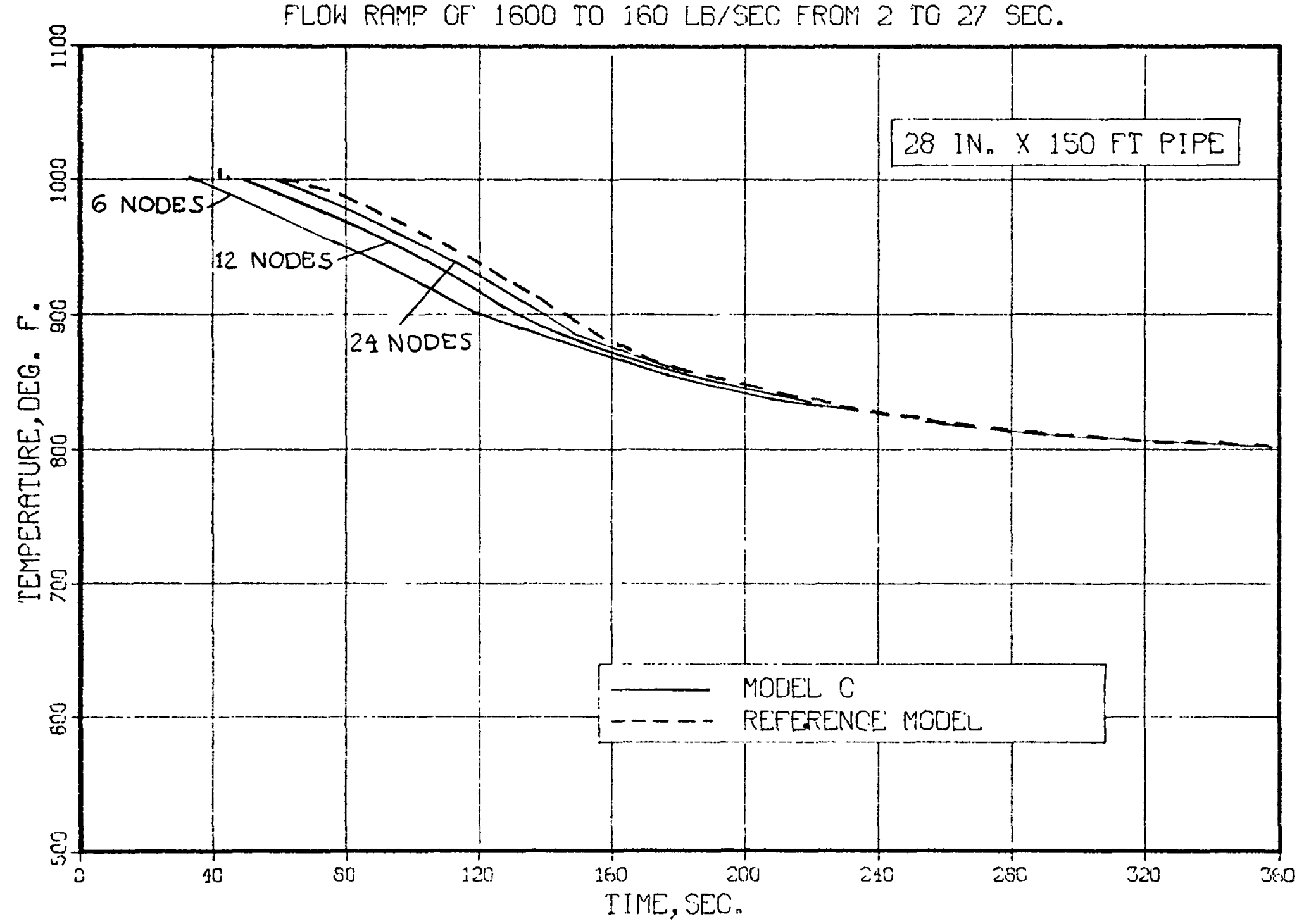


FIG. 11. MOUEL C SOUIUM OUTLET TEMPERATURES. AXIAL NODES VARIED TRANSIENT BASED ON CONDTTIONS SET IIB, TABLE 1.

$2 O D F$ INLET COOLANT TEMPERATURE DOWN RAMP.

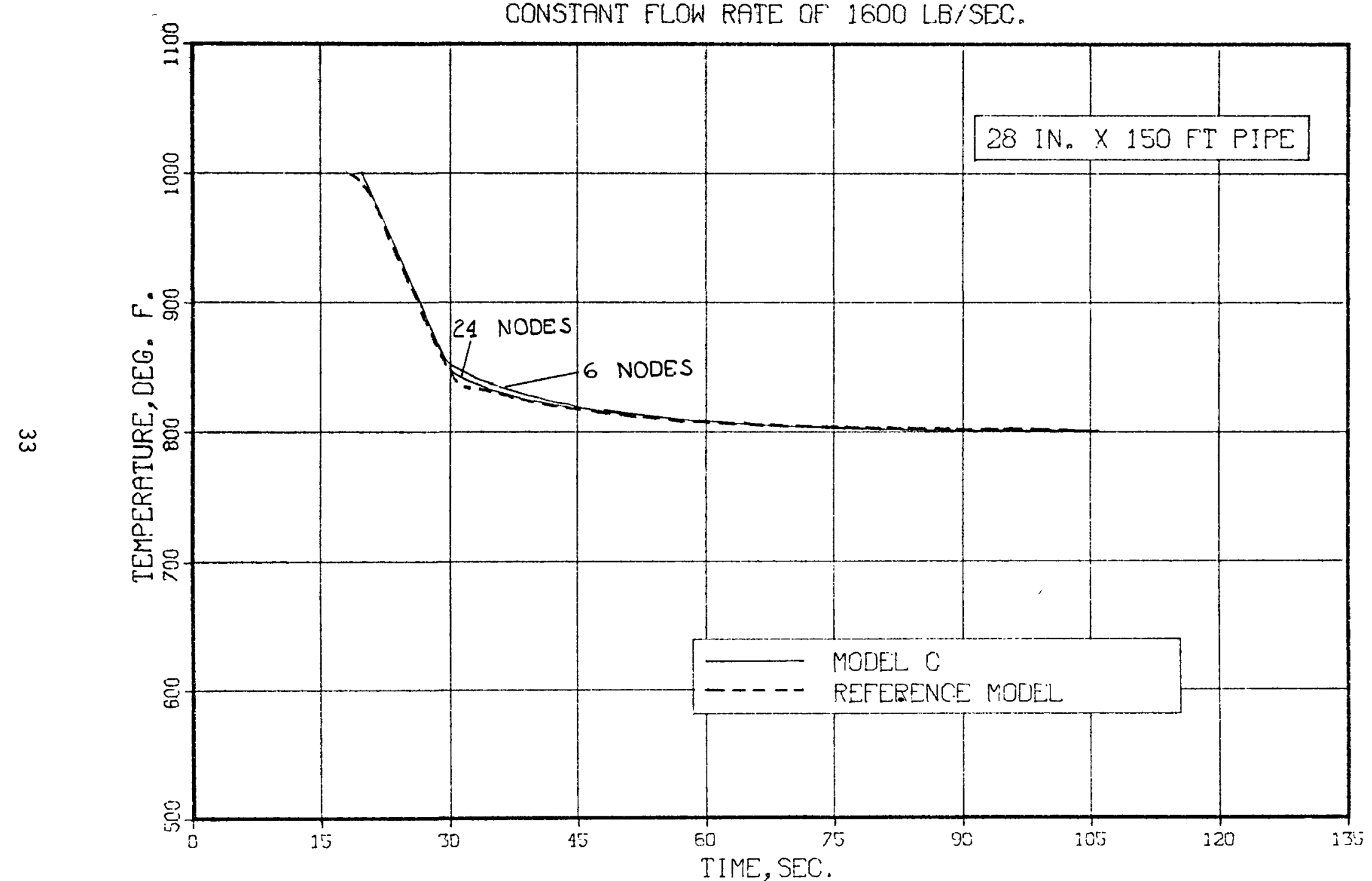


FIG. 12. MODEL C SODIUM OUTLET TEMPERATURES. AXIAL NODES VARIED TRANSIENT BASED ON CONDITIONS SET IIIA, TABLE 1. $200 \mathrm{~F}$ INLET COOLANT TEMPERATURE DOWN RAMP. FLOW RAMP OF 400 TO 40 LBISEG FROM 2 TO 27 SEC.

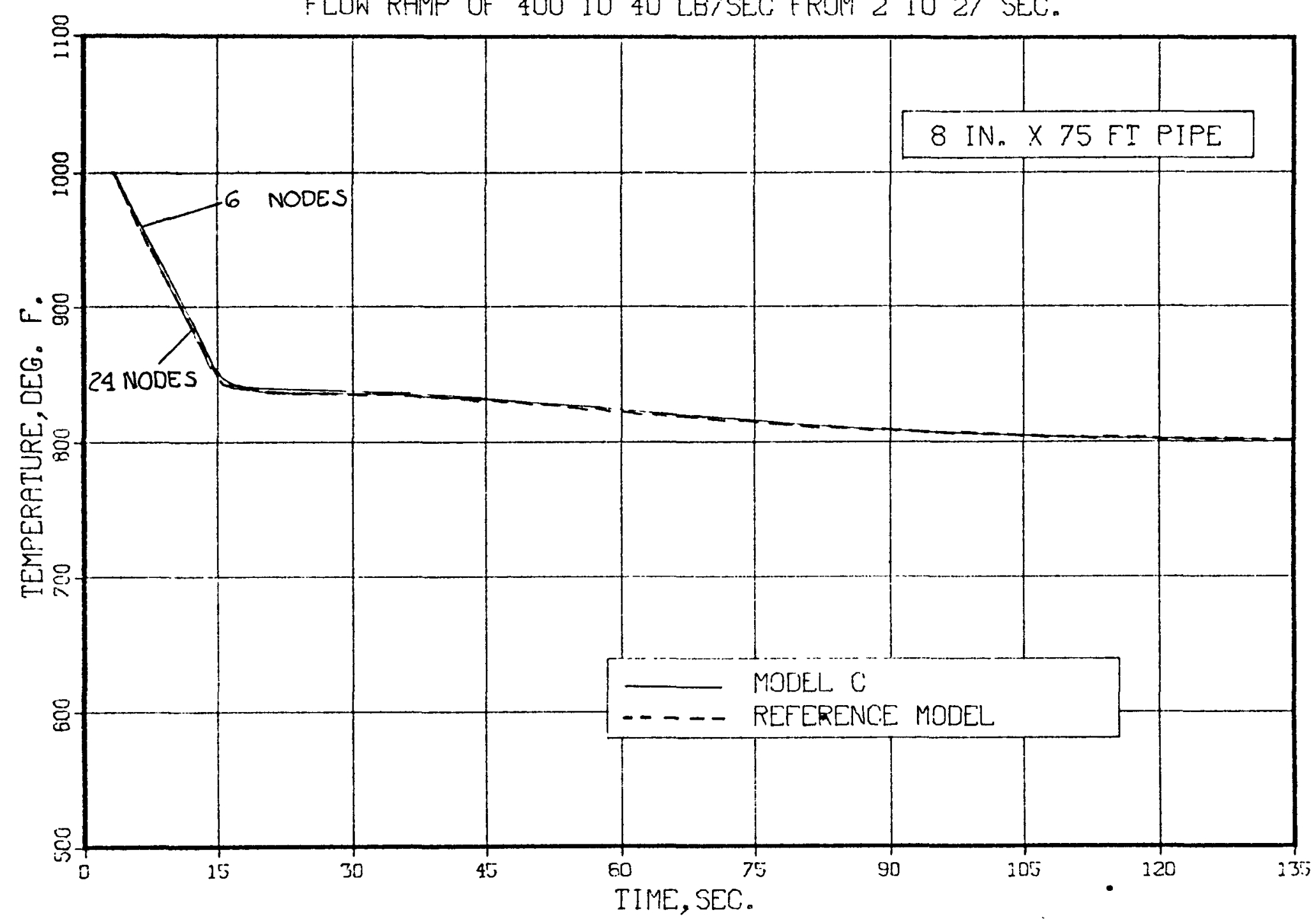


FIG. 13. MODEL $C$ SODIUM OUTLET TEMPERRTURES. AXIFL NCDES VARIED TRFNSIENT BASED ON CONDITIONS SET IIIB, TABLE 1.

$200 \mathrm{~F}$ INLET COOLANT TEMPERATURE DOWN RAMP.

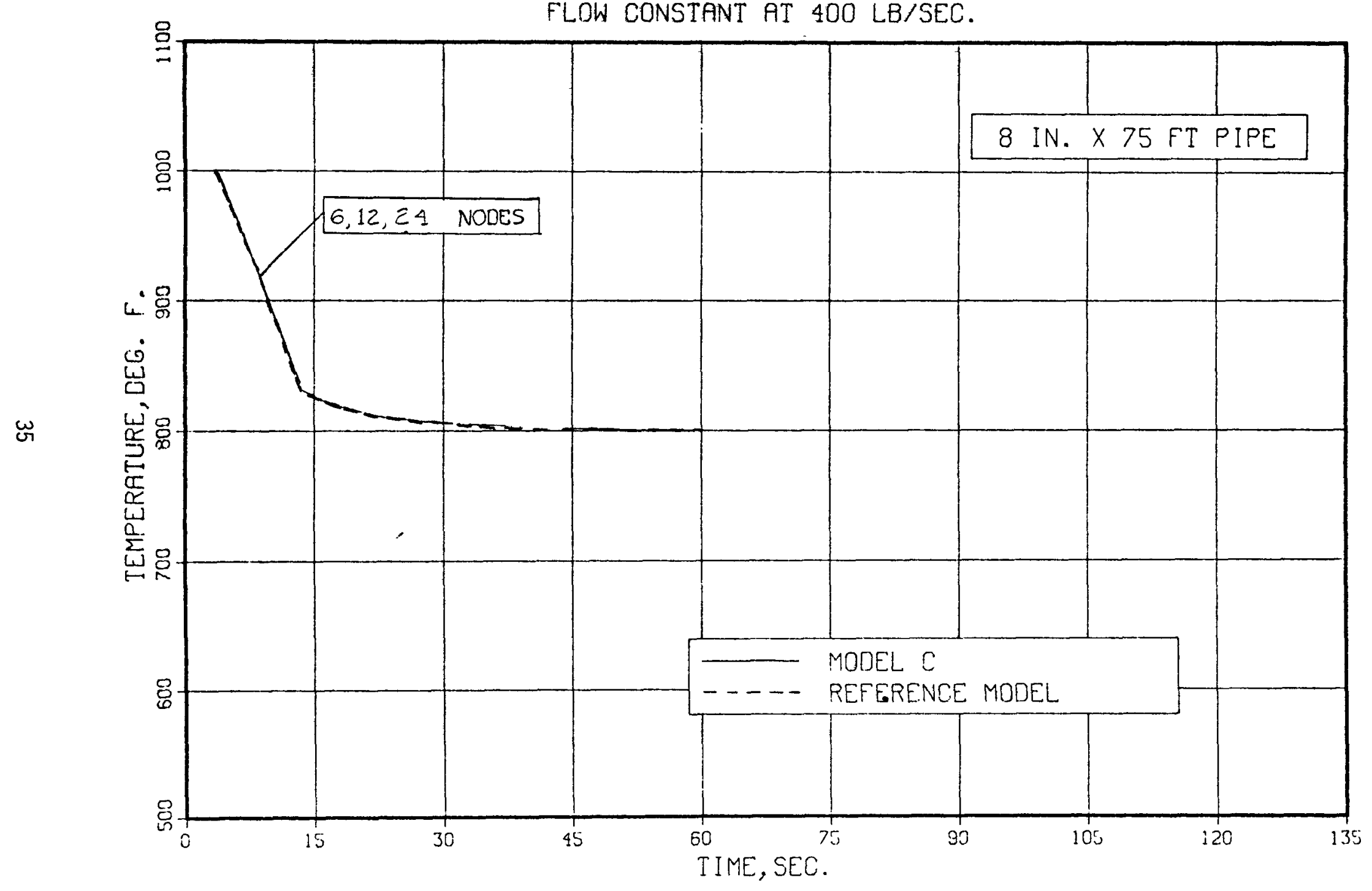


FIG. 14. MODEL $C$ SODIUM OUTLET TEMPERATURES. AXIAL NODES VARIED TRANSIENT BASED ON CONDITIONS SET IVA, TABLE 1.

$200 \mathrm{~F}$ INLET COOLANT TEMPERATURE DOWN RAMP.

RAMP FLOW FROM 31.6 TO 3.16 LB/SEC FROM 2 TO 27 SEC.

$\omega$

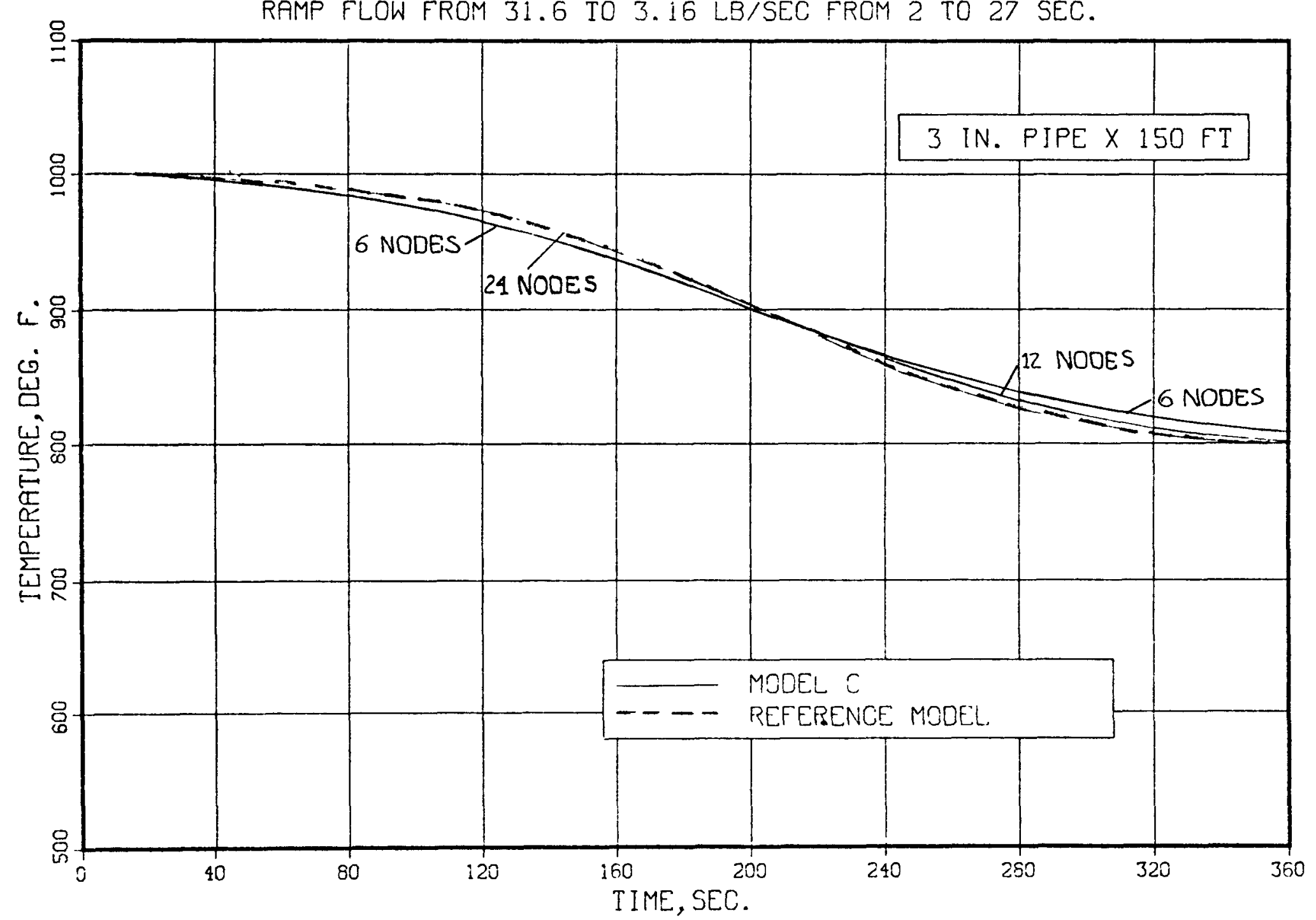


A 24 axial node model is satisfactory in most cases. Exceptions are for condition sets IE and IIA. Indications are that the minimum number of axial nodes for meeting the selection criteria is related to the coolant transport time. For example, 6 nodes are sufficient for the $75 \mathrm{ft}$ runs of $8 \mathrm{in}$. pipe of condition sets IIIA and IIIB, wherein the initial transport time is about 3 seconds. The data of Table 5 can be used to arrive at a rough rule of thumb on axial node selection: The number of axial nodes used in Model $C$ for a given pipe leg should be at least as great as the instantaneous coolant transport time during the time of the major temperature change.

Additional model development work continues because the number of nodes to satisfy condition set IE is impractical, but Model $C$ appears to be generally satisfactory otherwise.

Model AT

Model $A 1$ is similar to Model $A$ except that the 2 point difference approximation of $\partial T / \partial x$ in Model $A$ is replaced by the alternating 3 point approximation, which is also used in the reference model. The stability criteria for Model Al is changed accordingly.

For convenience, the pipe wall nodes and coolant nodes are in line, rather than staggered as they are in Models A, B and C. The Model A1 equations, which replace Equations (31) and (32) are then,

$$
\begin{gathered}
T_{c j}^{+}=\left[1-\frac{(U A)_{c / p} \Delta t}{(V \rho C)_{c}}\right] T_{c j}+\frac{W C_{c} \Delta t}{2\left(V_{\rho} C\right)_{c}} T_{c j-1}-\frac{W C_{c} \Delta t}{2(V \rho C)_{c}} T_{c j+1} \\
+\frac{(U A)_{c / p} \Delta t}{(V \rho C)_{c}} T_{p j}
\end{gathered}
$$

(for even nodes $j=2,4,6 \ldots j_{\text {end }-1}$ )

and 


$$
\begin{gathered}
T_{c j}^{\prime}=\left[1-\frac{1.5 W C_{c} \Delta t}{\left(V_{\rho} C\right)_{c}}-\frac{(U A)_{c / p} \Delta t}{(V \rho C)_{c}}\right] T_{c j}+\frac{2 W C_{c} \Delta t}{(V \rho C)_{c}} T_{c j-1} \\
-\frac{W C_{c} \Delta t}{2\left(V_{\rho} C\right)_{c}} T_{c j-2}+\frac{(U A)_{c / p} \Delta t}{(V \rho C)_{c}} T_{p j}
\end{gathered}
$$

(for odd nodes $3,5,7 \ldots j_{\text {end }}$ )

and

$$
T_{p j}^{\prime}=\left[1-\frac{(U A)_{c / p} \Delta t}{(V \rho C)_{p}}-\frac{(U A)_{p / a} \Delta t}{(V \rho C)_{p}}\right] T_{p j}+\frac{(U A)_{c / p} \Delta t}{(V \rho C)_{p}} T_{c j}+\frac{(U A)_{p / a} \Delta t}{(V \rho C)_{p}} T_{a}
$$

for the pipe nodes.

To assure positive coefficients on the $T_{c j}$ and $T_{p j}$ terms, it is necessary that these limits are met:

$$
\begin{aligned}
\Delta t & =\frac{\left(V_{\rho} C\right)_{c}}{(U A)_{c / p}} \\
\Delta t & =\frac{\left(V_{\rho} C\right)_{c}}{1.5 W C_{c}+(U A)_{c / p}} \\
\Delta t & =\frac{\left(V_{\rho} C\right)_{p}}{(U A)_{c / p}+(U A)_{p / a}}
\end{aligned}
$$

The effect of the negative coefficients for the $T_{c j+1}$ term of Equation (42) and $T_{c j-2}$ term of Equation (43) on stability is uncertain. As discussed later, these terms apparently play an important part in the selection of maximum $\Delta t$ 's for stable solutions.

Model Al was first checked out with a fixed, small 0.1 second, time step. Cases with from 6 to 96 axial nodes were run with the results as tabulated in Table 6 and as shown in Figure 15. 
TABLE 6

MODEL AT SODIUM OUTLET TEMPERATURES WITH A FIXED 0.1 SECOND

INTEGRATION TIME STEP AND FOR TABLE 1 CONDITIONS SET IA

\begin{tabular}{ccc}
$\begin{array}{c}\text { Number of } \\
\text { Axial Nodes }\end{array}$ & $\begin{array}{c}\text { Maximum Temperature } \\
\text { Error, }{ }^{\circ} \mathrm{F}\end{array}$ & $\begin{array}{c}\text { Maximum Lead/Lag Time Error, } \\
\text { seconds }\end{array}$ \\
\cline { 2 - 3 } 6 & 10 & 32 (1 lead) \\
12 & 3 & 10 (lead) \\
24 & 1 & 2 (1ag) \\
48 & 0 & 0
\end{tabular}

96 (Unstable solution developing--See Figure 15)

Comparison of these data with similar data for Models $A, B$ and $C$ shows that Model Al may be the most accurate of the models tested so far. However, indications are that Model AI may need to operate with more restrictive stability requirements than Mode1s A, B, or C; the 96 node Model Al case is essentially unstable as shown in Figure 15, whereas there are no indications of instability with Models A, B, or C, even with up to 624 axial nodes. More restrictive stability limits result in longer problem execution times, but other than that there are no disadvantages with small integration time steps.

Next, runs were made with variable integration time steps using the limits established by Equations (45) and (47) and variations of Equation (46); the $W C_{C}$ multiplier in Equation (46) was studied in steps of 1.5, 2.5, 5.0, and 10.0. Results are shown in Figure 16. The instability shown by the case with the 1.5 multiplier on the $W C_{C}$ term indicates that stability is not guaranteed by Equation (46). Apparently, the negative coefficients for the $T_{c j+1}$ and $T_{c j-2}$ terms in (42) and (43) enter into the stability limiting $\Delta t$. The development of an exact analytical expression for stability was unsuccessful. Instead, a criteria is established by trial and error by varying the $W_{C}$ multiplier in Equation (46). Results indicate that the instability threshold multiplier value is about 5 , for 48 or less nodes. A value of 10 is specified to be safe. 


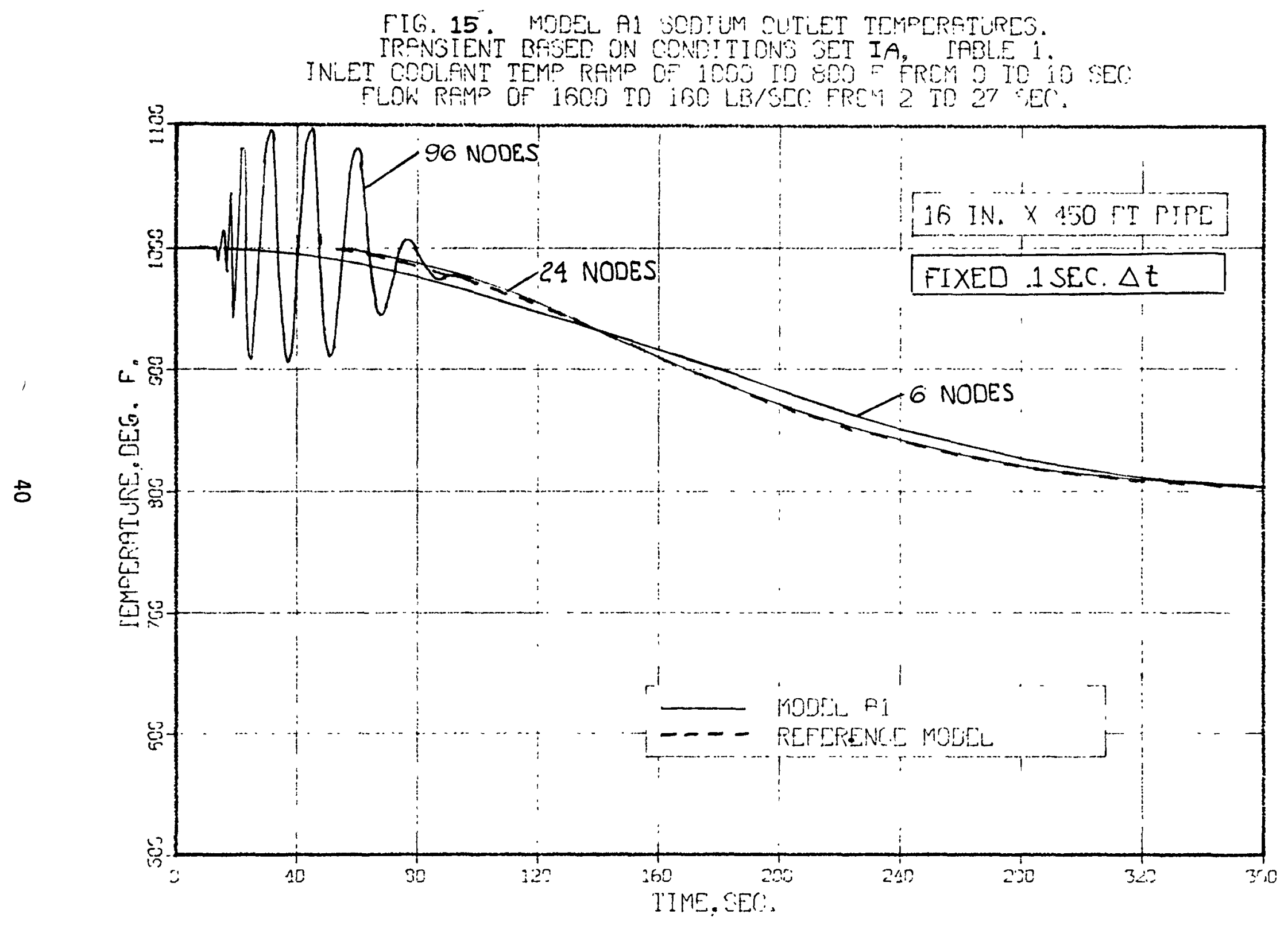


FIG. 16. MDDEL A1. USE STAETLITY LIMIT. SODILM OUTLET TEMD. IPANSIENT BASED DN CONDITIDNS SET IA, IABLE 1. INLET COOLANT TEMP RAMP OF 1000 TO $800 \mathrm{~F}$ FROM 5 TO 10 SEC FLOW RFMP OF 1600 TO 160 LE/SEC FFOM 2 TO 27 SEC.

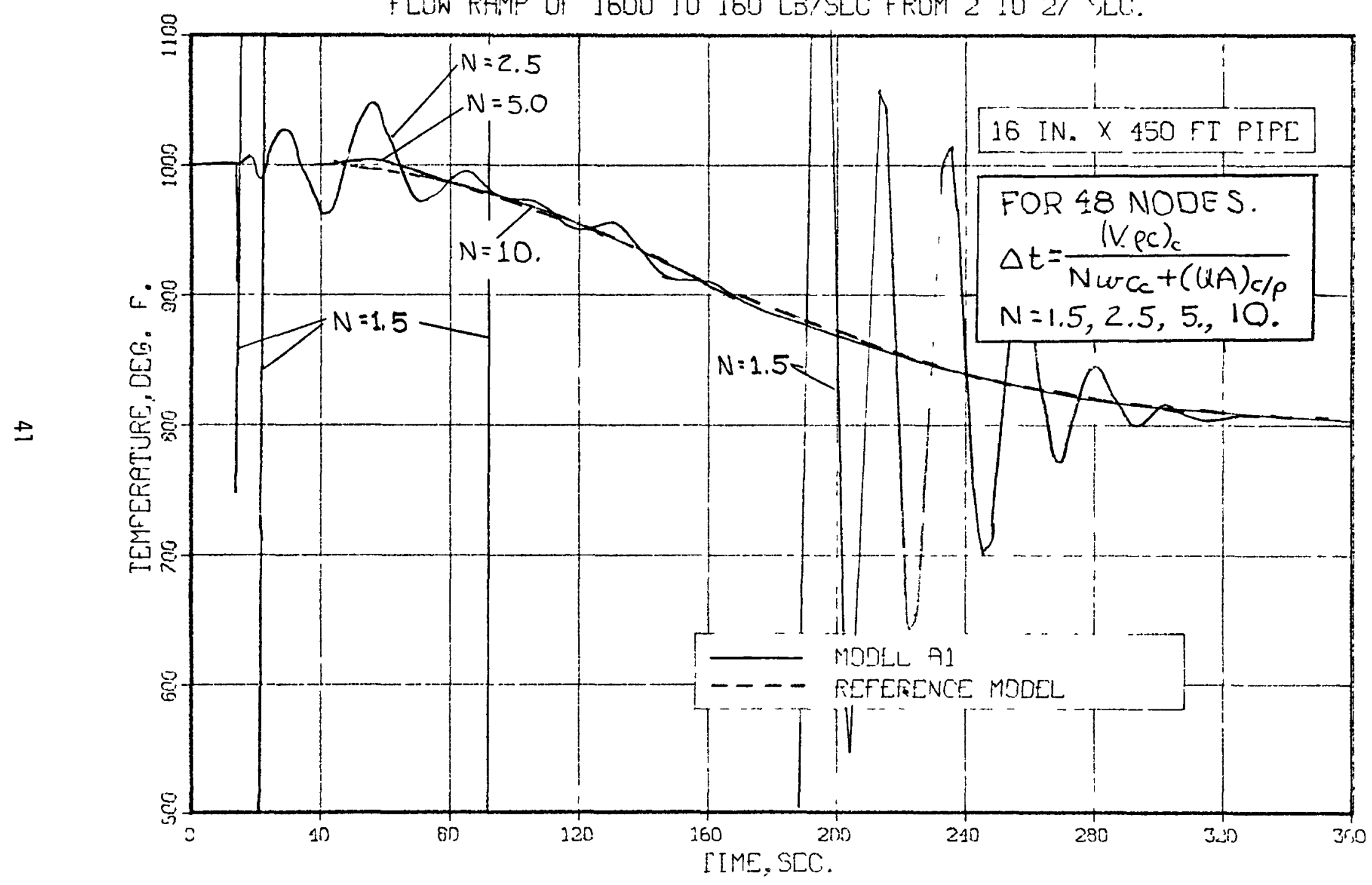


A series of runs was made for all conditions listed in Table 1 , using Model Al with the limiting $\Delta t$ given by,

$$
\Delta t=\frac{\left(V_{\rho} C\right)_{C}}{10 W C_{c}+(U A)_{c / p}}
$$

These results are shown in Figures 17 through 26 and key data are tabulated in Table 7. The model selection criteria is met with 24 nodes without exception for all cases. As in the case of Model C, 6 nodes are sufficient for the pipe runs with the short transport times.

\section{Mode1 Cl}

Although computer run times are not excessive with Model Al, with its relatively tight $\Delta t$ limitation, it would be worthwhile to run even faster if errors can be kept small enough. Thus, Model $\mathrm{Cl}$ was created as a variation of Model $\mathrm{C}$, in which Model $\mathrm{Cl}$ uses the 3-point difference approximations in place of the 2-point differences of Model $\mathrm{C}$. Model $\mathrm{Cl}$ would run faster than Model A1 because integrations are only done as each node is refilled, until the time the entire pipe is refilled. However, as shown in Figure 27, large errors resulted for cases run using Equation (48) for stability.

Further work with Model $\mathrm{Cl}$ was abandoned.

\section{Selection of Simplified Model}

The selection of the simplified model is between Model $C$ and Model Al. Model Al is the more accurate of the two models, but computer execution time is somewhat greater than for Model $C$. Computer execution times for cases run to 360 seconds with 24 axial nodes, under set IA conditions, are about 3.28 and 6.28 seconds for Models $C$ and $A 1$, respectively. With these rapid computer run times, the difference in execution times between the two models is judged to be unimportant. Therefore, Model Al is the final choice because of its superior overall accuracy, which can be easily seen by comparing the error data included in Tables 5 and 7. 
FIG. 17 . MCDEL AI WITH STPBILITY LIMITS. SCDILM OUTLET TEMP. IRANSIENT BASED DN CONDITIDNS SET IA, TABLE 1.

INLET CODLANT IEMP RAMP DF 1000 TO $800 \mathrm{~F}$ FROM $D$ TO 10 SEC FLOW RAMP OF 1600 TO $160 \mathrm{LB} / \mathrm{SEC}$ FROM 2 TD 27 SEC.

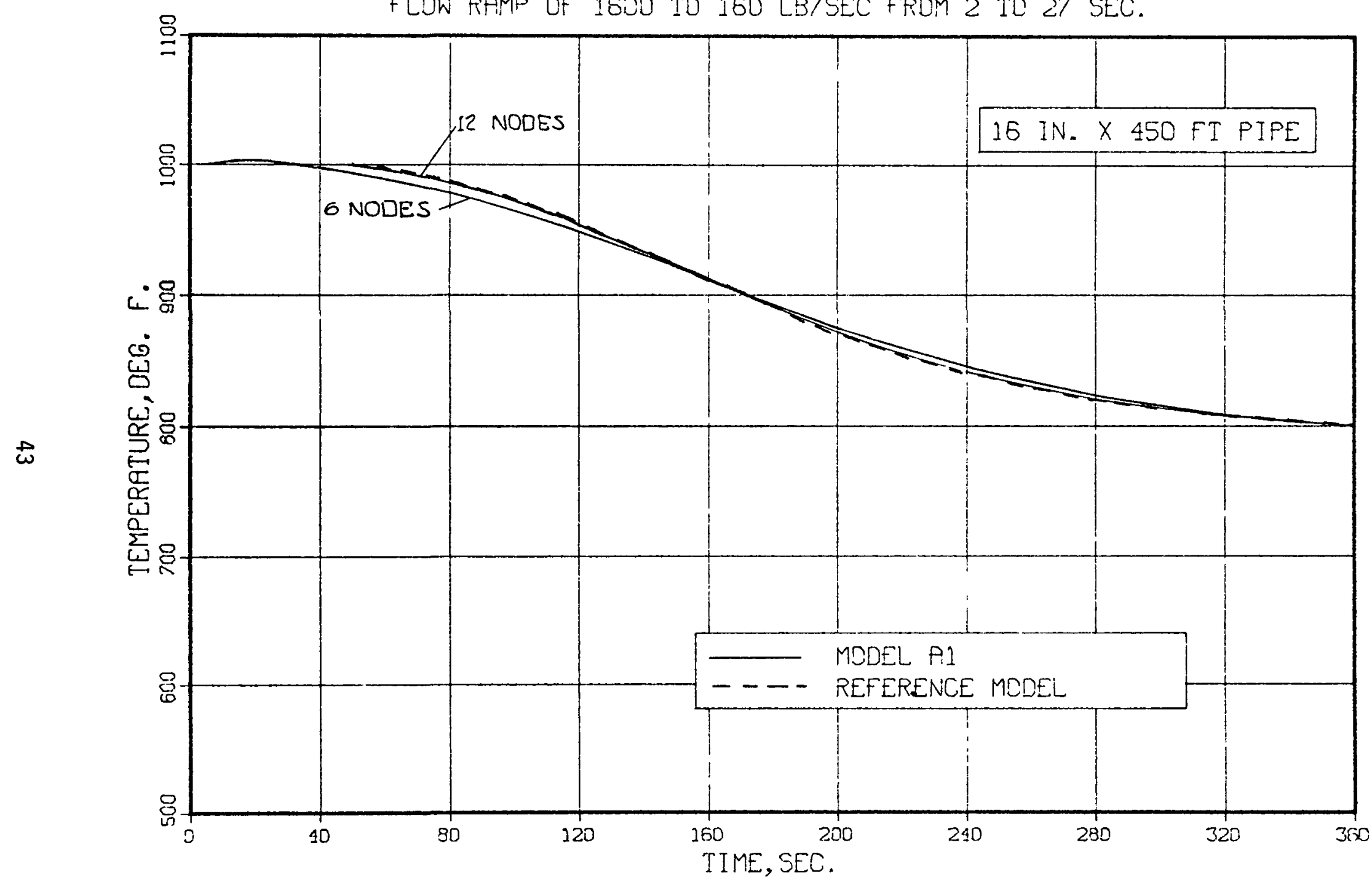


FIG. 18. MODEL A1 WITH STABILITY LIMITS. SODIUM OUTLEI IEMP. TRANSTENT BASED ON CIONDITIONS SET IB, TAELE ${ }^{3}$ IO SEO INLET GORLAN. FEW RATE CONSTANT AT 1600 LBISEC.

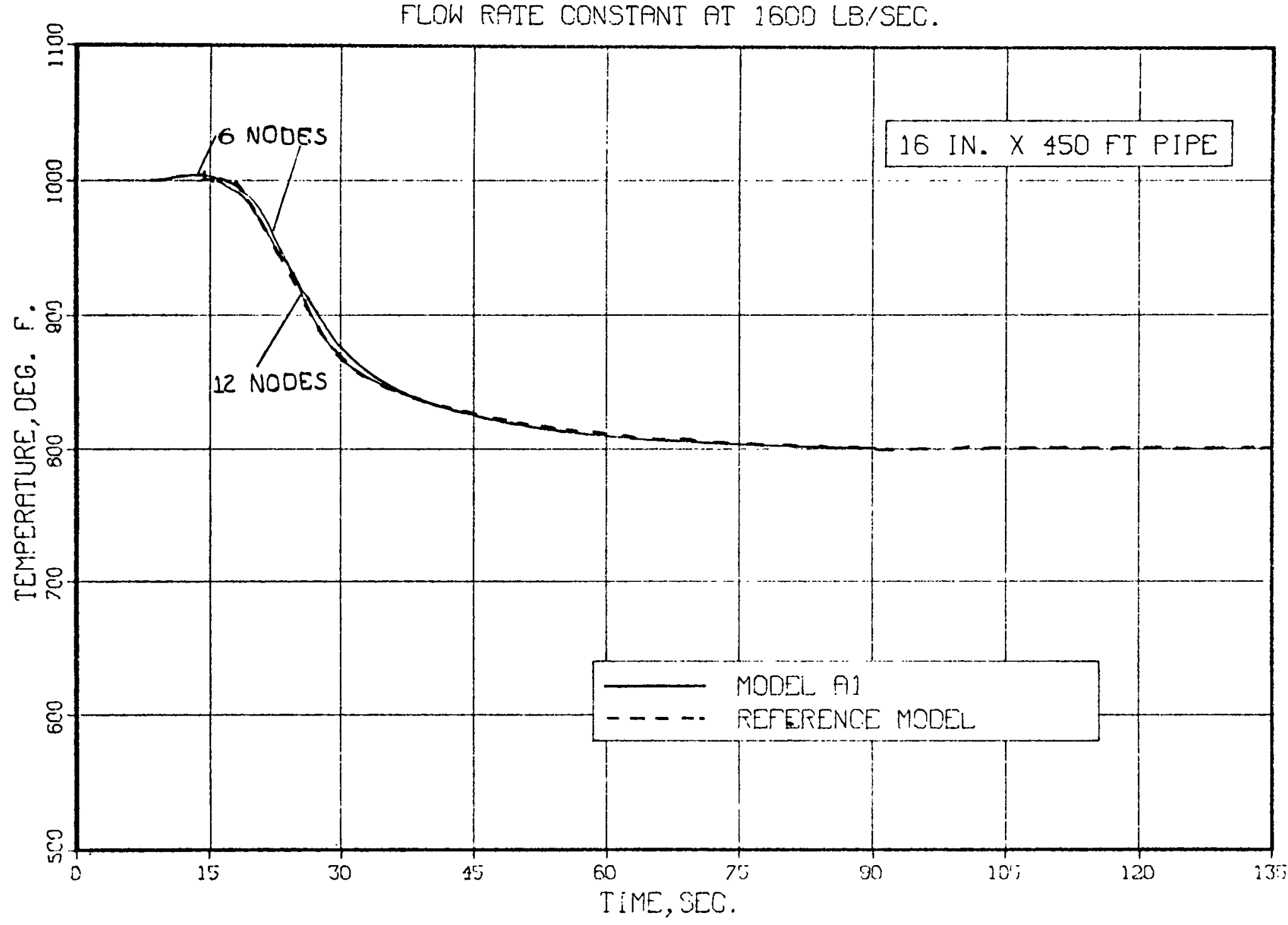


FIG. 19. MODEL AI WITH STABILITY LIMITS. SODIUM OUTLET TEMP. IRANSIENT BASED ON CONDITIONS SET IC, TABLE 1.

DOWN/LP RAMPS ON INLET SODTLM TEMPEFATURE.

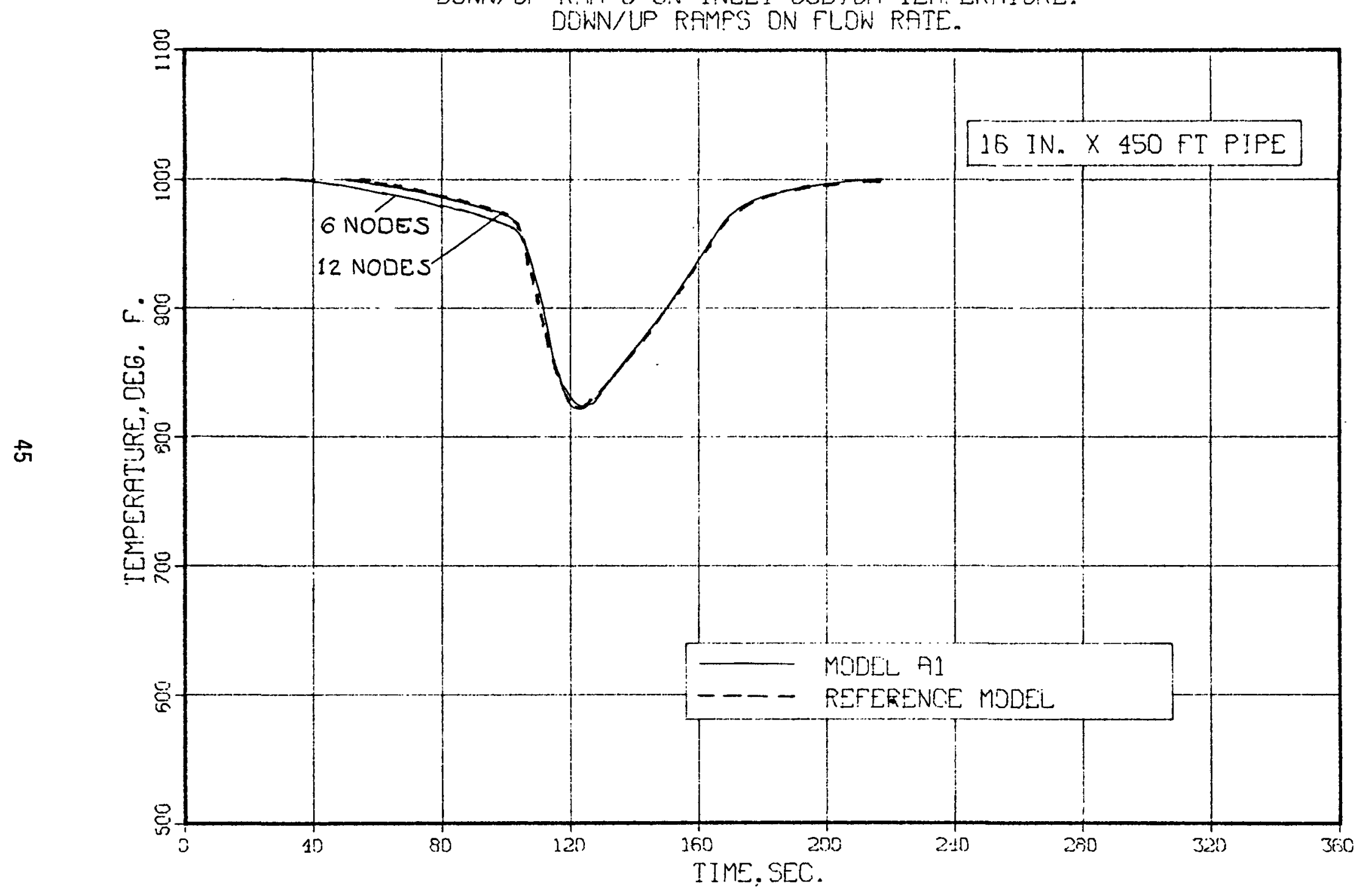


FIG. 20. MODEL A1 WITH STABILITY LIMITS. SCLIUM OUTLET TEMP. TRPNSIENT BASED DN CONDITIONS SET ID, TPBLE 1. 1000 TO 800 F TEMPEFATLRE RFMP FROM 70 TO I10 SEC.

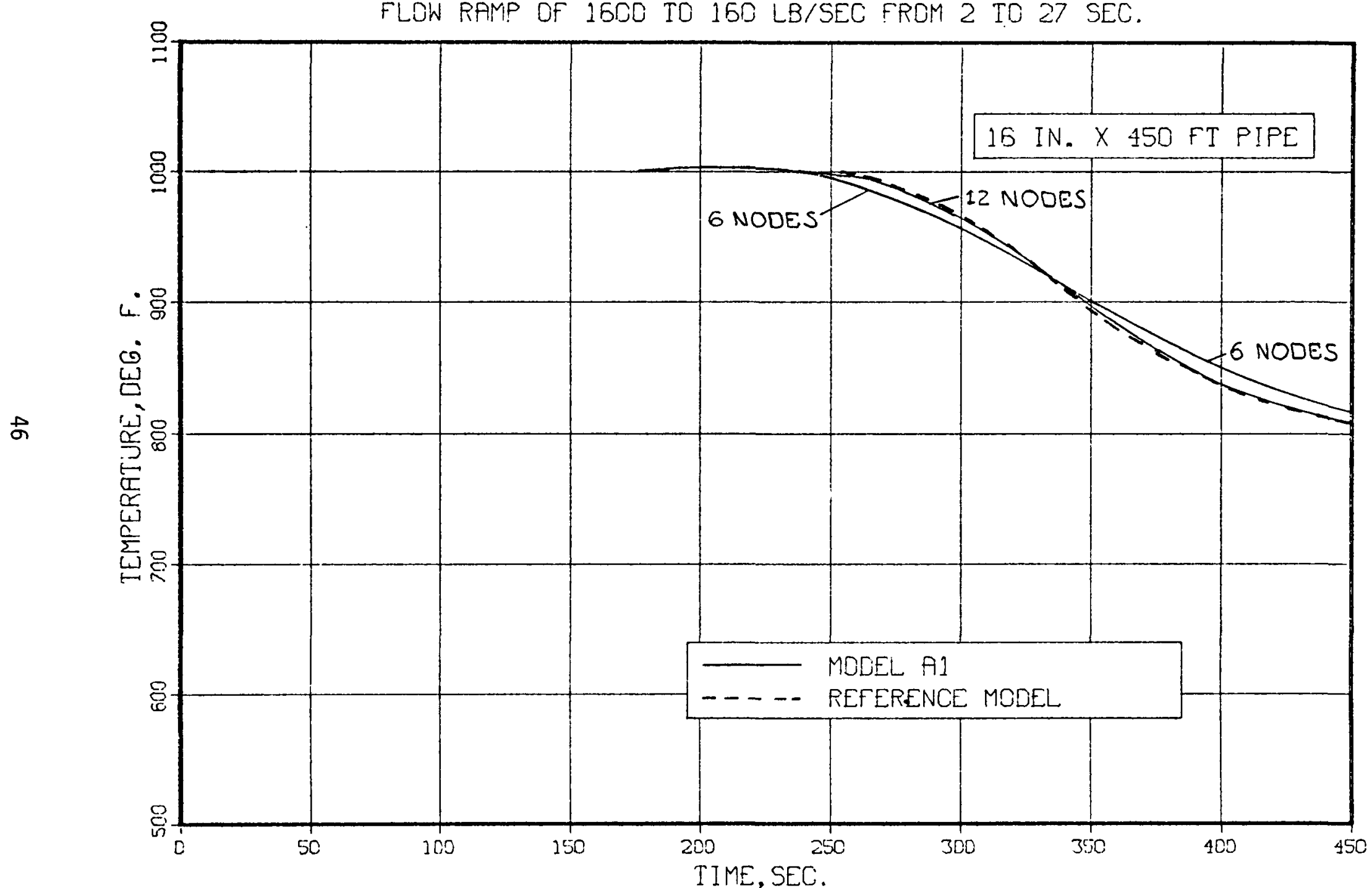


FIG.21. MODEL A1 WITH STABILITY LIMITS. SODIUM OUTLET TEMP. TRFNSIENT BASED DN CONDITIONS SET IE, TARLE 1.

INLET COOLANT TEMP. RAMP OF 1000 TO 800 DEG F FROM O TO 40 SEC

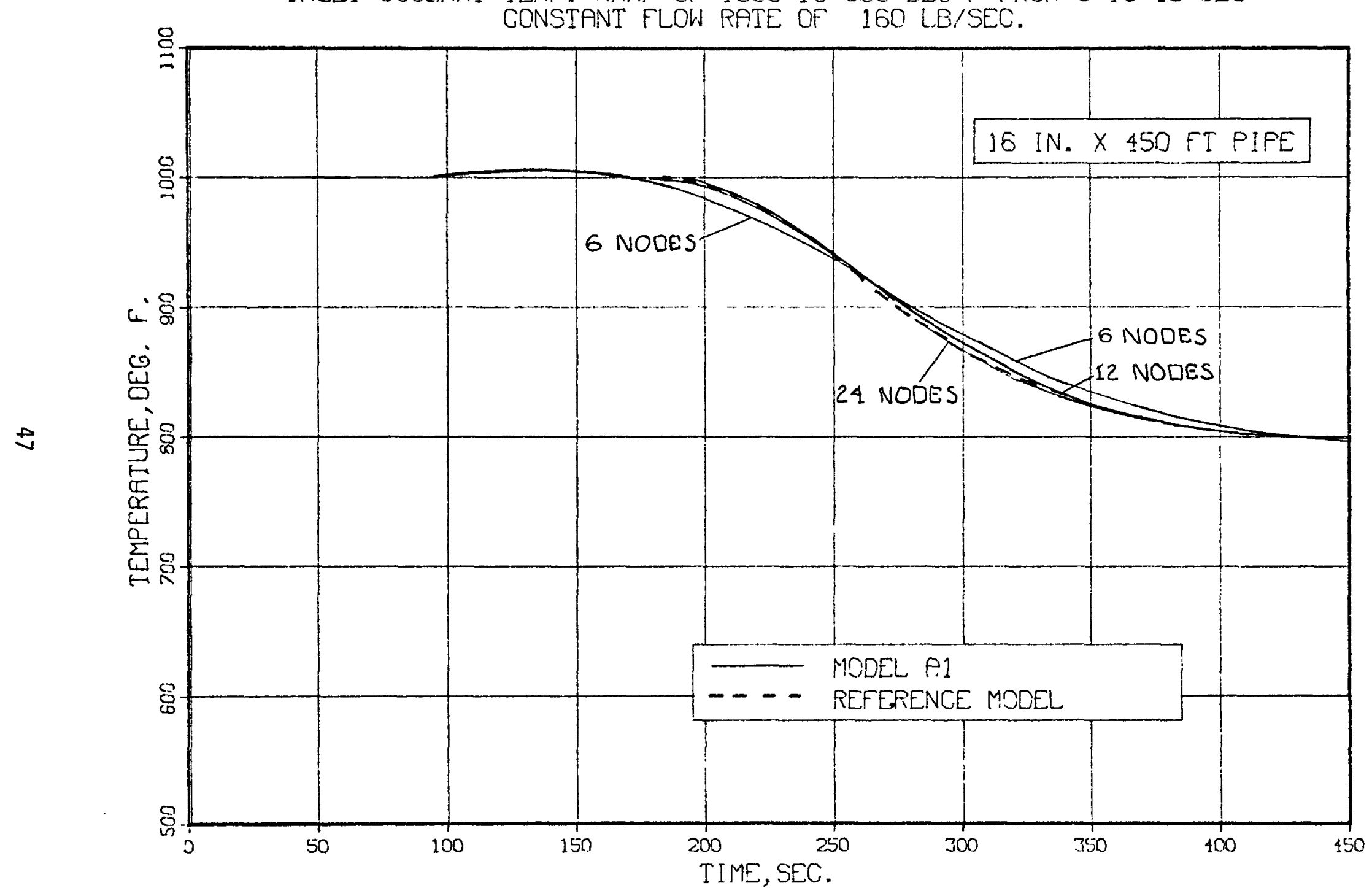


FIG.22. MDDEL A1 WITH STABILITY LIMITS. SODIUM OUTLET TEMP. TRPNSIENT BASED ON CONDITIONS SET IIA, TABLE 1.

INLET COOLANT TEMP RAMP OF 1000 TO $800 \mathrm{~F}$ FROM $O$ TO IO SEC

FLOW RAMP OF 1600 TD 160 LE/SEC FROM 2 TO 27 SEC.

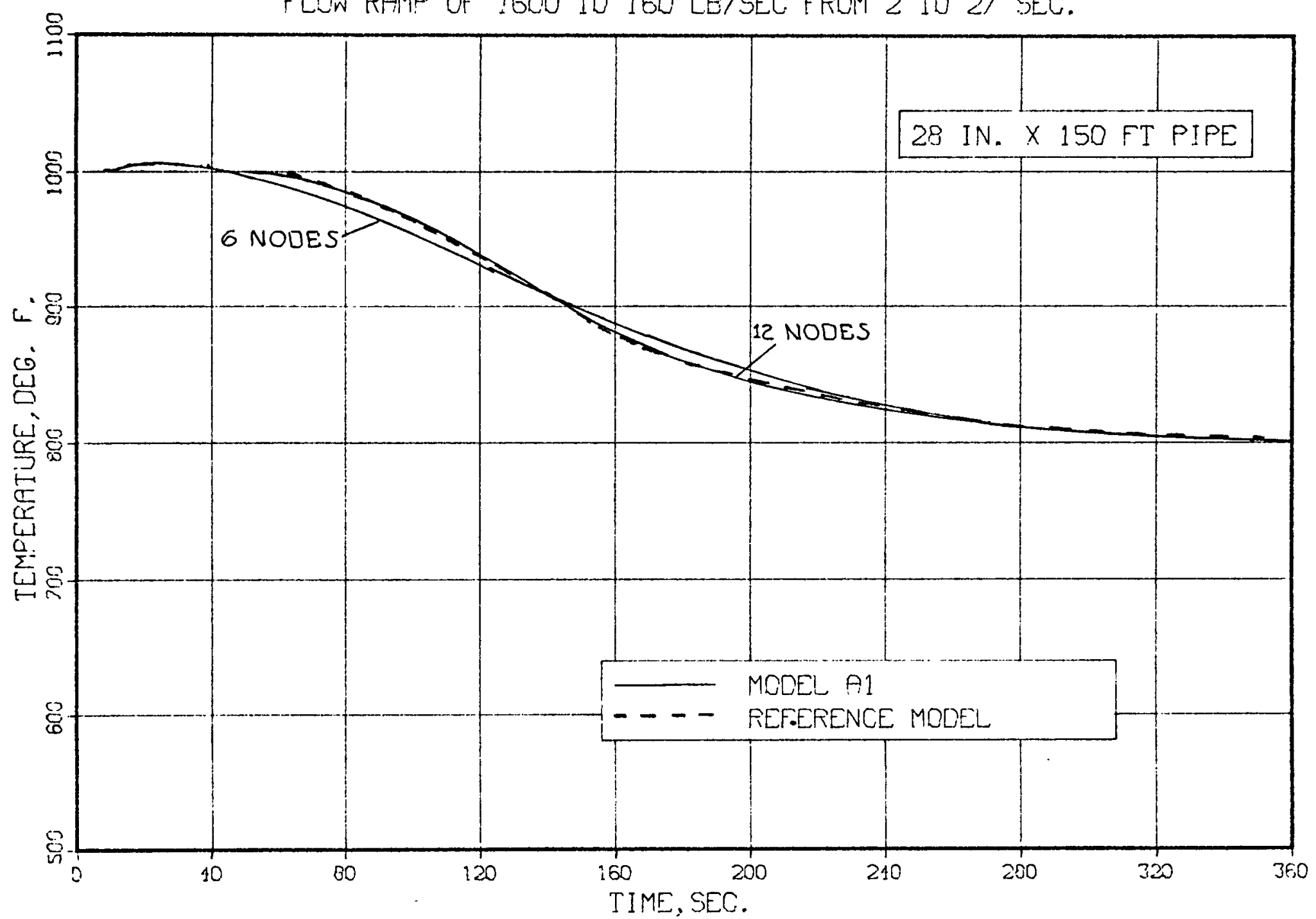


FIG.23. MODEL A1 WITH STABILITY LIMITS. SODIUM OUTLET TEMP. TRANSIENT BASED ON CONDITIONS SET IIB, TPELE 1.

INLET COOLANT TEMP RAMP OF' 1000 'TO 800 F FROM D TO 10 SEO FLDW RATE CONSTANT AT 1600 LB/SEC.

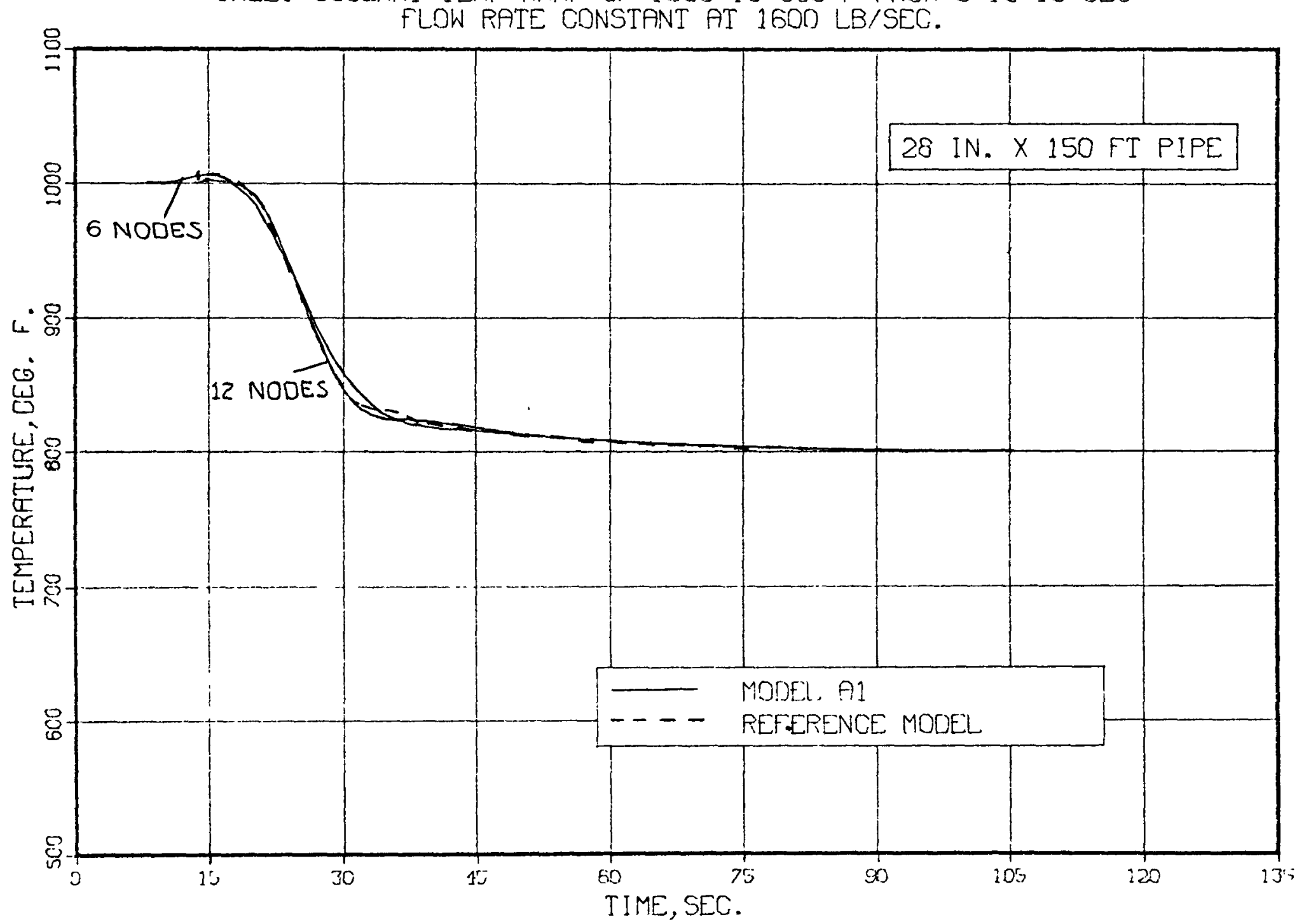


FIG.24. MODEL AI WITH STABILITY LIMITS. SODILM OUTLET TEMP. THANSIENT BASED ON CONDITIONS SET IIIF, IFBLE I

INLET C.OOLANT TEME FIAME OF 1000 TO BCD F FROM D TO 10 SEC FLOW RFMP UF 400 TO 40 L.B/SEC FFOM 2 TO 27 SEC.

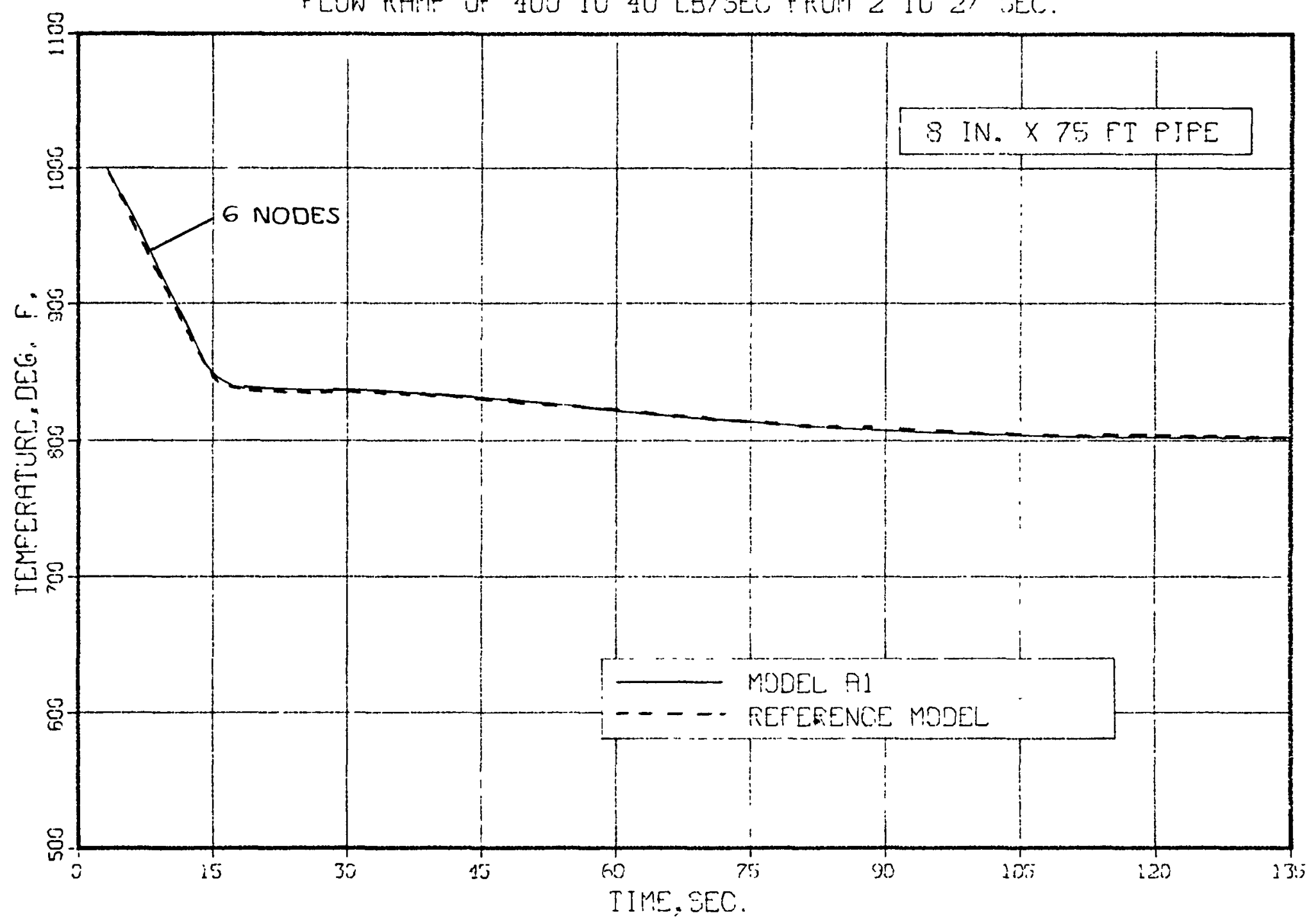


FIG. 25. MDOEL AI WITH STARTI.TTY LIMITS. SOOIUM OUTLFT TEMP. IFFANSIENT BASJED UN CONOITIONS SET IIIB, TABLE 1.

INLET COOLANT TEME RAMP UF 1000 TO 800 F FFIOM O TO 10 SEC I LOW CONSTANT FIT 4 UO LES/SEC.

G

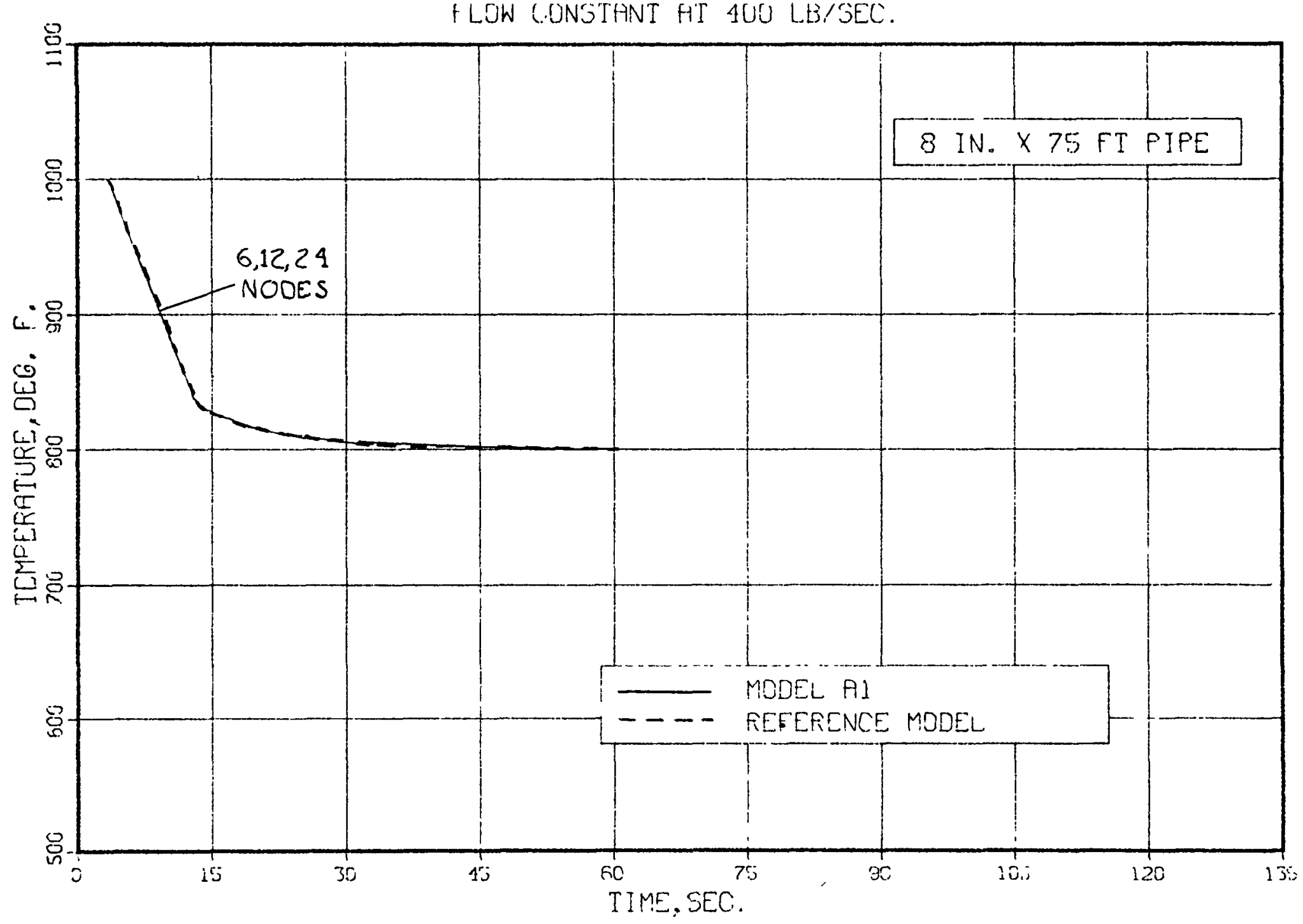


FIG.26. MODEL A1 WITH STRBILITY LIMITS. SODIUM OLTLET TEMP. TRANSIENT BASED DN CONDITIONS SET IVA, TAELE 1.

INLET COOLPNT TEMP RAMP OF 1000 TO 800 F FROM O TO 10 SEC RAMP FLOW FROM 31.6 TO 3.16 LB.'SEC FROM 2 TO 27 SEC.

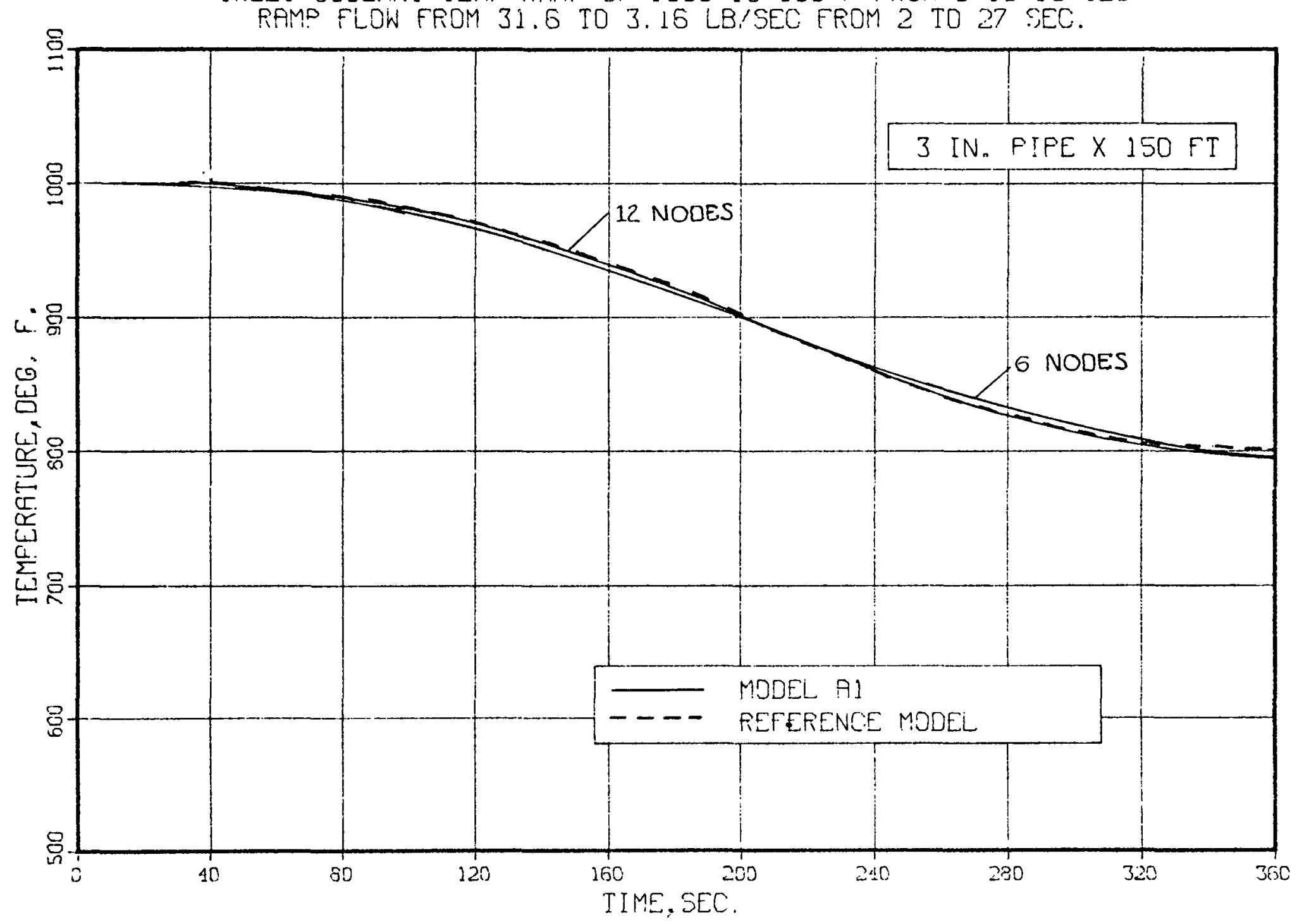


TABLE 7

FINAL CHECKOUT OF MODEL AI

\begin{tabular}{|c|c|c|c|c|c|c|}
\hline \multirow{2}{*}{$\begin{array}{c}\text { Conditions Set } \\
\text { As Defined } \\
\text { In Table } 1 \\
\end{array}$} & \multirow{2}{*}{$\begin{array}{l}\text { Pipe Size } \\
O D \times \text { Length } \\
\end{array}$} & \multirow{2}{*}{$\begin{array}{c}\text { Forcing Ramps } \\
T=\text { Teniperature } \\
F=\text { Flow } \\
(\text { See Table 1) }\end{array}$} & \multirow{2}{*}{ 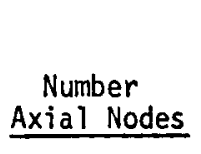 } & \multicolumn{2}{|c|}{$\begin{array}{l}\text { Maximum Outlet Coolant Errors } \\
\text { Relative to Reference Case }\end{array}$} & \multirow{2}{*}{$\begin{array}{c}\text { Initial } \\
\text { Steady State } \\
\text { Transport Time, } \\
\text { seconds } \\
\end{array}$} \\
\hline & & & & Temperature, ${ }^{\circ} \mathrm{F}$ & Lead or Lag Time, seconds & \\
\hline IA & $16^{\prime \prime} \times 450^{\prime}$ & T\&F down & $\begin{array}{r}6 \\
12 \\
24\end{array}$ & $\begin{array}{l}8 \\
2 \\
0\end{array}$ & $\begin{array}{c}20(\text { lead }) \\
10(\text { lead }) \\
0\end{array}$ & 18 \\
\hline IB & $16^{\prime \prime} \times 450^{\prime}$ & $\begin{array}{l}T \text { down; } \\
F \text { constant } \\
1600 \mathrm{lb} / \mathrm{sec}\end{array}$ & $\begin{array}{r}6 \\
12 \\
24\end{array}$ & $\begin{array}{r}10 \\
4 \\
3\end{array}$ & $\begin{array}{l}2 \text { (lead) } \\
2 \text { (lead) } \\
1 \text { (lag) }\end{array}$ & 18 \\
\hline IC & $16^{\prime \prime} \times 450^{\prime}$ & $\begin{array}{l}\text { T\&F down; } \\
\text { then back to } \\
\text { initial }\end{array}$ & $\begin{array}{r}6 \\
12 \\
24\end{array}$ & $\begin{array}{l}8 \\
2 \\
1\end{array}$ & $\begin{array}{l}25 \text { (lead) } \\
10 \text { (lead) } \\
5 \text { (lead) }\end{array}$ & 18 \\
\hline ID & $16^{\prime \prime} \times 450^{\prime}$ & $\begin{array}{l}\text { T\&F down; } \\
T \text { ramp delayed }\end{array}$ & $\begin{array}{r}6 \\
12 \\
24\end{array}$ & $\begin{array}{r}12 \\
5 \\
2\end{array}$ & $\begin{array}{r}20(\mathrm{lag}) \\
4(\mathrm{lag}) \\
3(\mathrm{lag})\end{array}$ & 18 \\
\hline IE & $16^{\prime \prime} \times 450^{\prime}$ & $\begin{array}{l}T \text { down; } \\
F \text { constant a } \\
160 \mathrm{lb} / \mathrm{sec}\end{array}$ & $\begin{array}{r}6 \\
12 \\
24\end{array}$ & $\begin{array}{r}14 \\
6 \\
4\end{array}$ & $\begin{aligned} 20 & (\mathrm{lead} / \mathrm{lag}) \\
5 & \left(\begin{array}{l}\mathrm{lag}) \\
3\end{array}(\mathrm{lag})\right.\end{aligned}$ & 180 \\
\hline IIA & $28^{\prime \prime} \times 150^{\prime}$ & T\&F down & $\begin{array}{r}6 \\
12 \\
24\end{array}$ & $\begin{array}{r}12 \\
4 \\
2\end{array}$ & $\begin{array}{r}15 \\
15 \\
5\end{array}\left\{\begin{array}{l}\text { lag) } \\
\text { lead } \\
\text { lead) }\end{array}\right.$ & 19 \\
\hline IIB & $28^{\prime \prime} \times 150^{\prime}$ & $\begin{array}{l}T \text { down; } \\
\text { F constant } 0 \\
1600 \mathrm{lb} / \mathrm{sec}\end{array}$ & $\begin{array}{r}6 \\
12 \\
24\end{array}$ & $\begin{array}{r}10 \\
6 \\
4\end{array}$ & $\begin{array}{l}4(\text { lead } / \text { lag }) \\
2 \text { (lead/lag) } \\
2 \text { (lead) }\end{array}$ & 19 \\
\hline IIIA & $8^{\prime \prime} \times 75^{\prime}$ & T\&F down & $\begin{array}{r}6 \\
12 \\
24\end{array}$ & $\begin{array}{l}1 \\
1 \\
0\end{array}$ & $\begin{array}{l}2 \text { (lead) } \\
2 \text { (lead) } \\
0\end{array}$ & 3 \\
\hline IIIB & $8^{\prime \prime} \times 75^{\prime}$ & $\begin{array}{l}T \text { down; } \\
\text { F constant } 0 \\
400 \mathrm{lb} / \mathrm{sec}\end{array}$ & $\begin{array}{r}6 \\
12 \\
24\end{array}$ & $\begin{array}{l}0 \\
0 \\
0\end{array}$ & $\begin{array}{l}0 \\
0 \\
0\end{array}$ & 3 \\
\hline IVA & $3^{\prime \prime} \times 150^{\prime}$ & T\&F down & $\begin{array}{r}6 \\
12 \\
24\end{array}$ & $\begin{array}{l}8 \\
6 \\
4\end{array}$ & $\begin{array}{l}15 \text { (lead/lag) } \\
10(\mathrm{lag}) \\
5(1 \mathrm{ag})\end{array}$ & 13 \\
\hline
\end{tabular}


FIG.27. MODEL C1 WITH STABILITY LIMITS. SODIUM OUTLET TEMP. TRANSIENT BASED ON CONDITIONS SET IA, TABLE 1.

INLET COOLANT TEMP RAMP OF 1000 TO $800 F^{\prime}$ FROM 0 TO 10 SEC

FLOW RAMP OF 1600 TO 160 LB/SEC FROM 2 TO 27 SEC.

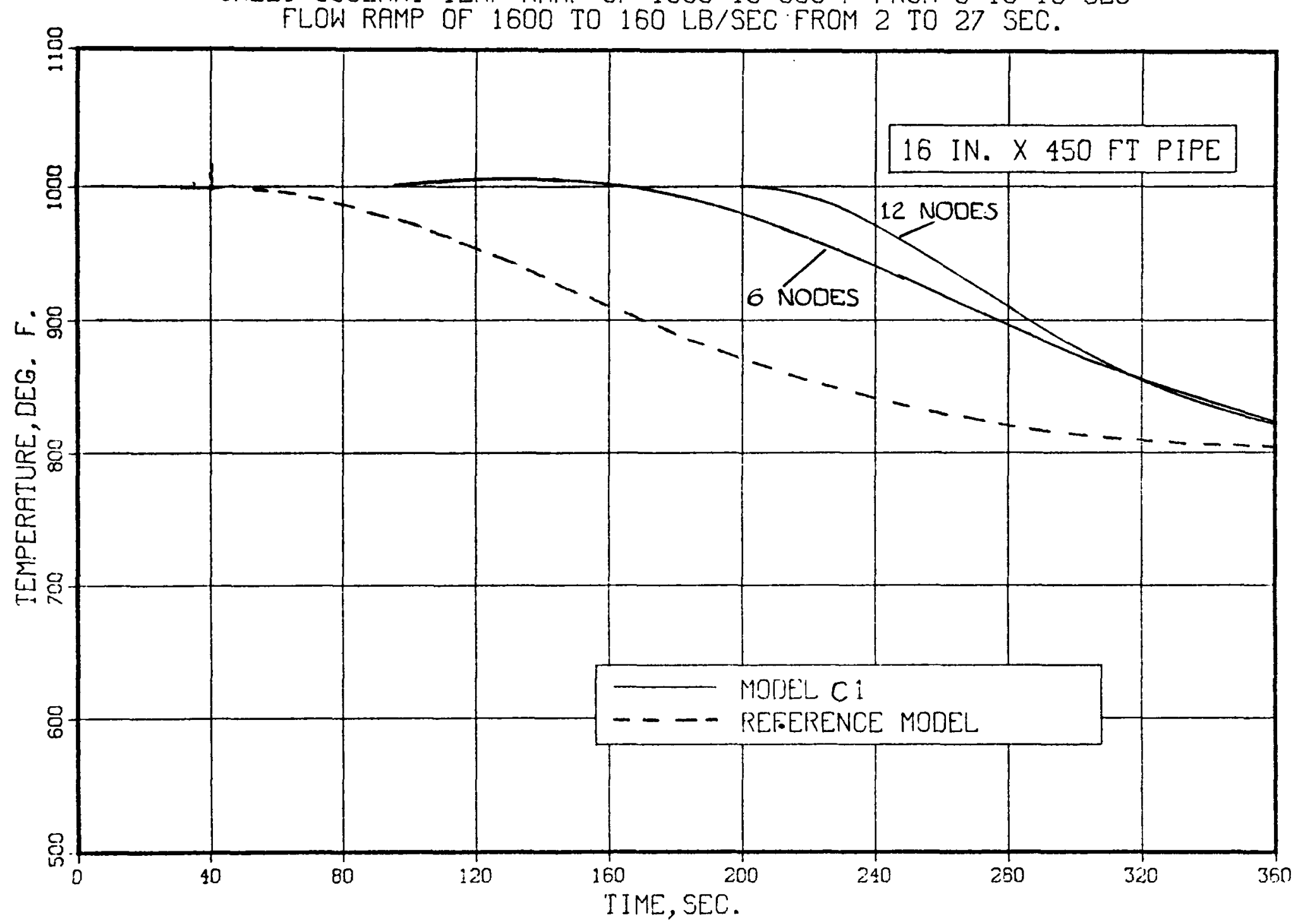


The subroutine, named PIPE, for determining coolant and pipe wall temperatures as a function of time and distance for pipe legs between FFTF components is based on Model AT. Key features of PIPE are listed in Table 8.

Some amplification of paragraph four in Table 8 is necessary. The FFTF's heat transport system (HTS) model is visualized to have about 29 individual pipe runs between components for the models with two identical HTS circuits representing the three actual circuits. The 29 runs allow for two dump heat exchanger module models in each of the two modeled secondary loops. Included in the pipe run count are runs to and from temperature sensors which are used for process control and/or plant protection trips, runs to and from a pipe break, and runs to and from tee junctions and/or area changes. Several of these runs are short in length and can be satisfactorily modeled by six or eight axial nodes. Thus, for good utilization of computer memory, the PIPE subroutine is dimensioned for 53 pipe legs with 8 axial nodes (or 9 nodal points) per leg. This is in place of say 29 pipe runs with 25 nodal points each. Note there is a distinction between pipe legs and pipe runs; several pipe legs may be combined to form a single pipe run (between components). The code allows for up to four legs in series to form a run, with a maximum of 32 nodes total. Fifty-one legs appear to be needed for the FFTF's model of the HTS considering node requirements for acceptable accuracy (24 nodes for long runs with long coolant transport times, 16 nodes for intermediate lengths, and 8 nodes for short runs with short transport times). Two spare legs have been allowed.

PIPE and its related subroutines and functions require, a large amount of computer storage capacity. If a computer storage problem arises when PIPE is incorporated into DEMO, some relief is possible by decreasing the maximum number of axial nodal points and/or the number of legs. About 212 locations are eliminated by dimensioning for 7 axial nodal points instead of 9 , and about 50 locations are eliminated by each reduction of one leg. of course, these reductions increase calculated temperature errors. 


\section{TABLE 8}

\section{KEY FEATURES OF PIPE SUBROUTINE}

1. It is based on pipe Model A1.

a. Explicit, numerical integration method used.

b. $\partial T / \partial X$ approximated by alternating three-point difference formula; central difference for even nodal points; backward difference for odd nodal points.

c. Stability of computations virtually assured by built-in time step limits.

d. Models three radial nodes, including an ambient temperature node where temperature is constant with distance. The other two nodes are sodium and pipe wal1. The ambient temperature can vary with time, if known.

e. The heat transfer resistance from the pipe's outside surface to the ambient temperature node is constant in time and distance.

2. Coded for positive or negative flows in any pipe run between components, but initial steady-state flow rates must be positive. Model convention is for positive flow to be in the direction of increasing axial nodal point numbers.

3. Cases can be executed using basic dimensional inputs from a data deck or execution can be done starting with default values in which case the leg data cards in the input data deck are omitted. To facilitate the inclusion of data statement default values in subsequent computer runs, punched card output can be specified by input integer control. Default values are provided for dimensional constants and initial condition values. Runs can be made using the dimensional constants alone or in combination with the initial condition values. Initial conditions are determined whenever default values are not applicable.

4. Dimensioned for up to 53 separate pipe legs with a maximum of 8 nodes per leg. Up to 4 legs can be in series to form a single pipe run between components (i.e., allows up to 32 nodes for any given pipe run).

5. Integrations are done at time steps different than that used in the MAIN Program. Usualiy the PIPE time step will be much greater than the MAIN Program step.

6. Outgoing pipe leg coolant temperatures are provided at the MAIN Program time intervals by second degree polynomial interpolation of PIPE subroutine data. Reports and plots of these output temperatures are based on the interpolated values.

7. Complete temperature data can be reported at specified intervals within the PIPE subroutine by integer control input.

8. The flow rate in each pipe leg of a series of continuing legs is based on the flow in the first leg of the series.

9. The heat transfer resistance across a gas gap, if it exists between the pipe and insulation, is neglected. This simplification is justified for FFTF sodium systems because of the high radiation heat transfer between the two surfaces in which the insulation's inside surface temperature is nearly equal to the pipe's outside surface temperature. If the PIPE subroutine is used for low temperature systems, it would be best to assume that the gap resistance is the same as an insulation resistance of the same thickness, by letting XINSUL equal the combined gap plus resistance thicknesses and setting XGAP equal to 0 .

10. If desired, the integration time step in the PIPE subroutine can be limited to a numerically small input specified value. 
In order to debug the PIPE subroutine, it is necessary to write a stand-in main program and stand-in routines to provide forcing coolant flow and temperature data as functions of main program time. DEMO wil1 provide these inputs once the PIPE subroutine is incorporated in it. MAIN is the name given the stand-in main program and FORCE is the name given the stand-in routine for coolant input flow rate and temperature data. MAIN, FORCE, and PIPE are used in conjunction with four other subroutines and/or functions, which are listed and described in Table 9. Flow charts of these programs, except for FIND and PHIF, are shown in Figures 28 through 32. The symbols used in these charts and in the program are listed in the MAIN program and PIPE subroutine listings included in Appendix A.

The program is written in Fortran for a Control Data Corporation CYBER 74-18 computer. Input Data for Program MAIN

The input data are read in from the MAIN program by a series of six. card types. Provisions are made to run a single case only, because it is unlikely that multiple DEMO cases will be run. Input cards are arranged as follows:

1. First card - Case identification information: 7A10 format.

2. Second card - Program controls in the order given: free form input. DTAU ENDTME IREPTX MAIN program integration time step, sec. Run stop time, sec. Reporting interval for MAIN program output. Data reported every IREPTX time steps of MAIN.

IPLOTX Plot data storage interval. Data stored every IPLOTX time step of MAIN. NDEBUG Control integer for reporting al1 temperature data from PIPE subroutine.

NDEBUG $=0$ By-pass reports NDEBUG $=K$ Report data every $K$ time steps of PIPE $(K=1)$. 
TABLE 9

\section{AUXILIARY SUBROUTINES AND FUNCTIONS FOR PIPE}

Name of Function or Subroutine

LEG

UCOEF

FIND

PHIF

\section{Description}

LEG is a subroutine which does the following:

1. Linear interpolation of MAIN program data to give incoming sodium temperature and flow rate at the time used in the PIPE subroutine.

2. Calls PIPE subroutine for transient calculations.

3. Second degree polynomial interpolation of PIPE data to give outgoing sodium temperature at the time of the MAIN program.

UCOEF is a subroutine to provide (1) physical property data for sodium and stainless steel pipe wall as a function of the volumetric average temperatures at each time plane of the PIPE subroutine, (2) corresponding heat transfer coefficients, and (3) products of overall coefficients times surface areas.

FIND is a general purpose binomial interpolation function to search a two-dimensional array and to return the interpolated value corresponding to a one-dimensional argument. Specifically, it is used here with PHIF to give the heat transfer correction function $\phi$, from tabulated data included in PHIF.

PHIF is a function which provides an eddy diffusivity correction factor $\phi$ for the liquid metal Nusselt Number equation (7). By the method of Dwyer, (3)

$$
\begin{aligned}
& \bar{\psi}=1-\frac{\phi}{\operatorname{Pr}}, \text { where } \\
& \operatorname{Pr}=\text { Prandt } 1 \text { number } \\
& \phi=1.82 /\left(\frac{\varepsilon_{\mathrm{m}}}{\varepsilon_{\mathrm{v}}}\right)^{1.4} .
\end{aligned}
$$


Figure 28. MAIN Flow Chart

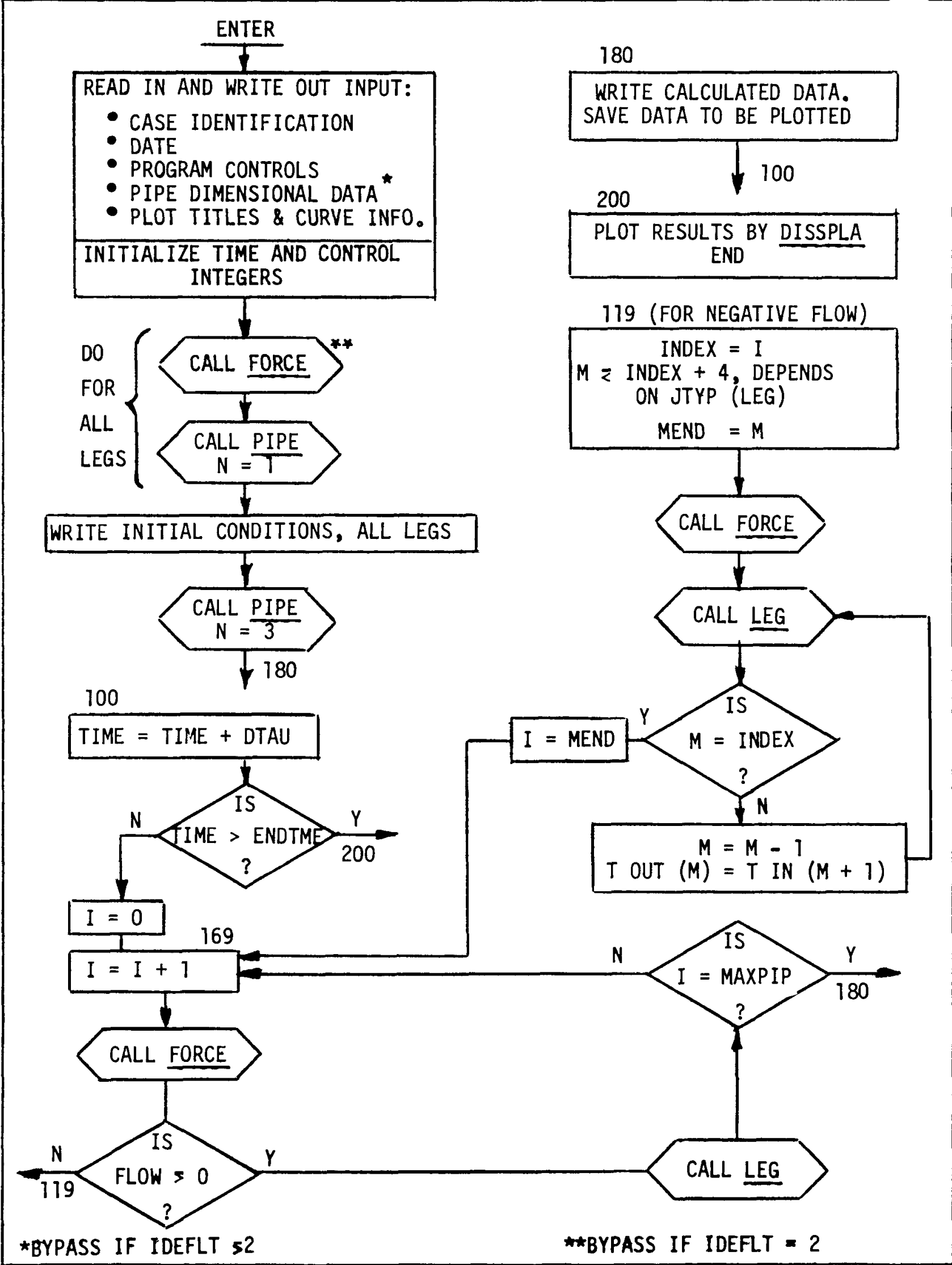


Figure 29. FORCE Flow Chart

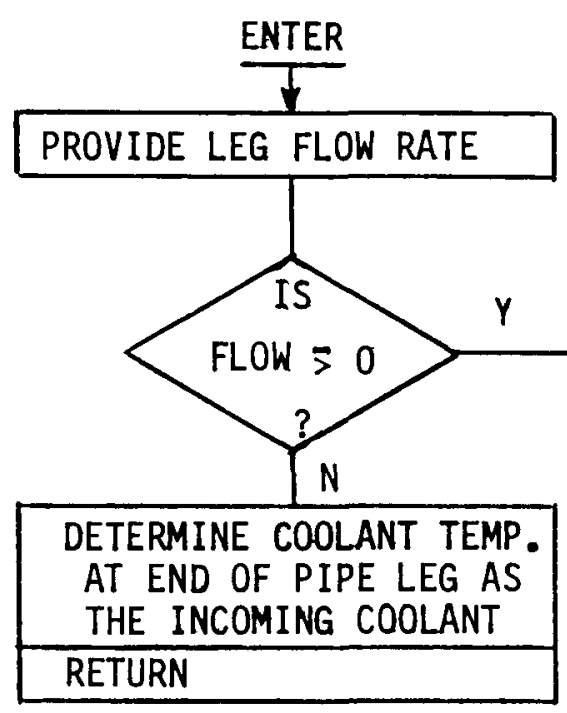

DETERMINE COOLANT TEMP. AT START OF PIPE LEG AS THE INCOMING COOLANT

RETURN

DETERMINE COOLANT TEMP.

AT END OF PIPE LEG AS

THE INCOMING COOLANT

RETURN

Figure 30. LEG Flow Chart

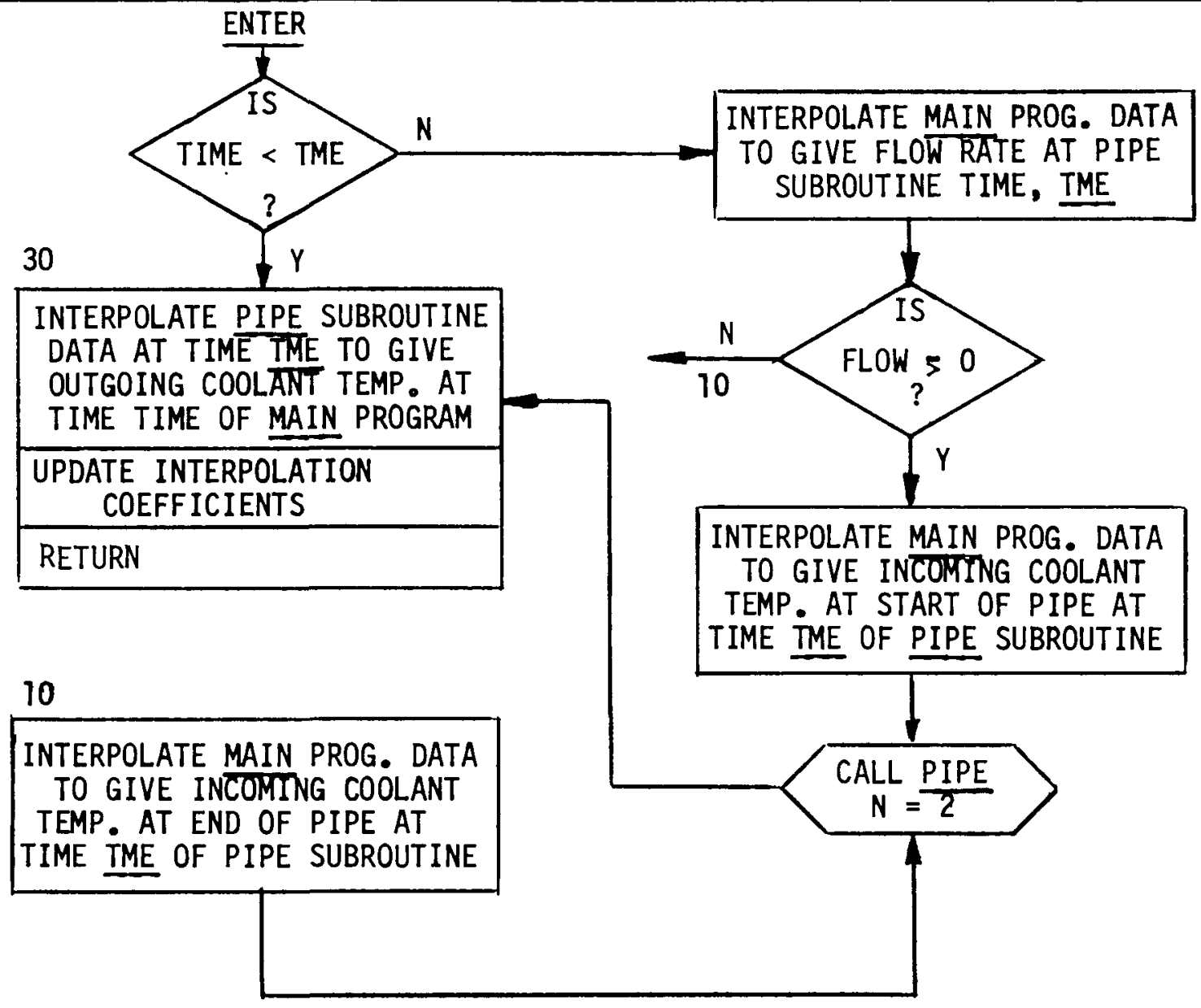




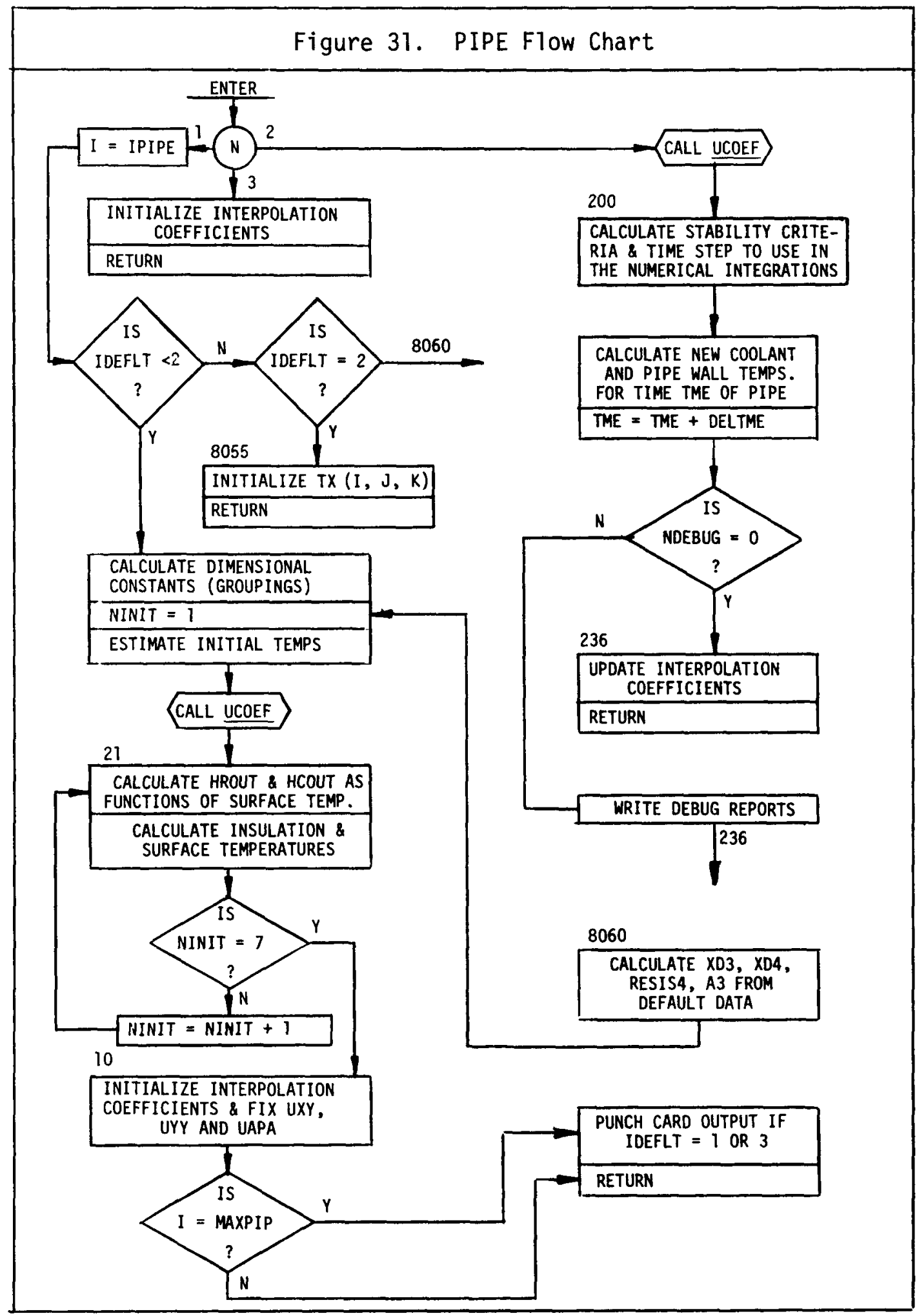




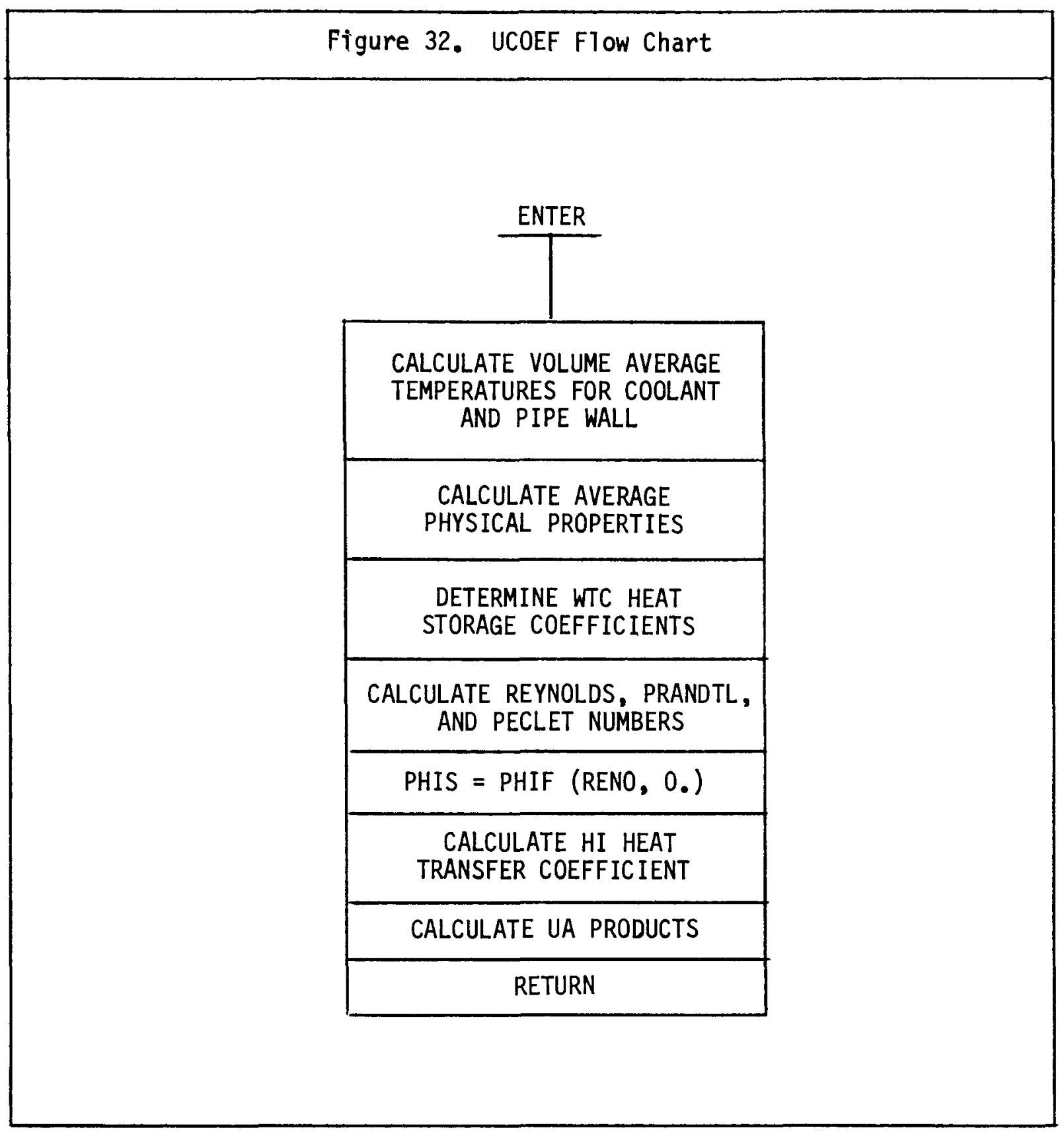


NOPLTS

IDEFLT

IDEFLT

3. Third card

IPIPE
NODES
JTYP
MAXSTP
TCELL
OD
ID

\section{LNTH}

KINSUL

XINSUL

XGAP
Total number of plots to be made.

Designates source of input data and punched output control:

IDEFLT $=0$ Get basic inputs from input data deck and by-pass punched output.

IDEFLT $=1$ Get basic inputs from input data deck and punch out dimensional constants and initial values.

IDEFLT=2 Use default input data values and bypass punched output.

IDEFLT $=3$ Use default dimensional constants and calculate initial values and punch them out.

IDEFLT=4 Use default dimensional constants, calculate initial values but by-pass al1 punched output. 
be arranged in consecutive numerical order by leg number, starting with 1. If IDEFLT $>2$, omit the third card type data cards from the data deck.

4. Fourth card type in free form input: a-1 followed by 10 zeros all separated by commas. This single card denotes the end of the leg data as a check that the third card types have been entered properly. If IDEFLT $>2$, omit the fourth card type from the data deck.

5. Fifth card type. Plot heading cards with $7 A 10$ format. The first card gives the first line of the headings for all plots. Subsequent cards give a second line in the headings for the individual plots.

6. Sixth card type in free form input. This single card enters curve identification coordinates for plot legends.

The stand-in MAIN program is set up to plot temperatures for 10 or less legs on individual plots. Outgoing and incoming leg coolant temperatures are drawn on each plot. Up to 1000 points can be plotted for each variable. Plotting is done using DISSPLA ${ }^{(5)}$, with the commands as shown near the end of the MAIN program listing.

Program MAIN and its subroutines and functions were debugged by checking output against similar output from the computer runs using Model Al. 


\section{REFERENCES}

1. B. T. Fairchild, H. R. Wengrow, F. P. May, AMOS, Numerical Integration of Differential Equations with The Adams-Moulton-Shell Method, Department of Chemical Engineering, University of Florida, Gainesville, Florida, March, 1965.

2. A. L. Gunby, Intermediate Heat Exchanger Modeling for FFTF Simulation, BNWL-1367, Battelle-Northwest, Richland, Washington, May, 1970.

3. D. E. Dwyer, "Eddy Transport in Liquid Metal Heat Transfer," J. AIChE, 9, p. $261,1963$.

4. LMFBR Demonstration Plant Simulation Model, DEMO, WARD-D-0005, Rev. 2, Westinghouse Electric Corporation, Madison, Pennsylvania, July 30, 1974.

5. DISSPLA Beginners and Intermediate Manual (Version 1), Integrated Software Systems Corporation, San Diego, California, October, 1973. 


\section{APPENDIX A}

PROGRAM LISTING

Page

Function FIND ................. A-2

Subroutine FORCE ................. A-4

Subroutine LEG . . . . . . . . . . . . . . A-6

Program MAIN ................... A-7

Function PHIF .................. A-14

Subroutine PIPE ............... . . A-16

Subroutine UCOEF ................ A-33 
FUNCTISV FINDIDATA, ROWS, COLS, $X, Y, V A L)$

INTEGER KOWS, COLS, $X, Y, X Z J W, Y K O N, X L J L, Y L O L$

LOGICAL LOGIC

UIMEYSION DATA (ROWS, COLS)

VALU $=$ = ABS (VAL)

IF $(x) \quad 1,2,3$

$1 X F \cup H=-x$

$\mathrm{YKOH}=Y$

MAXP $=$ COLS

LOGI $=$.FALSE.

IF (DATA (XKOW, MAXP-1) -DATA (XZJW, MAXP) $20,2,21$

20 IF IVALUE-OATA $X R O H$, MAXP) $4,18,18$

21 IF (VALUE-DATA (XROW, MAXP)) $18,18,4$

1 b IF (YKOW) 31,31,30
30 BIND=DATA(YROW, MAXP)

$$
\begin{aligned}
& 2 \text { FINO }=-1.0 E+38 \\
& \text { GC TO } 13
\end{aligned}
$$

$3 \times C O L=x$

YCOL $=r$

MAXP $=$ ROWS

LOGIC = .TRUE.

IF IOATA MAXP-1,XCOL) -DATA(MAXP, XCOL) $22,2,23$

22 IF (VALUE-DATA(MAX\$, XCOLI) +,19,19

AXP,XCJLI) $19,19,4$

19 IF (YCOL) $31,31,32$

31 FINO=FLOAT (MAXP)

GO TO 13

32 BIND=DATA (MAXP, YEJL)

GC T2 16

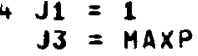

$\equiv J 2=(J 1+J 3) / 2$

IF (LOGIS) GO TO

$A=$ (VALUE - DATA $(X 20 W, J 11)$ (IOATAL XROW,J2) - JATA(XROW,J1) GC TO 7

- $A=$ (VALUE - DATA(J1, XCOL) )/IOATA(J2,XCOL) - DATA(J1, XCOL))

7 if $(A-1.0), 8,10,3$

8 IF $(\mathrm{J} 2-\mathrm{J1}$. LE. 1$)$ GJ TO 10

$J 3=J 2$

GC TO $\overline{3}$

9 If $(J 3-J 2$.LL. 1$)$ GO TO 10

$\mathrm{J1}=\mathrm{JL}$

$10 \mathrm{~J} 2=$ MINO(MAXP-1,J2)

$\mathrm{J} 2=\operatorname{MAXO}(2, \mathrm{~J} 2)$

If (LOTOS)

$X_{1}=\operatorname{OATA}(X R O N, J 5-1)$

$x_{2}=$ OHTH(XROW,J2)

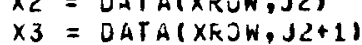

$X 3=$ OATA XKOW,JZ
IF (YROW) $34,34,33$

$33 V_{1}=$ EATA $(Y R O W, J 2-1)$

$r 2=0 A T H(Y R U W, J L)$

$Y S=$ DATALYFUW,J2+1)

GC TJ 12

$11 \times 1=J A T A\left(J<-1, \times\left(J_{-}\right)\right.$

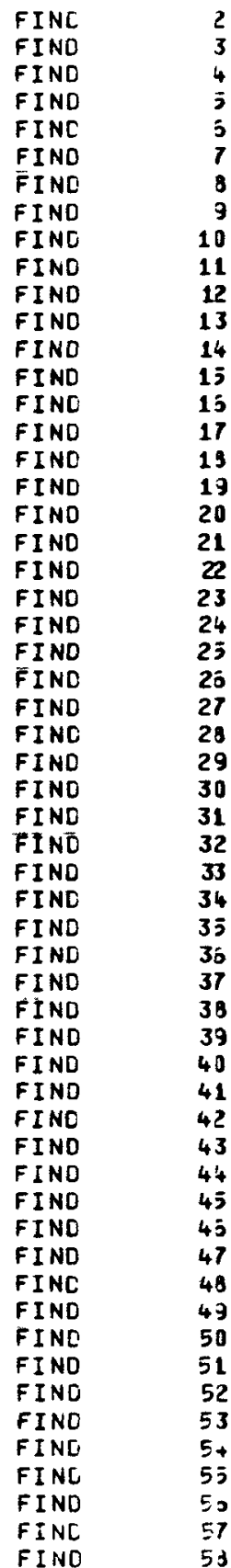



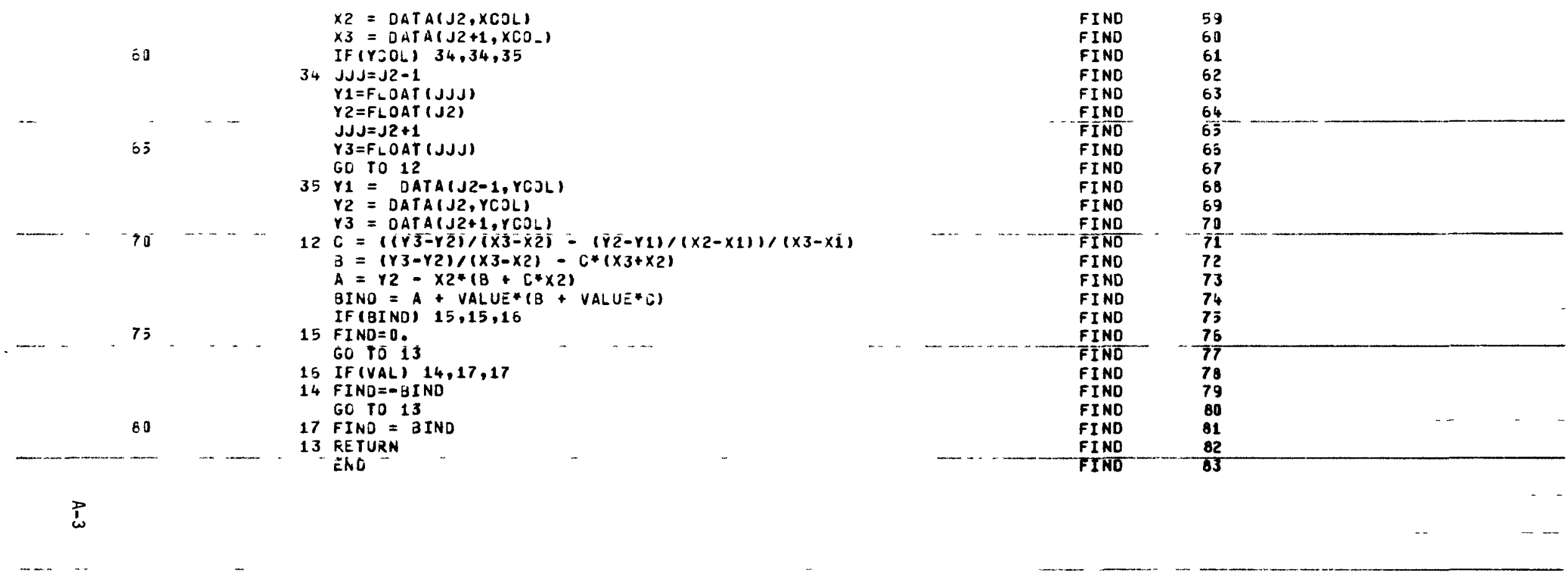
SUBRUUTINE FURCE(WX,TIN,TOUT, TITL, I) C FCRUE PRJVIDES FLOW RATE ANO INCOMING SOOIUM TEMPEFATURES FOR ALL C PIPE LEGS, AS A FUNITIJN OF TIME.

SEE PIP_ SUBRUUTINE FÖR DLFINITIJN CF OTHEK TEPAS.

THIS JEBJG RUN SET UP FOR 10 PIPE LEGS.

DEAUG FORCING DATA SET UP FOR FLOW ZEVERSAL IN CONTINUING AND C CONNECTING LEGS $4,5,6$, AND WITH + FLOW ONLY IN ALL OTHER LEGS.

OIMENSION TIN (53), TOUT (53), WX $(53)$

GO TO $(100,2200,2200,400,2200,600,700,800,2200,2200), I$

C DATA FOR PIPE LEG 1 FOLLONS.

$\checkmark$ JCWN RAMP TO 10 PERJENT FLOW OVER $2 \bar{S}$ SEC. STAKTING AT 2 SEC.

$100 \mathrm{HX}(1)=150$.

IF (TIME. LE.2.) $W X(1)=1600$.

FLOHF ISTMEOTH

C JOHN KAMP FROM 1000 TO 800 F IN 10 SEC. FROM ZERJ TIME. $T I N(1)=1000,-20, * T I M E$ IF (TIME.GT.1B.) TIN(1) = BO0 GC TO 2200

C DATA FOR PIPE LEG 4 FOLLOWS

C DOWN KAMP FROM 1600 TJ 160 LB/SEC FROM 2 TO 27 SEC, THEN RAMP FROM

C 160 TC -160 AT 100 TO 150 SEC.

$400 \quad W X(4)=160$.

IF (TIME.LE.2.) $W \times(4)=1600$.

IF (TIME.GT .2 ..AND. TIME.LT.27.) NX(4)=1715.2-57.6*TIME

IF (TIM = GT.100..AN), TIME,LT.150.) WX(4) $=800,-6.4^{*}$ TIME

IF (TIME.GE. 150.) WX( 4$)=-160$.

IF (HX(+) . GE.O.) GO TO 401

GO TO 2200

C FLOW IS + SO TIN NEEDED AS COOLANT INLET TEMP TO LEG.

401 TIN $(4)=1000 .-20$. FTIME

IF (TIME.GT.10.) TIN $(4)=600$.

C DATA FOR PIPE LEG 6 FOLLOWS.

600 IF 1 HX(6) . GE.0.1 GO TO 2200

ᄂ FLOW IS NEGATIVE SO PRJVIJE INLET CJOLANT TEMP TO END OF THIS FIPE LEG

C KAMP TOUT FROM 9OOS TÖ 700 F FROM 123 FO $225 \mathrm{SEC}$ TOUT $(6)=1249 .-2.44^{*}$ TI YE IF (TIMC.GT.225.) TOJT(G) $=700$. GO TO 2200

C DATA FOR PIPE LEG 7 FOLLOHS.

C DOWN RAMP TJ 10 PEFCENT FLOW OVER 25 SEC. STARTING AT 2 SEC.

$700 \quad W \times(7)=+0$.

IF (TIME.LE.2.) $W \times(7)=400$.

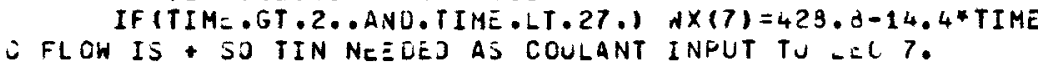

$\checkmark$ OLWN RAMP FRUM 1000 TO 300 F IN $10 \quad 3=0$. FROM ZERO TIME. TIN $(7)=1000,-20 . * I I Y E$

IF (TIME.GT.10.) TINIT) $=800$.

GC TO 2500

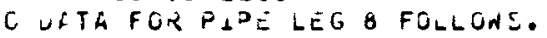

FORCE

FORC

F T RCE

FJRCE

FORCE

FORCE

FORCE

FORCE

FORCE

FORCE

FORCE

FORCE

FORCE

FORCE

FORCE

FORCE

FORCE

FORCE

FORCE

FORCE

FORCE

FORCE

FORCE

FORCE

FORCE

FORCE

FORCE

FOR.CE

FÓRCE

FORCE 
60

C DOWN RAMP TO 10 PERJEVT FLOW OVER 25 SEC. STARTING AT 2 SEC. $300 \mathrm{WX}(8)=3.16$ IF (TIHE. LE.2.) $H \times(8)=31.6$ FLOW IS + SJ TIN NEEDEJ AS COOLANT INPUT TO LEG C DOWN RAMP F ZOM 1000 TO 800 F IN 10 SEC. FROM ZERO TIME. $\operatorname{TIN}(\bar{\theta})=1000,-2 \overline{0}$, FTI $M E$

$65 \quad 2200$ IF (TIME.GT.10.) TIVI $(8)=800$. 2200 RETURN

$$
\text { ENO }
$$

\begin{tabular}{ll} 
FORCE & 59 \\
FORCE & 60 \\
FORCE & 61 \\
FORCE & 62 \\
FORCE & 63 \\
FORCE & 64 \\
\hline FORCE & $6 \overline{65}$ \\
FORCE & 65 \\
FORCE & 67 \\
FORCE & 60
\end{tabular}

59
60
61
62
63
64
$6 \overline{5}$
65
67
68




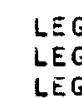

$i$ REFER TO PIPE SUBROJTIN= FOR DEFINITION OF SYMEOLS.

LEG

, KINSUL (53), LNTH(53), MAXSTP (53), OD (53)

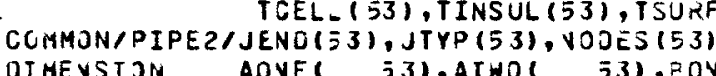

10

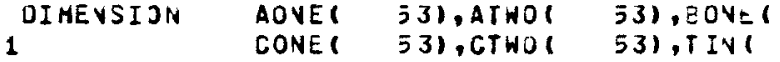

2

TME ( 53),TM11 531, TOSAV

TX(2, 9.53), WRATE 531 , WSAVI

53), BTWOI

53), TISAV 531 ,

531 , TCUTL 53 ).

IFITIME.LT.TMEIII) 60 TO 30

$X T X X=(T M E(I)-T M L(I)) / J T A U$

6 LINEAR INTERPOLATION FOR FLOW ANO IVCOMING COULANT TEMPERATURES AT

C TIME TME.

WFATE(I) =WSAV $(I)+X T X X *(W X(I)-W S A V(I)$

IF (WRATE(I).LT.0.) GO TO 10

20

$T \times(1,1, I)+1$

10 JTOP $=J E N D(I)$

$T X(1, J T J P, I)=T O S A V(I)+X T X X *(T O U T(I)-T O S A V(I))$

$\mathrm{C}$

20 CONTINUE

C IALL FIPE FOR UPOATE OF TEMPERATURE DATA.

CALL PIPE 12, I, NDEBUG, IDEFLT, WRATE, TML, TX, AONE, BONE, CONE, ATWO, BTWO, LEG 1 STWO, HAXPIPI

inTERPOLATE WITH SECONJ DEgREe POLYNOMIAL IN TIME AT DTAU STEPS. IF (WX (I).LT . O.) GO TO 40

TCUT $(I)=A O N E(I)+B O N E(I) * T I M E+2 O V E(I) * X X A A$

$$
\text { GO TO } 20
$$

$40 \operatorname{TIN}(I)=A T W O(I)+3 T W J(I) * T I M E+C T W J(I) * X X A A$

EO HSAV(II $=W X(I)$

C SAVES PRECLEDING TIME JATA FOR LATEZ LINLAR INTEKPOLATION ON FLOW AND

C TEMPERATURES AT TIME TYE.

TISAV (I) $=$ TIN (I)

TCSAY $(I)=$ TOUT (I)

$T M 1(I)=T I M=$

KETURN

END 
PROGRAM MAIN(INPUT, TAPE5 = INPUT, OUTPUT, TAPE6= JUTPUT, PUNCH)

PIFE LEGS. FLOW IS FOSITIVE IN ALL - MAIN IS SUB ROUTINE IS ARRANGED ACLOROINELY.

IDENT CASE IOENTIFIGATION.

PLOT CONTROL INTEGEZ.

IPLOTX PLOT DATA STORAGE CONTROL INTEGER. DATA STOREO EVERY IPLOTX TIMES OF THE MAIN PROGRAM.

IREPT REPORTIVG CONTROL INTEGER.

IREFTX DATA REPORT CONTROL INTEGER. DATA REPORTED EVERY IREPTX

ITIME TIMES OF THE MAIN PROGRÄM.

COUNTS NUMBER OF CALOJLATIONS AT OTAU STEPS IN HAIN PROG.

NOPLTS TOTAL NUMBER OF PLOTS TJ BE NADE.

NPCT

COUNTS THE NUMBER OF TIMTS PLOT OAT

STORED TOJLANT TEMP. AT START OF PTA ARE STORED.

STORED SOJLANT TEMP. AT START OF PIPE FOR PLOT,F.

PLTI

PLT2

PLT1X

PLTIY

COOROINATE FOR CURVE IDENTIFICATION IN PLOT LEGENDO-

COORDINATE FOR CURVE IDENTIFICATION IN PLOT LEGEND.

GOORDINATE FOR CURVE IDENTIFICATION IN PLOT LEGEND.

TIMEPL

TIME PLOT OATA STOREO,SEC. TEELL (53), TINSUL (53), TSURF
COMHON/PIFE2/ JEND(53), JTYP (53), VODES (53)

C H OIMENSION IS SET JP FOR A TOTAL O= 10 PLOTS, WITH NO MOEE THAN 70 C CHAKACTERS PER HEADING LINE.

\begin{tabular}{|c|c|c|c|c|c|}
\hline ENSION & $\begin{array}{l}\text { AONES } \\
\text { CONEI } \\
\text { THEI } \\
\text { TXI2, }\end{array}$ & $\begin{array}{l}531 \text {, ATHOI } \\
531 \text {, CTHOI } \\
\text { 531, TY11 } \\
3,531 \text {, HRATEI }\end{array}$ & $\begin{array}{l}531, \text { BOVER } \\
531 \text {, TIN } \\
531 \text {, TOSAVI } \\
531 \text {, WSAVI }\end{array}$ & $\begin{array}{l}531, \text { BTHO } \\
53 \text {, TISAV } \\
53 \text {, TOUT } \\
53 \text {, WX }\end{array}$ & $\begin{array}{l}531, \\
531, \\
531 ; \\
531\end{array}$ \\
\hline
\end{tabular}

REAL IJ, KINSUL, LNTH, IUAXSTP

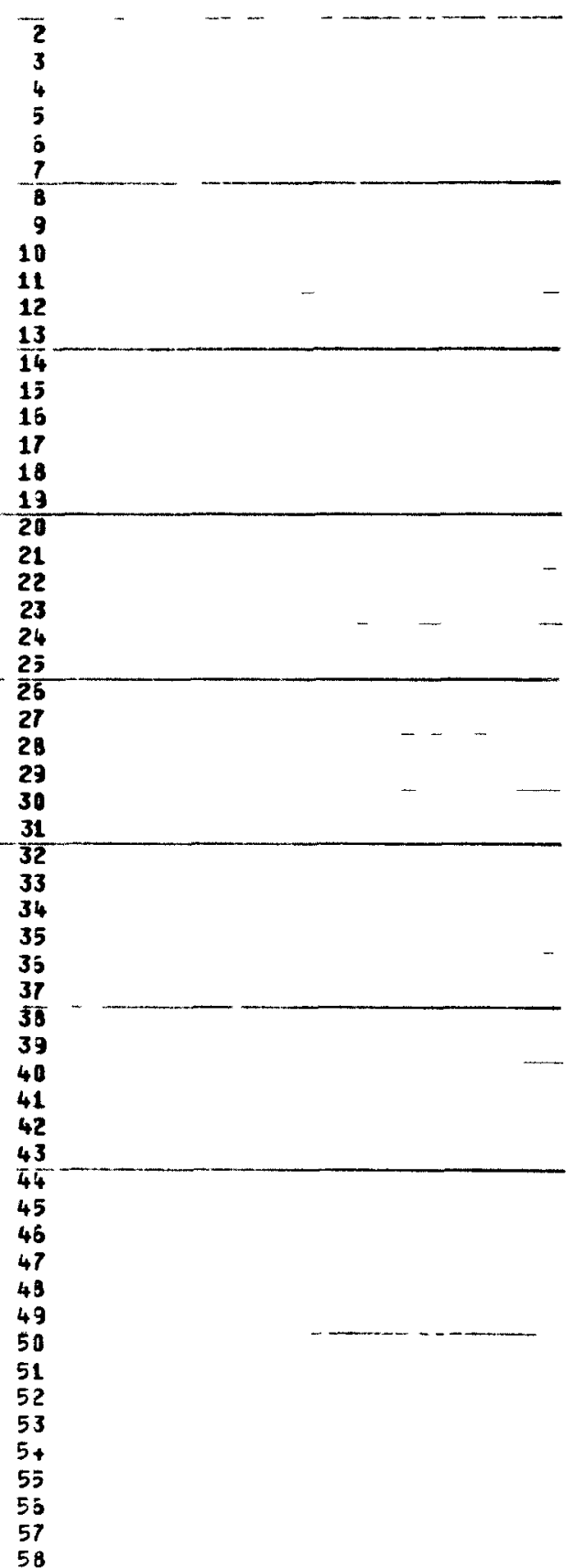


$x \quad 10000000 E+04, \quad .16000000 E+04$
$X \quad 31600000 E+02$,

$.40000000+03, .31600000 E+02$,

$0.31600000 E+02$, MAIN $x$.

$\times 0$.

$x \quad 0$ :

$x \quad 0$

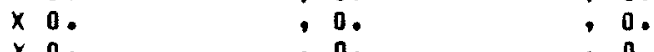

65

, 0 .

$x \quad 0$.

:

$x \quad 0$.

$\begin{array}{ll}x & 0 \\ x & 0 \\ x & 0\end{array}$

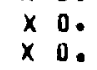

D.

- 0 .

, 0 .

, 0 .

- 0.

$\because 0$.

0.

, 0 .

10.

- 0 .

$\times 0$.

- 0 .

, 0.

OATA (TIN(I), I $=1,53)$ )

.10000000E+04, .10000000E+04, .10000000E+04, .10000000E+04, $X .10000000 E+04, .10000000 E+04, .10000000 E+04, .10000000 E+04$ $\times .10000000 E+04, .10000000 E+04,0 ., 0$.

$x 0 . \quad 0 . \quad 0 . \quad$, 0 .

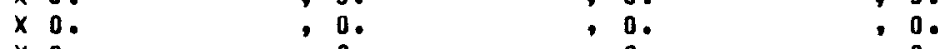

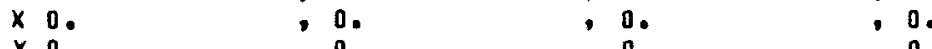

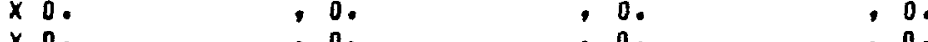

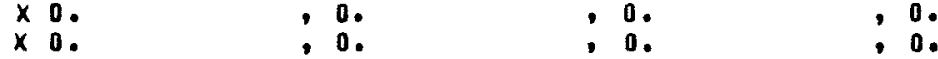

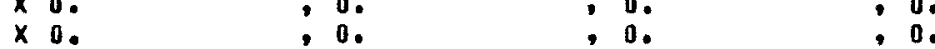

$\times 0 . \quad: 0 . \quad: 0 . \quad: 0$

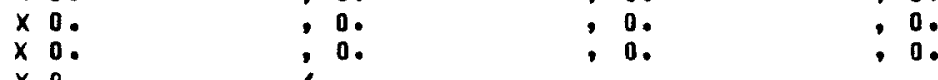

DATA MAXPIP/10/

DEFAULT VALUE IS SET TO 10 FOR DEBUg RUNS WITH A 10 LEg MOOEL. C CORKECT THE DATA STATEMENT VALUE AFTER THE HLAT TRANSPORT SYSTEM MODEL MAIN $C$ IS FIXED.

$$
\begin{aligned}
& \text { CALL DATETETADI } \\
& \text { CALL CALCOM }
\end{aligned}
$$

C KEAD IN JATA ANO WRITE IT BACK OUT.

$$
\text { READ(5,1008) IDENT }
$$

1008 FORMAT (7A10)

$$
\text { WEITE }(5,1011) \text { IOENT, ETAD }
$$

FORMATIIH, "MAIN PRO GRAM TIME STEP IS", F 10.6, "SEGONDS. THE RUN W MAIN

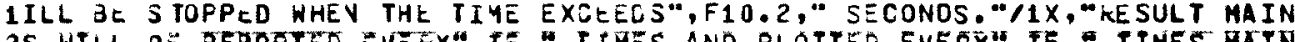
S WILL OE REPORTEO EVEKY"IS, TIMES AND PLOTTEO EVERY", I5, " TMES MATN 3. NDEBUE IS", I3," AVD THERE ARE TO BE", I3," PLOTS. IDEFLT IS*, I2, I MAIN C 2,3 , OK 4 .

$$
\begin{aligned}
& \text { IF (IJEFLT.GE.2) GO TO } 40 \\
& \text { CC } 10:=1,54
\end{aligned}
$$


$\begin{array}{lllll}\text { PRJGRAM MAIN } & 74 / 74 & \text { GPT }=1 & 04 / 03 / 75 & 13.35 .15\end{array}$

115

120

125 IF $(I, E) .54)$ GO TO 15 READ*,IPIPE, NODES(I), JTYP(I), MAXSTP(I), TCELL(I), OD(I), IOII) $i$ LNTH(I), KINSUL (II) XINSUL (II) XGAP (I)

C DENite THE END OF PIFE LEg DATA aY a CARO PUNCHED WITH A - 1 IIN C COLUHNS 1 AND 2 SAYI FOR IPIPE FOLLJHED BY 10 ZEROS, ALL SEPARATED BY C COMMAS.

30 IF (IPIPE.LT.OI) GO TO 20 IF (IPIPE.NE.I) GO TO 25 GO TO 10

15 READ $(5,1001)$ IPIPE

1001 FORHAT (I2)

$$
\text { GO TO } 30
$$

10 CONTINUE

$20 \operatorname{MAXPIP}=I-1$ GO TO 40

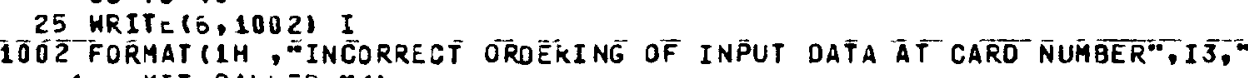
1 EXIT CALLED. $\cdots / 1$

$$
\text { CALL EXIT }
$$

40 WRITE $(6,1003)$ MAXPIP

1003 FORMATIIH, "INPUT PIPE OATA CARJ VALUES FOK"“,I3, PIPE LEGS IN THE

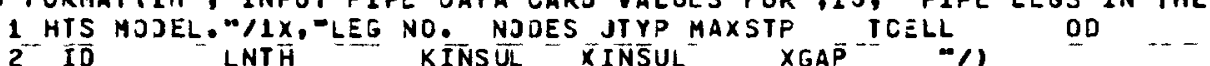
2 ID $50 \quad I=1$, MAXPIP PRINT $(0,1004)$ I,

(I), JTYP (I), MAXSTP(I),TCELL(I), OD (I), 1004 FORMAT 3 I6, BF 10.4$)$

\section{CONTINUE
50 JTOPANOPLTS}

JT OP $=N O P L T S+1$

DO $48 \mathrm{~J}=1, \mathrm{JTOP}$

$\operatorname{READ}(5,1020)(H(I, J), I=1,7)$

48 CONTINUE

1020 FORMAT (TA10)

FFITE $(6,1021)$

150

1021 FCRMAT (

$0049 \mathrm{~J}=1$, JTOP

49 WRITE $(5,1019) \quad(H(I, J), I=1,7)$

1019 FORMAT $(10 X, 7 A 10)$

155 KCAO*, $(P L T 1 X(M), M=1,2),(P L T 1 Y(M), M=1,2),(F L T 2 Y(M), M=1,2)$ HRITE $(\dot{0}, 1025)(P L T 1 X(M), M=1,2),(P L T 1 Y(M), M=1,2),(P L T 2 Y(M), M=1,2)$

1025 FORMAT (- PLOT LEGEND SARO \%/OF10.2)

TI $M E=0$.

IFLOT $=1$

IFLOT $=1$

$M F T=0$

$M=0$

155

IF (IDEFLT.EQ.2) GJ TO 53

FCHCE IS SJBROUTINL WHIOH PROVIJES =LOW FATE ANO INCOMING COOLANT C TEMPLKATURES AS FUIACTION OF TIME FOR ALL PIPC LEOS.

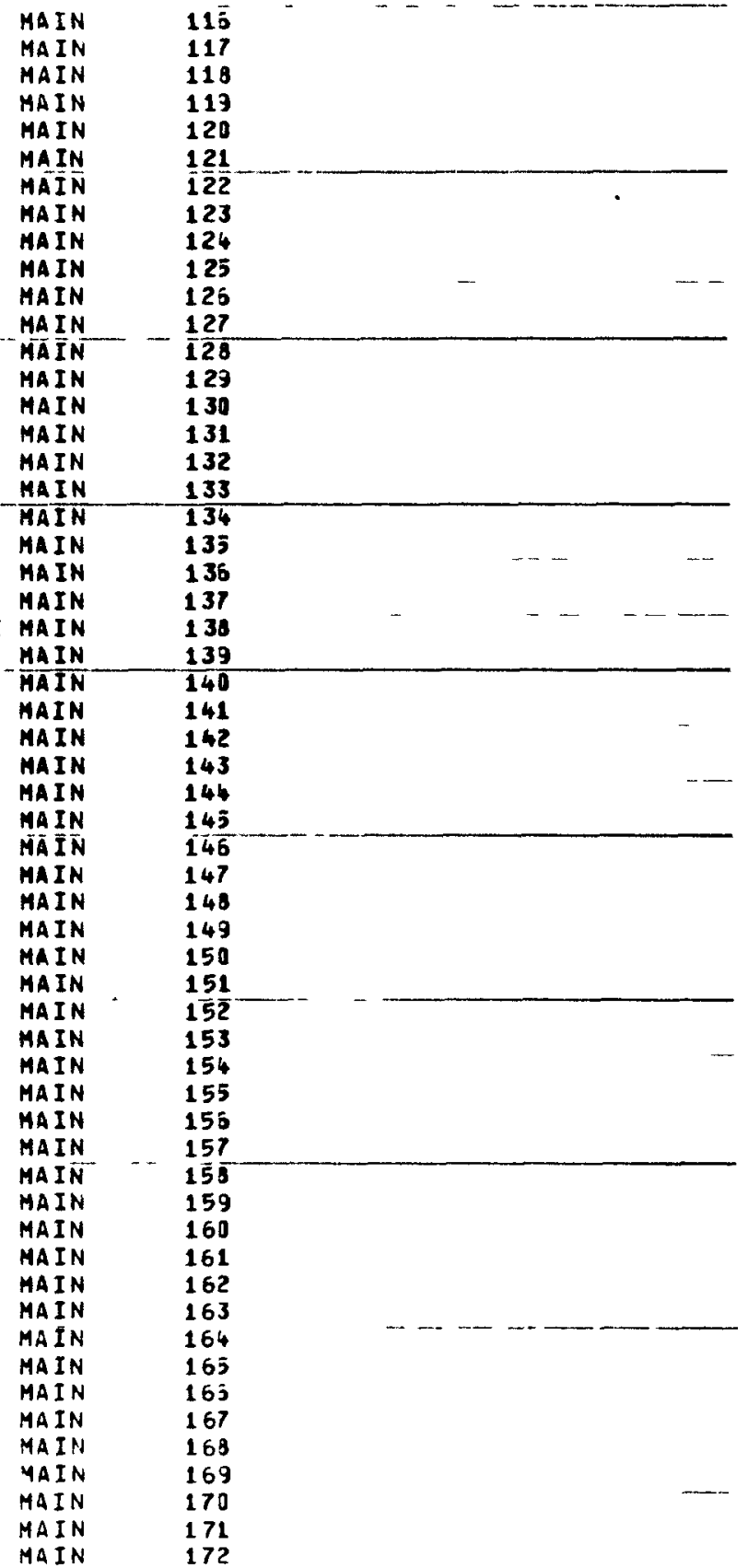


$52 M=I+1$

IF (IDEFLT.EQ.2) GO TO 51

195
$\frac{1}{0}$
0

51 CONTINUE

54 WRITE 6,1013$)$

1013 FORMAT (1H1, “CALCULATEJ INI IIAL VALUES FOLLOW-...1/1) WEITE $(0,1006)$

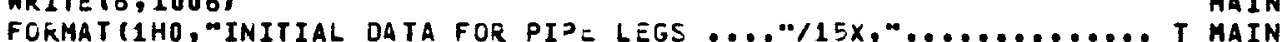

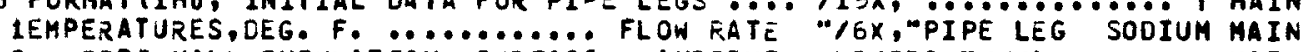
2 PIPE HALL INSULATION SURFACE AMBIENT LB/SEC -/II) SOOIUN MAIN OC $60 \mathrm{~K}=1$, MAXPIP HKITE $(0,1005) K, T X(1,1, K), T X(2,1, K), T I N S U L(K), T S U R F(K), T C E L L(K)$, MAIN 1 WKITE $(0,1005) K, T X(1,1, K), T X(2,1, K), T I N S U L(K), T S U R F(K), T C E L L(K)$, MAIN 1005 FORMAT (I 10,F12.2,5F10.2) $c$ C CALL FIPE TO INITIALIZE INTERPOLATION LOEFFICIENTS SO THAT INITIAL MAIN C VARIAELES, NHICH ARE NJ LONGER VELSEJ, CAN BE EQUIVALENCED TO THESE MAIN C IATERFOLATION COEFFICIENTS.

210 60 CALL PIPEI3,K, NDEBUG, IDEFLT, AX ,TME, TX, AGNE, BONE, CONE, ATWO, BTHO, MAIN 1 CTHO, MAXPIPI
GC TO 180

$21 j-$

MaIN PROgRAY TRANSIENT CALCULATIONS FOLLOW.....

MAIN

100 TIME $=$ TIME +DTAU IF (TIME.GT.ENDTHE) GO TO 200

$220^{-\cdots}-\ldots 169 \mathrm{I}=0$ $I=0$

IF (JTYP(I),EQ.1) GJ TJ 170 GC TJ(101,102,103,10 T, 105,100

L THIS DEBUG ZUN IS SET JP FOQ ONLY 10 LEGS. THE ABCVE GO TO MUST BE C CHANGED IF THE NO. JF LEGS IS

C CALL LEG FUR UPDATIVG TEMPERATURES.

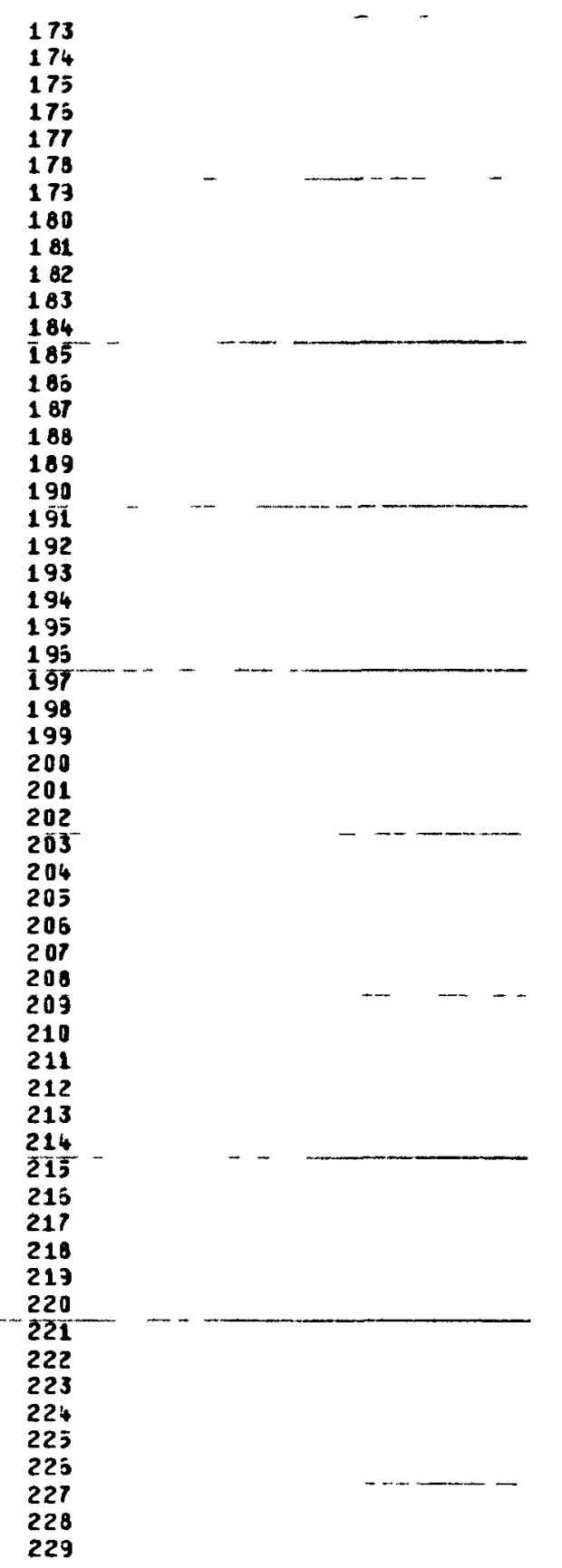


230$$
1
$$
IF (I.EQR. $Y A X P I P)$ GJ TO 180 IF $(J \operatorname{Tr} P(I+1), E Q .0)$ Go ro 169

$W X(I+1)=W X(I)$

TIN $(I+1)=$ TOUT(I)

GO TO 159

101 CALL FORCE (WX, TIN, TJUT, TIME, 1) IF (HX(1),GE.0.) GJ TO 170 GO TO 160

102 CALL FORCE (HX, TI N, TOUT, TIME, 2 ) IF (HX(2).GE.0.) GO TO 170

103 CALL FORCE ( $W X, T$ IN, TOUT, TIME, 3) IF (WXI 3).GE.0.) GJ TO 170 GO TO 160

104 CALL FORCE (WX, TIN, TOUT, TIME, 4) IF (WX (4).GE.0.5) GO TO 170 GO TO 160

105 CALL FORCE (WX, TIN, TOUT, TIME,5) IF (HXI 5).GE.0.) GJ TO 170 GO TO 160

106 CALL FORCE (WX,TIN, TOUT, TIME, 6$)$ IF (WTXT G). GE.0.) G5 TS 170 GO TO 100

107 GALL FORCE (WX,TIN, TOUT, TIME, 7$)$ IF (HX(7), GE, D.) GO TO 170

$$
\text { IF (WX (7) }
$$

108 GALL FORGE (HX, TIN, TOUT, TIME, B) IF (WXI B).GE.0.) GO TO 170 GO TO 100

109 CALL FORCE (WX, TIN, TOUT, TIME, 9) IF (HX( 9).GE.0.) G) TJ 170 GO TO 160

110 CALL FORCE (WX, TIN, TOUT, TIME, 10 IF (HX(10). GE.O.) SO TO 170

C FLOW IS NOW NEGATIVE. FINU LAST LES OF SERIES OF CONTINUING LEGS IF C ANY, SO THAT CALCULATIONS CAN BE MADE BACKWAROS FRON THE LAST LEG TO C THE STARTING LEG OF THE SERIES.

\section{$I I=I+4$ \\ DC $151 \quad Y=I, I I$}

$H X(M)=W X(I N D E X)$

IF (JTYP $(M+1), E Q, 0, J R, 4, E Q . M A X P I P)$ GO TO 162 $1 E 1$ CCNTINUE

c $1 E 2$ MENO=M

C MEND IS LAST LEG OF SERIES STARTING WITH INOEX IF (MEN]. EQ. INJEX) GO TO 170

CALL FOROE (HX, TIN, TOUT, TIML, MENJ)

C CALL TO FORCE PROVIJES INLET C'OJLAVT TEMP TO ENE OF LAST NODE OF

$C$ LAST LEG OF SERI $=S$ JF JONTINUING L $=3 S$.

103 GALL LESIM, TIME, TYE, OTGU,WX,WRAT = WSAV, IIN, TOUT, TISAV, TOSAV,TX,

TH1, AOV =, BONE, CONE, ATWJ,BTWJ, UTWU, ICEFLT, MAXDIP, NDEOUG)

MAIN 230

MAIN

MAIN

MAIN

MAIN

MAIN

$\frac{\text { MAIN }}{\text { MAIN }}$

MAIN

MAIN

MAIN

MAIN

MAIN

MAIN

MAIN

MAIN

MAIN

MAIN

MAIN

MAIN

MAIN

MAIN

MAIN

MAIN

MAIN

MAIN

MAIN

MAIN

MAIN

HAIN

MAIN

MAIN

MAIN

MAIN

MAIN

MAIN

MAIN

MAIN

MAIN

MAIN

MAIN

MAIN

MAIN

MAIN

MAIN

MAIN

MAIN

MAIN

MAIN

MAIN

NAIN

MAIN

MAIN

MAIN

MAIN

MAIN

MAIN

MAIN

MAIN

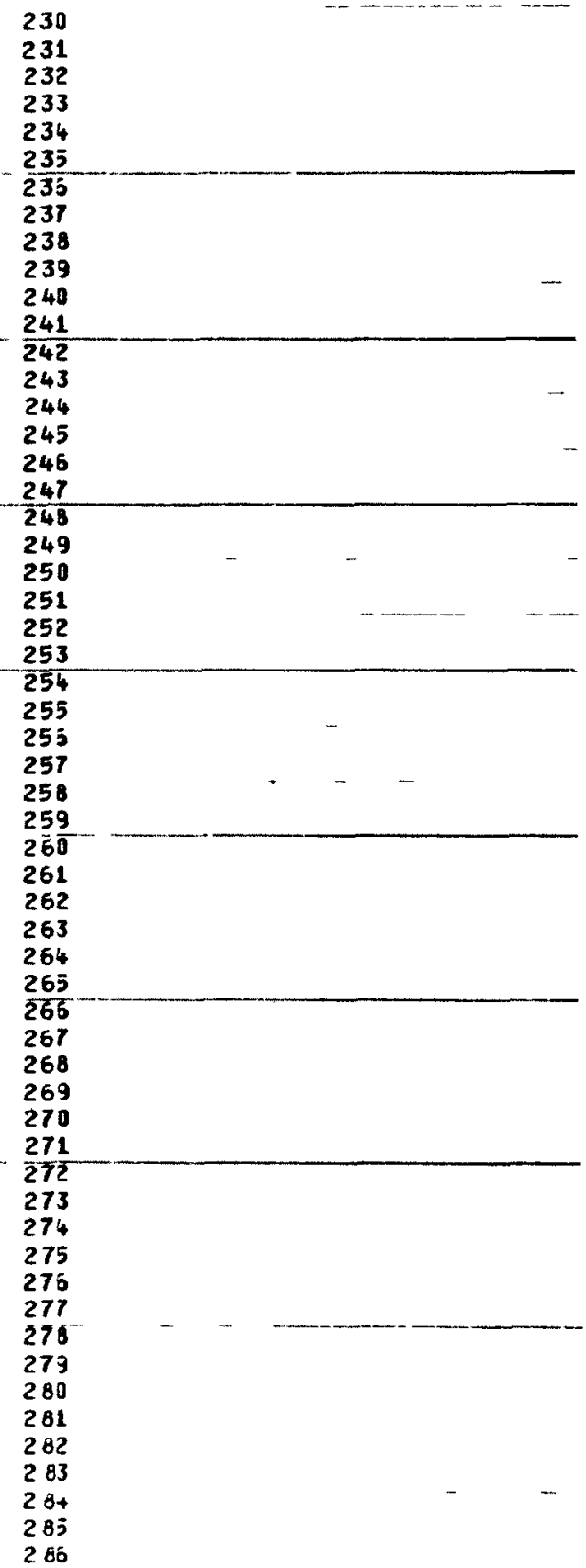



GO TJ 169

180 IT IME $=$ ITIME +1

$29 \overline{3}$

300

305
C

C WEITE FEPORTS OF COJLAVT TIMPERATURES IF CALLEO FOR BY IREPTX REPORT MAIN -ING FREQUENCY.

HFIT $\equiv(5,1026)$ TIHE

1026 FORMAT $(1 H 1,2 x, \cdots$ TIM=, ",F10.3," SECONDS. DIFE LEG DATA. $\cdots / 1$ WR IT $=(0,1022)$

1022 FCRMATI11X, “OOOLANT TEMPERATURES, DEG.F., AT FLOW $12 \times, \cdots E G$ IVLET

OUTLET

RATE
LB/SEC.

$$
\begin{aligned}
& \text { DO } 181 \quad I=1 \text {, MAXPIP } \\
& \text { WFIT } 16,1028) \text { I, TIV(I), }
\end{aligned}
$$

1028 FCKMATII5, F15.3,9X,F 10.3,8X,F10.3)

CCMTINUE

IREPT = IREPT+IREPTX

182 IF (IPLOT.NE.ITIME) GO TO 100

c

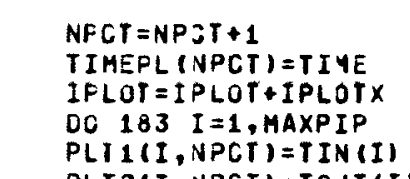

MAIN

MAIN

$\rightarrow \operatorname{MAIN}$

\% MaIN

MAIN

MAIN

MAIN

MAIN

MAIN

MAIN

MAIN

TAIN

MAIN

MAIN

MAIN

MAIN

MAIN

MAIN

MAIN

MAIN

MAIN

MAIN

MAIN

MAIN

MAIN

MAIN

MAIN

MAIN

MAIN

MAIN

MAIN

220 CONTINUE

CALL TITLE(1H, -1,"TIME, SECONDS\$", 100,"TEMF_RATJRE,DEG F.\$", 100,9. MAIN $1, E$.

CALL HEADIN $(H(1,1), 100,2,2)$$$
J=K+1
$$

MAIN

CALL HEADIN $(H(1, J), I 00,2,2)$

CLLL INTAXS

CALL GKAF(0.,40,360,0500,0100.,1100.)

CALL BLNK $1(3,3,6,4, .8,1.4,1)$

CALL GRIU $(1,1)$

GALL RESET $(\infty B L N<5 \infty)$

CALL CURVE ITIREPL, PLT22,NPOT,OI

CALL CURVE (PLTIX,PLTIY, 2,0)

CALL DASH

MAIN

MAIN

MAIN

MAIN

MAIN

MAIN

MAIN

MAIN

MA IN 
PRJGRAM MAIN $\quad 74 / 74 \quad$ OPT $=1$

CALL CURVE (TIMEPL,PLT11,NPCT,O)

CALL CURVE (PLT1X,PLT2Y, 2, 0)

345

CALL MESSAG (.PIPE JUTL $=T \%, 100,5,1,15)$

CALL MESSAG "PIPE INLET \$०, 100,5,..91

CALL FRAME

CALL ENOPL (K)

350

250 CONTINUE

CALL DONEPL

CALL EXIT

END
FTN $4 \cdot 2+74351$

$04 / 03 / 75$

MAIN

MAIN

MAIN

MAIN

MAIN

MAIN

MÁIN

MAIN

MAIN

MAIN

$-$
345

345

346

347
348

349

350

351

352

353

354

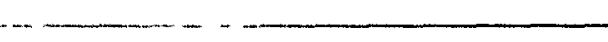




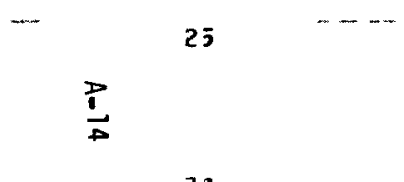

3)

\section{FURCTION PHIFINRE, PI}

FUNCTION PHIF RETUZVS THE MAXIYJM CDOY REYNOLDS NUMBER CORRECTOR NRE IS REYNOLDS NJMBER

D IS HEAT EXCHAVGLR PITCH-TO-DIAMETER RATIO. FOR THE TUBE SIDE. USE $P=0$.

DIMENSION $\times(2,3)$, PHI $(18,5)$

REAL NRE

DATA $(x(2, J), J=1,3) / 1,300,1,375,1.700 /$

PHI (I,J) IS MAXIMJM EDDY REYNOLOS NUMBER CORRECTOR FUNCTIONE- PHIF $J=1$ FOR REY NOLDS NUMBE? $J=2$ FOR TJBES

$J=3$ FOR PITCH-TO-OIAMET $=R$ RATIO OF 1.300 $J=4$ FOR PITCH-TO-DIAMETER RATIO OF 1.375 $J=5$ FOR PITCH-TD-DIAMETER RATIO UF 1.700

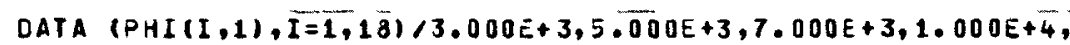
1
2
3
4 1 3 OAT 1
2
3
4 OATA $(P H I(I, 4), I=1,18)$ 1
2
3 DAT 1 2. $000 E+4,4.000 E+4,7,000 E+4,1,000 E+5$, 2.0OOE+5, 4.0OOE+5,7.000E+5,1.000E+6,

$2,000 E+5,4.000 E+5,7.000 E+6,1.000 E+7$,
$2.000 E+7,5.000 E+7$,
ORTA (PHI $(I, 2), I=1,181,5.200 E-2,3.250 E-2,2.400 E-2,1.450 E-2$, $6.800=-3,3.000 E-3,1.490 E-3,8.800 E-4$. $3.570 E-4,1.400 E-4,6.600 E-5,3,900 E-5$, $1.490 E-5,5.400 E-6,2.400 E-6,1.390 E-6$, $4.750 E-7,1.560 E-71$

TA (PHI II, 3), I=1,18) /1.700E-1,1.100E-1,8.400E-2,6.000E-2, $2.900 E-2,1.400 E-2,6,800 E-3,4,200 E-3$, $1.700 E-3,6.600 \mathrm{E}-4,3.000 E-4,1.900 \mathrm{E}-4$, 7.000E-5,2.500E-5,1.010E-5,5.800E-6, $2.810 E-6,4.700 E-7 /$ $3.200 \mathrm{E}-2,1.400 \mathrm{O}-2,7.400 \mathrm{E}-3,4.700 \mathrm{E}-3$,
$3,900 \mathrm{E}-3,7.800 \mathrm{E}-4,3.500 \mathrm{E}-4,2.060 \mathrm{E}-4$, $8.200 E-5,2.580 E-5,1.200 E-5,7,000 E-5$, $2.400 \mathrm{E}-6,5.300 \mathrm{E}-7$, 1 (1.60) $4.300 E-2,2.000 E-2,1.010 E-2,6.500 E-3$, $2.700 E-3,1.070 E-3,5.000 E-4,3.00 O E-4$, $2.200 E-4,4.600 x-4,2.070 E-4,6.600 E-5$, 3

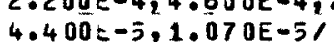

100 FCRMAT 11 HO/5X65HPITIH- TO 1R THAN 1.7, $P=E 15.7$ DiaMETER RATIO IS LESS THAN 1.3 OK GREATE 25X77HTHE MAXIMUM EOOY REYNOLOS NUMBEF CORFECTOR IS NOT DEFINED FOR 3 THIS VALUE OF P.I 45X47HEXIT WILL BE CALLED FROM FUNCTION PHIF. NRE IS E15.7 1 IF $(P) 10,1,2$

PHIF =FIND(PHI, 18,5,1,2, NRE) GO TO 11

2 IF $(P-1.3) 10,3,4$

3 PHIF =FIND $(P H I, 18, \overline{5}, 1,3$, NRE $)$ GC TJ 11

4 IF $(P-1.375) 6,5,6$

5 PHIF $=F I N D(P H I, 18,5,1,4$, NRE $)$ GO TJ 11
PHIF

PHIF

PHIF

PHIF

PHIF

PHIF

PHIF

PHIF

PHIF

PHIF

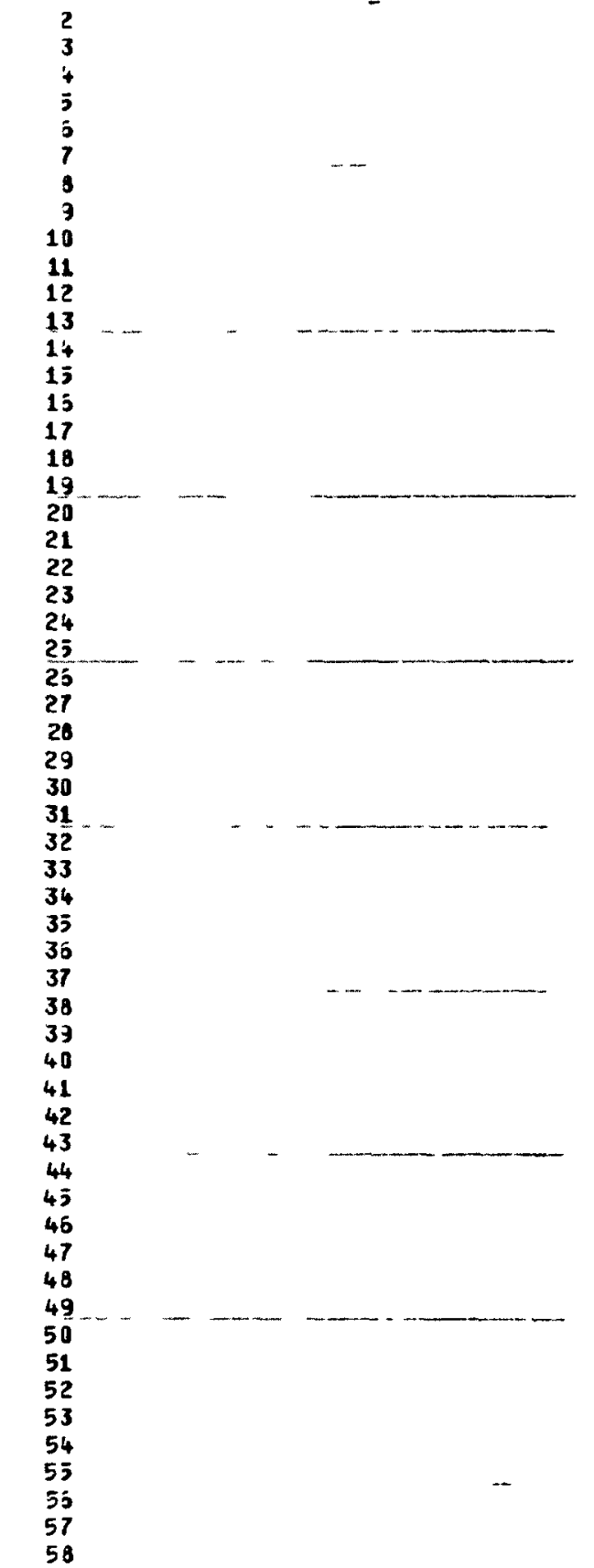

HI

PHIF 
13. 35.26 .

6 IF $(P-1,7) 8,7,10$

PHIF =FIND(PHI, 18, $5,1,5$, NRE)

$$
\text { GO TO } 11
$$

8 DC $9 J J=1,3$

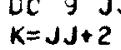

$X(2, J J)=F I N D(P H I, 18,5,1, K, N B E)$

PHIF $=F$ IN $O(X, 2,3,1,2, P)$

GO TO 11

10 WFITÉ $(6,100)$ P,NRE

CALL EXIT

11 RETURN

PHIF 60

PHIF 61

PHIF 62

PHIF 63

PHIF $\quad 63$

PHIF 65

65

PHIF

PHIF

PHIF

PHIF

PHIF

65
67
68
69
70

-

-

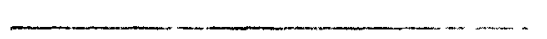


SUBROUTINE PIPEIN, IPIPC, NOEBUG, IOEFLT, WY, TME, TX, AONE, BONE, CONE ATWO,BTHO, CTWO,MAXPIP) C URES FOR INITIAL CONDITIONS ANO SOOIPE WALL AND INSULATION TEMPERAT- PIPE C FUNCTIONS OF TME FOR JONSTANT AMBIENT TEMPERATURE. PIPE A AONE ATHC A 3 BONE BTWC C CONE CTWO CTWO DELTAX DELTME D VRA OTAU HCOUT HI
HFOUT I

ICALC I D
I OEFLT

INDEX IPIFE I $Z$

NODE HEAT TRANSFER SURFACE AREA/3600.,SQFT-HR/SEC. COEFFICIENT FOK SECOND OEG. POLYNOMIAL INTERPOLATION. COEFFICIENT FOR SECOND DEG. POLYNOHIAL INTER FOLATION. NODE HEAT TRANSFER SURFACE AT IN SULATION SURFACE 3600 , SQF T - HR/SEJ.

COEFFICIENT FJR SECOVD JEG. POLYNOHIAL INTER POLATION. COEFFICIENT FJF SECJND JEG. POLYNOMIAL INTERPOLATION. SPECIFIC HEAT, BTU/ (LB-F)

COEFFICIENT FOR SESOND DEG. POLYNOMIAL INTERPOLATION. COEFFICIENT FOR SECONO DEG. POLYNOMIAL INTERPOLATIONO NODE LENGTH,FT.

INTEGRATION TIME STEP, SEC.

$3600+I D / F L J W$ AREA FOR REYNOLOS NO., SEC/ (FT-HR)

TIME STEP IN MAIN PROGFAM,SEC.

CONVECTION HEAT TRANSFER COEFFICIENT AT INSULATION OUTSIDE SURFACE, BTU/ (HR-SQFT -F),

SOOIUM FILM COEFFICIENT, BTÜ/(HR-SQFT -F)

RADIATION HEAT TRANSFER COLFFICIENT TO AMBIENT FROM INSULATION SURFACE, BTU/(HR-SQFT-F).

KADIAL NODE LJCATION....

$I=1$ SODIUM OR SODIUM TO PIPE WALL NODE.

$I=2$ PIPE WALL OR DIPE WALL NDDE TO OUTSIDE PIPE $I=3$ INSULATION INSIDE SURFACE TO AVG. DIA.

PIPE

PIPE

PIPE

PIPE

PIPE

PIPE

PIPE

PIPE

PIPE

IPE

PIPE

PIPE

IPE

PIPE

PIPE
PIPE
PIPE

PIPE

PIPE

PIPE

PIPE

OF TIMES TRANSIENT CALCULATIONS MADE IN

NOJTINE.

PIPE ID, IN.

DESIGNATES S OURCE OF INPUT DATA AND FUNCHED OUTPUT CONTROL PIPE IDEFLT $=0$ GET BASIC INPUTS FROM INPUT DATA DECK AND PIPE GY-PASS PUNCHED OUTFUT.

IDEFLT 1 GET BASI GET BASIO INPUTS FROH INPUT DATA DECK AND PIPE
PUNCH OUT OIMENSIONAL CONSTANTS AND INITIAL PIPE

$\begin{array}{ll}\text { VALUES } & \\ \text { USE JEFAJLT INPUT OATA VALUES AND OY-PASS } & \text { PIPE } \\ & \text { PUNCHED OUTPUT. }\end{array}$

PIPE
PIPE

IOEFLT 3 USE DEFAJLT DIMENSIONAL CONSTANTS AND PIPE

IOEFLT $=4$ CALCJLATE INITIAL VALUES AND PUNCH THEA OUT PIPE TE INITIAL VALUES BUT BY-PASS ALL PUNCHED PIPE OUTPUT.

LEG NUMBER FOR FIRST LEG IN A SERIES OF CONTINUING PIPE PIPE LEG NUMBER FOR FIRST LEG IN A SERIES OF CONTINUING PIPE - PIPE
LEGS.

LEG IDENTIFICATION NUMBEK.

AN ARRAY FOR INTEGER DIHENSIONAL CONSTANTS PUNCHED CARD OUTPUT. IL IS EQUIVALEVCED TO BLOCK COHMON IPIPE2/. FOR EXAMPLE...

(IZ $(I, 1), I=1,53)$ ARE VALUES FGR JEND.

IIZ $(I, 3), I=1,53)$ ARE VALUES FOR NODES.

AXIAL NODAL POINT

NOGAL POINT NUMBER AT ENE OF PIPE LEG.

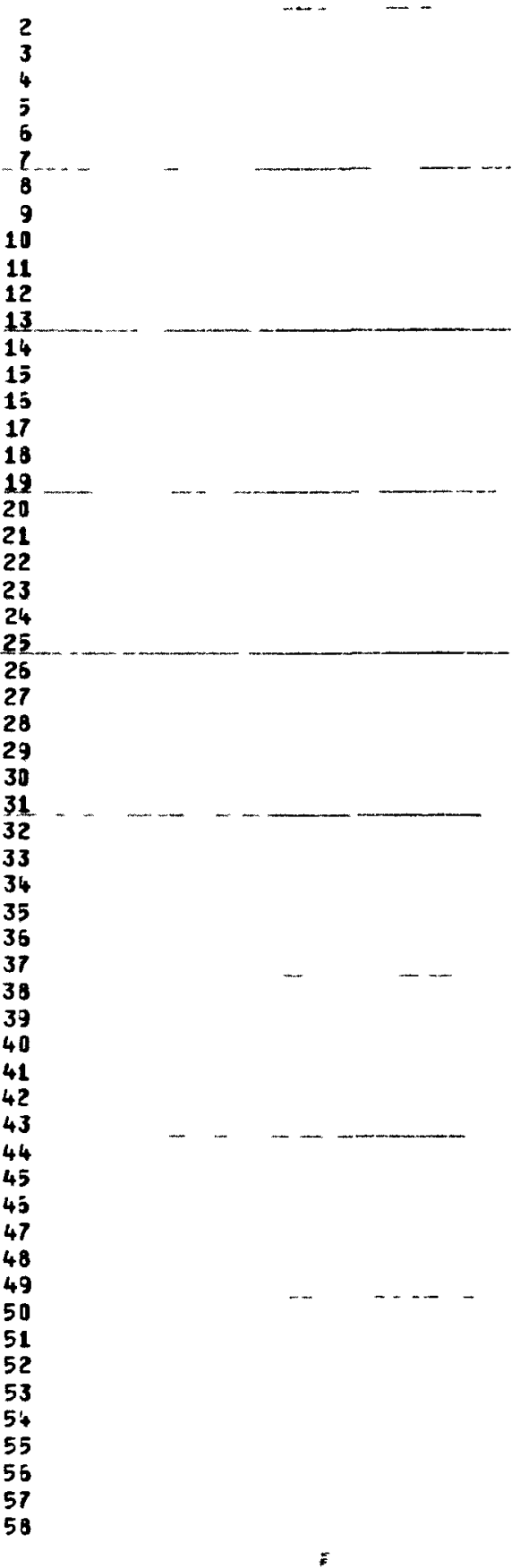


KINSUL

KM

LNTH

MAXPIP

N

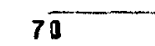

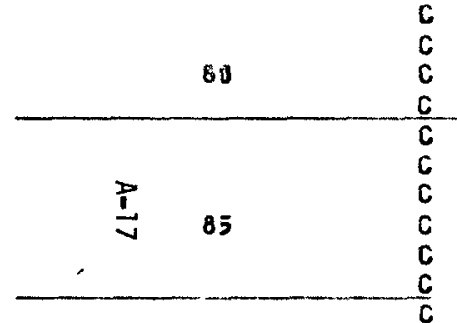

90

\section{NINIT}

NODES

NUNO

DO

P ENO

PHIS
PIOVR4

PRND

PSIS

90 C RESIS

RESIS

RHO

START

START2

TAU1

TAU?

TBARI

TBAR 2

TCELL

TIME

TIN

TISAV

$T \mathrm{ME}$

TMI

TOSAV

TUUT

TSAVia

NODAL POINT NO. AT END OF PIPE LEG.

TYPE OF JUNCTION AT START OF PIPE LEG....

$$
\begin{aligned}
& \text { JTYP }=0 \quad \text { LEG CONNECTS TO A COMPONENT. } \\
& \text { JTYP=1 LEG IS CONTINUING. }
\end{aligned}
$$

INSULATION THERMAL CONDJCTIVITY, BTU/ (HR-FT-F)

THERMAL CONOUCTIVITY, BTU/ (HR-FT-F)

PIPE LEG LEVGTH,FT.

TOTAL NUMBER OF LEGS IN THE SYSTEM BEING MODELED.

MAXIMUM ALLOWABLE INTEGRATION TIME STEP, SEC.

LEG NUMBER FOR LAST LEG IN A SERIES OF CONTINUING PIPE LEGS.

PUE SUBOJIINE ARGUMENT . . .

$N=1$ PERFORM IYITIAL VALUES CALCULATIONS.

$\mathrm{N}=2$ PERFORH TRANSIENT CALCULATIONS.

$N=3$ INITIALIZE INTERPOLATION COEFFICIENTS

NCALC CONTROL INTEGER FOR FREQUENCY OF DEBUG REPORTING IN THE PIPE SUBROUTINE.

NOEBUG WRITE CONTROL FOR COMPLETE TEMPERATURE DATA IN PIPE SUBROUTINE.

\section{NOEBUG $=0$ REPORTS BY-PASSED.}

TSAVIB

NDEBUG $=K$ REPORT EVERY K CALC

NUMBER OF AXIAL NODES IV A LEG.

NUSSELT NUMBER.

PIPE OD, IN.

PECLET NUMBER.

EDOY DIFFUSIVITY CORRECTOR FUNCTION FOR PSIS.

PI/4.

PRANDTL NUMBER

CORRECTOR ON PECLET NUMBER IN MODIFIED LYONS EQUATION. CORRECTOR BY THE HEI HOD OF DHYER,AICHE J,9,P261,1963. REYNOLOS NUMBER.

HEAT TRANSFER RESISTANCE TERM,FT .

HEAT TRANSFER RESISTANCE TERM FOR INSULATION,FT.

DENSITY,LB/CUFT.

PRECEEOING TIME-ONE STEP BACK ON TME,SEC.

PREVIOUS TIME-TWO STEPS BACK ON TME SEC.

LIMITING TIME STEP FOR STABILITY OF PIPE EQUATION,SEC.

LIHITING TIME STEP FOR STABILITY OF SODIUM EQUATIONS,SEC. VOLUME AVERAGE SODIUM TEMPERATURE, F.

VOL UME AVERAGE PIPE WALL TEMPERATUFE,F.

AMBIENT TEMPERATURE OF SPACE AROUND THE PIPE LEG,F.

TIME IN MAIN PROGRAM,SEZ.

COOLANT TEMP. AT START OF PIPE, F.

INSULATION NOOE INITIAL TEMPERATURE, F.

COOLANT TEMP. AT START OF PIPE AT FRECEEDING TIME OF MAIN PROGRAM, F.

TIME IN PIPE SUBROUTINE, SEC.

PRECEEDING TIME OF MAIN PROGRAM, SEC.

COOLANT TEYP. AT END OF PIFE AT PRECEEDING TIME OF MAIN PROGRAM, F.

COOLANT TEMP. AT END OF PIPE,F.

COOLANT TEYPEZATUQL AT END OF PIPE AT PRECEEOING TIME,TME PIP

TSAVZA

COOLAN

ME, F.

GOOLANT TEMPEZATURE AT END OF PIPE AT PREVIOUS TIML-THO

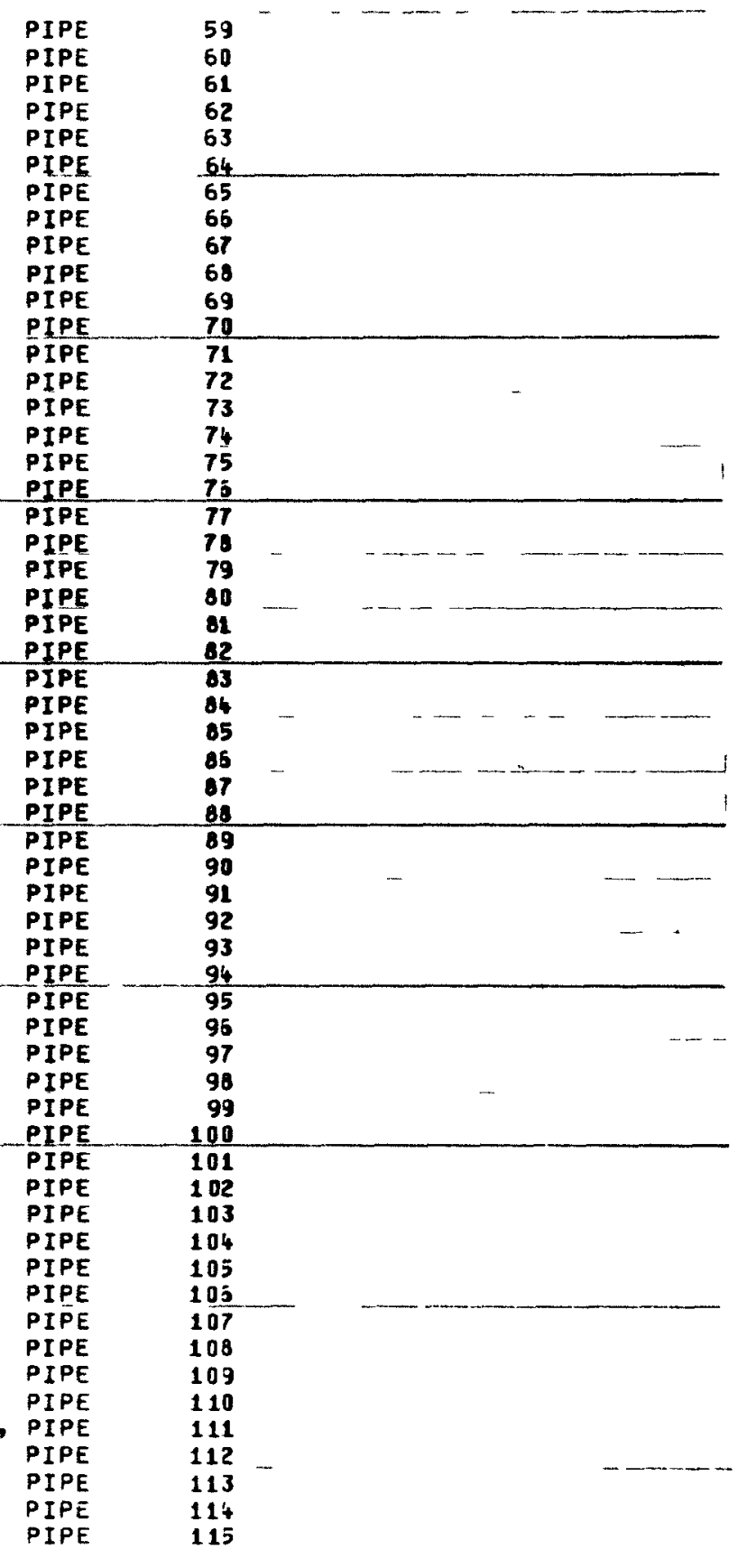


115

TSAV2B STEPS BACK ON TML,F.

COOLANT TEMPEZATURE AT STAET OF PIFE AT FREVIOUS TIME-THO PIPE STEPS BACK ON TME,F

TSURF

$T X$

UAPA

VOLNA

WHATE

WSAV

WTC

$X 01$

$X 01$
$X D 2$

$x 02$
$\times 03$

$\times 03$

$X 04$

X XINSUL

INSULATIGN SURFAC

OF OYEKALL U AND SURFACE, BTU/(SEG-FI)

UA PRODUCI FOR HEAT TRAVSFER FROM FIPE NODE TO AMBIENT, BTU/ (SEC-F)

VOLUME OF SOOIUM NODE, CUFT.

SODIUH =LOW RATE,LB/SEC. (AS USED IN PIPE SUBFOUTINE)

FLOW RATE AT PFECEEOING TIME OF MAIN PFOG. L L BSEC.

HEAT STORAGE IERM,BTU/F,

WEIGHT OF PIPE WALL NDOE, LBS.

SODIUM FLOW RATE,LB/SEC. (AS USEO IN MAIN PROGRAM)

SOOIUM FLOW RATE,LB/SEO. (AS USED IN PIPE SUBROUTINE)

PIPE ID,FT.

INSULATION IO,FT.

INSULATICN OO,FT.

GAS GAP THIC KNESS BETHEEN PIPE AND INSULATION, IN.

INSULATION THICKNESS, IN.

REAL NO, VALUE OF MUMBE? OF AXIAL NODES.

TEMPORARY SYMBOL FOR COOLANT TEMP., F.

TEMPORARY SYMBOL FOR COOLANT TEMP

TEMPORARY SYMBCL FOR PIPE HALL TEMP. OF

TEMPORARY SYMBOL FOR PIOË WALL TEMP..,F.

PUNCHED CARO JUTPUT. Y IS EQUIVALENCED TO LALELEOUS IPIPE3\%.

FOR LXAMPLE...

(Y $(I, J), I=1,53, J=1,2)$ ARE VALUES FOR $A$.

(Y) (I, 21$), I=1,531$ ARE VALUES FOR XNODES

AN ARRAY FJR JIMENSIONAL CONSTANTS AND INITIAL VALUES

PIPE IPIPEI\%.

FOR EXAMPLE.

$(Z(I, 1), I=1,53)$ ARE VALUES FOR IO

$(2(I, 10), I=1,53)$ ARE VALUES FOR XINSUL TCELL ( 53$),$ TINSUL (53), TSUR,F
TEYC (53), JTYP (53), NODES (53)

A $(2,53), C(2,53), D E L T A X(53)$, OOVRA (53), RESIS $(3,53)$,

PIPE

1

DIMENSION

RHO1 (53), UA $(2,53)$, UAPA (53), UXX (53), UYY (5)

PIPE -HTC $(2,53)$, HTPIPE $(53)$, XD1(53), XNODES (53) PIPE

2

AONE ( 53), ATWOI 53), BONEI 53),BTWOI 53),

CONE( 53),CTHOI 53), ICALC 53),NCALC ( 53),

START ( 53), START2( 53), TME ( 53), TSAVIA (53),

TSÄV1B( 53$)$, TSAVZA ( 53$)$, TSAVZB( 53 ), TX(2, 9,53),

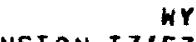
53

DI MENSION I Z $(53,3), Y(53,21), Z(53,10)$

EQUIVALENCE $(I D, Z)$, (JEND,IZ), (A,Y)

EQUIVALENCE (OD, TSAVIA), (ID, TSAVIB), (LNTH, TSAVZA),

1 (XINSUL, TSAV2B), (T INSUL, START), (TSURF, START2),

2 (XGAP, ICALC), (NODES, NCALC)

REAL IO, KINSUL, LNTH, MAXSTP

GATA PIOVR $4 / .785398 /, P I / 3.14159 \%$ 
SUBROUTINE PIPE $\quad 74 / 74 \quad$ OPT $=1 \quad$ FTN $4.2+74351 \quad 04 / 03 / 75 \quad 13.35 .29$.

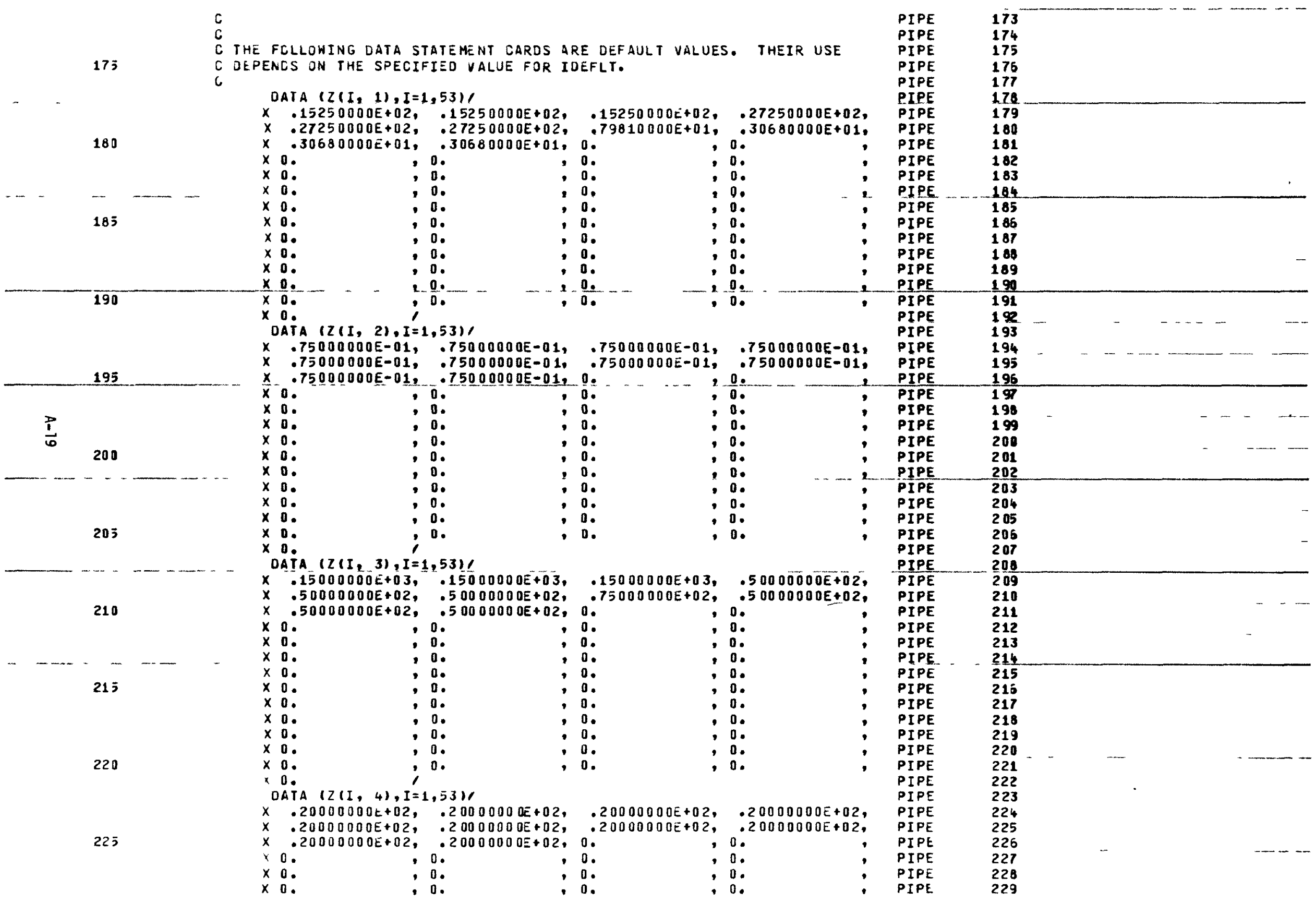




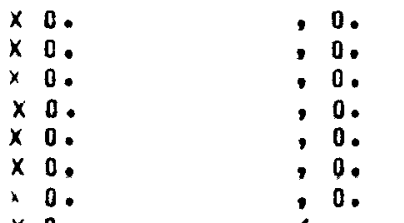

0
0
0
0
0
0
0

, 0.

0.

: 0 .

: 0 .

$: 0$.

DATA $(Z(I, 5), I=1,53)$,

$.16000000 E+02, .16000000 E+02, .10000000 E+02, .28000000 E+02$, $\times .28000000 E+02, .28000000 E+02, .86250000 E+01, .35000000 E+01$, $X .35000000 E+01, .35000000 E+01$,<smiles>[Y]</smiles>

$x=$

$x=0$

245

$\begin{array}{ll}x \\ x & 0 . \\ x & 0.0\end{array}$

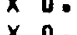

$x$

$x \quad 0$.

$x$ a.

$\begin{array}{ll}x & 0 \\ \times & 0 \\ x & 0\end{array}$

: 0 .

0 .

DATA

$I=1,53)$,

10.

: 0 .

ATA $12(I, 6)$,
$.10000000 E+0$

$10000000 E+03, \quad 10000000+03$,

.10000000E+03, $10000000 E+03,0$

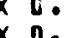

$x 0$.

$: 0$

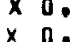

10.

$x \times$

- 0 .

260

265

$x 0$.

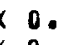

$x=0$

$x$ D.

, 0 .

$x$ o.

i.

, 0 .

$\therefore 0$.

0.

0.

o.

0.
0.
0.

, 0

10.

: 0.

, 0.

, 0.

: 0

; 0 .

, 0.

: 0 .

i.

10

, 0 .

- 0 .

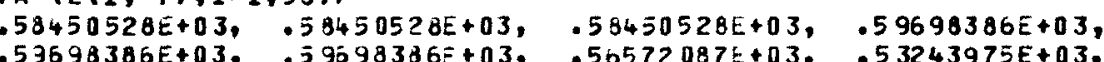
$x .53698386 E+03, .59598386 E+03$,

270 $x .53243975 E+03, .53243975 E+03$,

10.0

$\times 0.00$

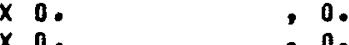

:

275

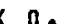

$\times 0$.

$x \quad 0$

$x$
$\times$

- 0.

, 0.

$x 0$.

,

X.

$; 0$

$10000000 E+03, \quad 10000000 E+03$, $10000000 E+03, .1000000 E+03$, 0 .

D. $(2(I, B), I=1,53)$

$X .22492235 E+03, \quad .22492235 E+03, \quad .22492235 E+03, \quad .22937383 E+03$, $X .22937383 E+03, .22337383 E+03, .21854242 E+03, .20805760 E+03$,

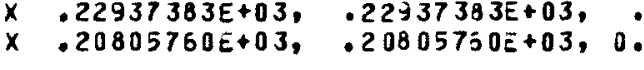

, $0 . \quad, 0$.

(

(

, o.

, 0

- 0 .

- 0

0

: 0 .

0

, 0 .

:

:

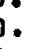

.

.

280

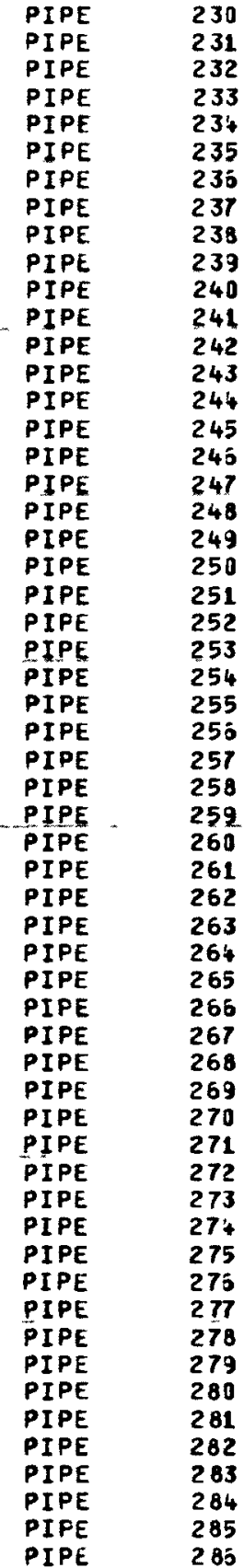


SUBROJTINE PIFE $74 / 74$ OPT=1 FTN $4.2+74351 \quad 04 / 03 / 75 \quad 13.35 .29$.

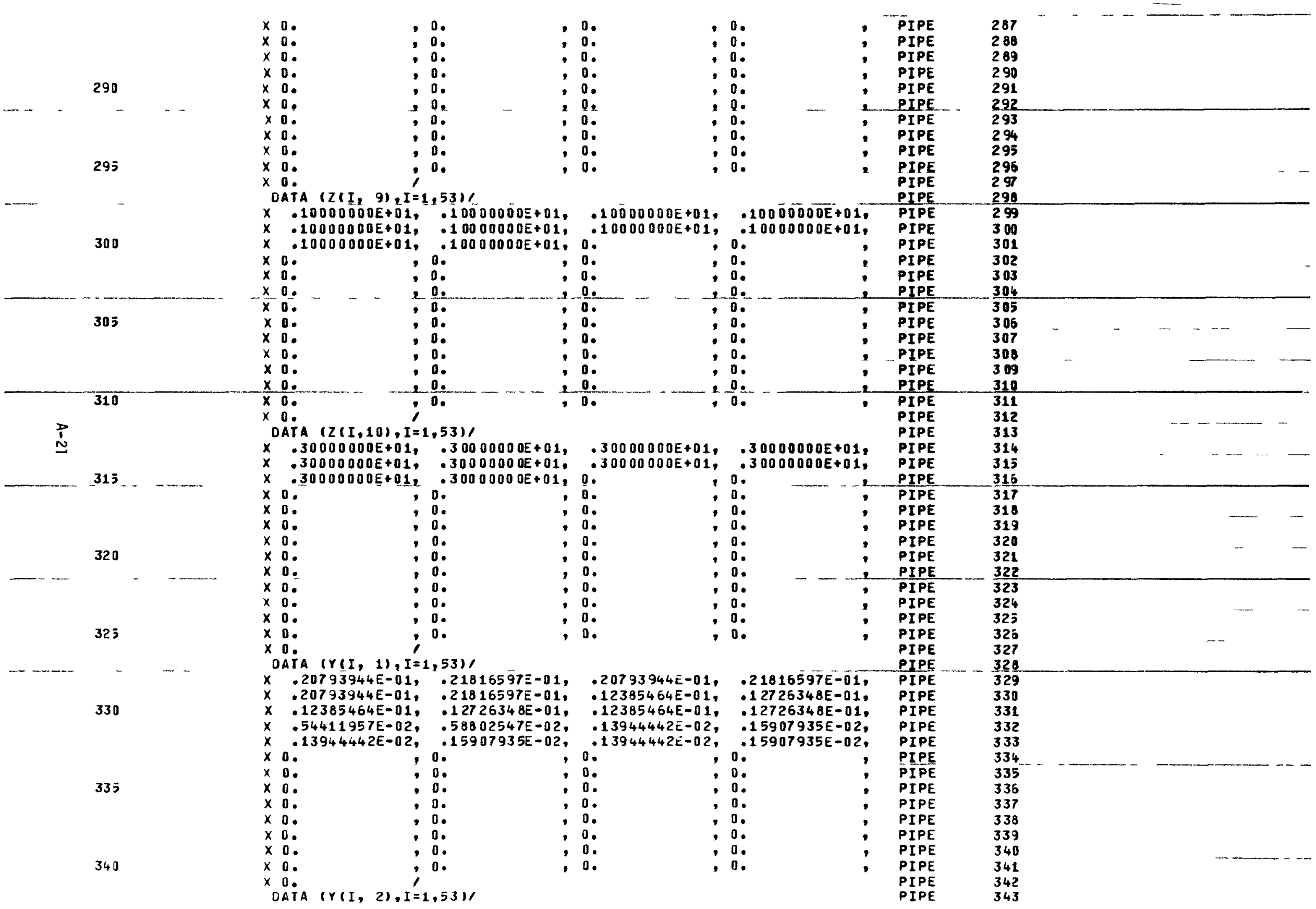




\begin{tabular}{|c|c|c|c|}
\hline $\begin{array}{ll}x & 0 . \\
x & 0 \\
x & 0 . \\
x & 0 . \\
x & 0 . \\
x & 0 . \\
x & 0 . \\
x & 0 . \\
x & 0 . \\
x & 0 . \\
x & 0 \\
x & 0 . \\
x & 0 .\end{array}$ & 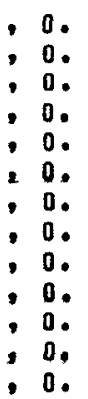 & 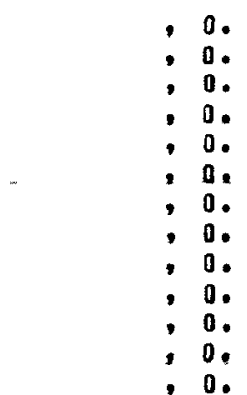 & $\begin{array}{ll}1 & 0 . \\
: & 0 . \\
: & 0 . \\
: & 0 . \\
: & 0 . \\
: & 0 . \\
: & 0 . \\
: & 0 . \\
: & 0 . \\
: & 0 . \\
: & 0 .\end{array}$ \\
\hline
\end{tabular}

0 .

. 0 .

DATA $(Y(I, 3), I=1,53)$,

$.13625000 E+00,030060000 E+00$,

.30060000E+00, .13625000E+00, .30060000E+00,

उ3006000E+DO, $13625000 E+00$,

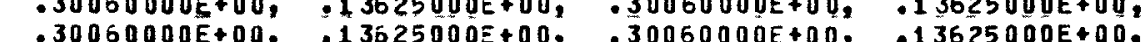
$.30060000 E+00, .13625000 E+00, .30060000 E+00, .13625000 E+00$, $x 0$.

365 0. $x 0$.

$x$

0.

0.

$x=$

$:$ :

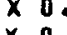

$\begin{array}{rl}x & 0 \\ x & 0\end{array}$

20.

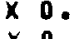

$\therefore 0$.

$\times 0$.

, 0 .

DATA $(Y(I, 4), I=1,53)$,

$x 0$. : 0 .

380

$x 0$

$: 0$.

$\begin{array}{ll}x & 0.0 \\ x & 0\end{array}$

$\begin{array}{ll}x & 0 \\ x & 0\end{array}$

$x=0$

$\begin{array}{ll}x & 0 \\ x & 0\end{array}$

i.

$x$

:

$\begin{array}{ll}x & 0 \\ x & 0 \\ x & 0\end{array}$

$\begin{array}{rr}x & 0 \\ x & 0 \\ x & 0\end{array}$

$\begin{array}{ll}x & 0 \\ x & 0\end{array}$

$\begin{array}{rl}x & 0 \\ \times & 0 \\ & 0\end{array}$

$: 0$ :

$: 0$.

$\times 0$

- 0.

- 0

1.

0.

:

: 0 .

$: 0$

, 0

: 0.

;

io.

: 0 .

:

:

DATA (Y $(I, 5), I=1,53)$,

: 0.

: 0 .

0

0

0.

- 0 .

- 0 .

- 0 .

i.

:

0 .

: 0

: 0

, 0.

$: 0$.

:0.

0 .

, D.

,

$: 0$.

,

i.

$x+18750000)^{\circ}, 1=1$

$.62500000 E+01, \quad .62500000 E+01$,

$x \quad .62500000 E+01, \quad .62500000 E+01$,
$x \quad .62500000 E+01, .625000000+01$,

390

$x+$

$x 0$.

395

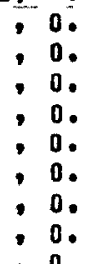

$18750000 E+02$, $.62500000 E+01$
$.62500000 E+01$ 0 .

; 0 .

$\begin{array}{ll}x & 0 \\ x & 0\end{array}$

$x 0$.

$x \quad 0$.

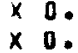

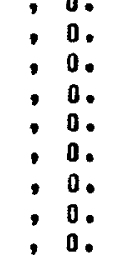

: 0 .

$: 0$.

, 0 .

0.

: 0.

, 0 .

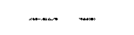

PIPE 344

PIPE 345

$\begin{array}{ll}\text { PIPE } & 346 \\ \text { PIPE } & 347\end{array}$

PIPE 348

PIPE 343

PIPE 351

PIPE 352

PIPE 353

PIPE 354

PIPE 355

PIPE $\quad 356$

$\begin{array}{ll}\text { PIPE } & 357 \\ \text { PIPE } & 358\end{array}$

PIPE 35

PIPE 360

PIPE 361

PIPE 362

PIPE 363

PIPE 365

PIPE

PIPE

PIPE

PIPE 369

PIPE 371

PIPE 372

$\frac{\text { PIPE }}{\text { PIPE }}-\frac{37}{37}$

PIPE 374

PIPE 375

PIPE 377

PIPE 37

$\frac{\text { PIPE }}{\text { PIPE }}-379$

PIPE 38

PIPE 382

PIPE 383

IPE 38

PIPE -

PIPE 386

PIPE 387

PIPE 380

PIPE 390

IPE 39

PIPE 392

PIPE 393

PIPE 394

PIPE 395

PIPE 396

PIPE -

PIPE 
$\begin{array}{llllll}\text { SUBROUTINE PIPE } & 74 / 74 & \text { OPT }=1 & \text { FTN } 4.2+74351 & 04 / 03 / 75 & 13.35 .29 .\end{array}$

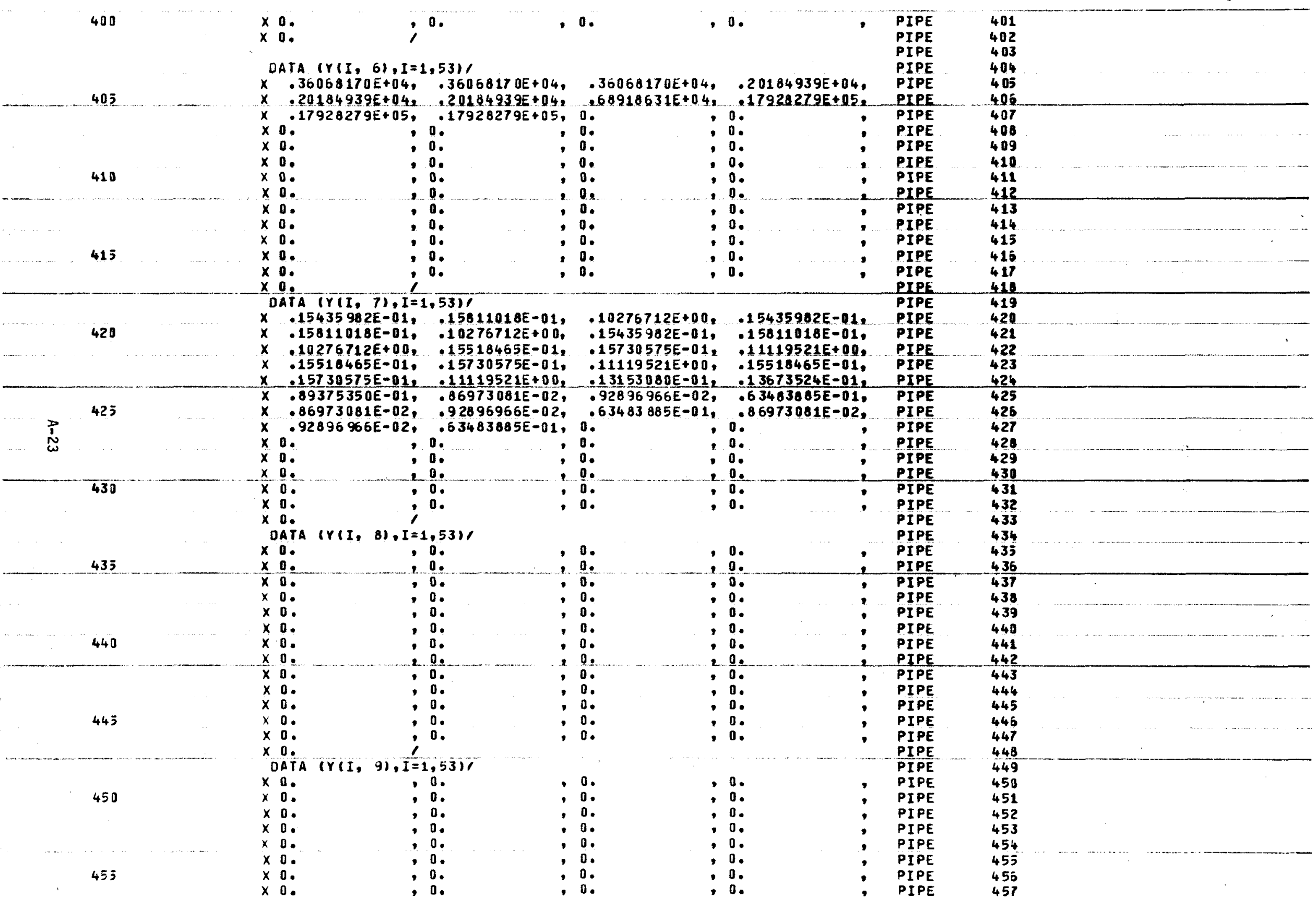




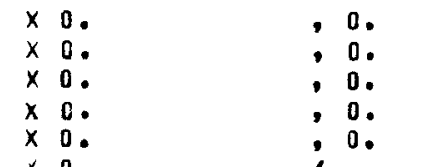

$\begin{array}{ll}1 & 0 . \\ : & 0 \\ : & 0 . \\ 0\end{array}$

, 0.

0.
0.
0.

PIPE $\quad 458$

$x$ x

0

TA (Y I I 10), I $=1,53)$,

$x \quad .51389150 E+02, .51389150 E+02, .51389150 E+02$,

$x \quad .51389150 E+02, .51389150 E+02, .51383150 E+02$, $\times \quad .51389150 E+02, .51389150 E+02$, $x \quad 0$

$x$

, 0.

i.

$\times 0$.

:

$x+0$.

, 0 .

$\begin{array}{ll}x & 0 \\ x & 0\end{array}$

0.

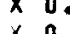

$x$

$x=0$

$x=0$

0.

:.

$\rightarrow 0$

, 0 ,

, o.

, 0 .

, 0.

0.

: 0 .

$.13972398=+02$.

, 5311

1590705E-01, .13972398E+02, .15907053E-01, $.64272398 E+02, \quad .15907053 E-01, \quad .6+279684 E+01, \quad .85764420 E-02$, $.42368430 E+01, .85764420 E-02, .64279684 E+01, .85764420 E-02$, $X: 14453925 E+01, \quad 18797033 E-02, \quad 14453925 E+01, \quad 18777033 E-02$, $x 0$

0 .

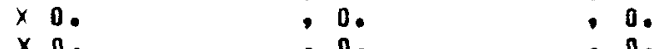

$\because 0$.

$x \quad 0$

:.

$x$ O

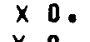

$x \quad 0$

, 0 .

$\times 0$.

, 0 .

$\therefore 0$.

$\because 0$.

, 0 .

OATA $(Y(I, 12), I=1,53)$

$\begin{array}{ll}x 0 . & , 0 . \\ x 0 . & 0 .\end{array}$

$x$ D.

$\begin{array}{ll}x \\ x & 0 \\ x & 0 \\ x & 0\end{array}$

, 0.

$\times 0$.

- 0.

$x \quad 0$

- 0.

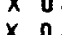

- 0 .

- 0 .

$x \quad 0$

$x=0$

$x$
$x$

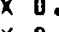

- 0 .

, 0 .

- 0 .

, 0

- 0.

- 0 .

$: 0$.

$0 . \quad, 0$.

(7)

, o. 0

:0.

, 0 .

- 0 .

, 0 .

, 0 .

: 0 .

- 0 .

- 0 .

: 0 .

: 0 .

, 0 .

:

:0.

i.

10

, 0 .

$: 0$.

:0.

: 0 .

: 0 .

$.73436626 E-02, \quad .73436626 E-02, \quad .73436626 E-02, .38404939 E-02$, $X .38404339 E-02, .38+04939 E-02, .23788332 L-02$,

$x .97548826 E-03, .97548826=-03,0$.

, 0.

$\times 0$.

$: 0$.

: 0 .

0.

: 0 .

$97548826 E-03$,

$51389150 E+02$,

PIPE

PIPE

PIPE

IPE

PIPE

PIPE

PIPE

IPE

PIPE

IPE

PIPE

PIPE

PIFE

PIPt

PIPE

IPE

PIPE

PIPE

PIPE

PIPE

PIPE

PIPE

PIPE

PIPE

PIPE

PIPE

PIPE

PIPE

PIPE

PIPE

PIPE

PIPE

PIPE

PIPE

PIPE

PIPE

PIPE

PIPE

PIPE

PIPE

PIPE

PIPE

PIPE

PIPE

PIPE

PIPE

PIPE

PIPE

PIPE

PIPE

PIPE

459
460
460
461
462
463
464
467
465
467
468
469
470
471
472
473
474
473
47
476
477
478
479
480
480
481
482
483
484
48

474

478
479

491
492

493

494
495

495

499

502

50

505

506
507

508

509

511

512

514 


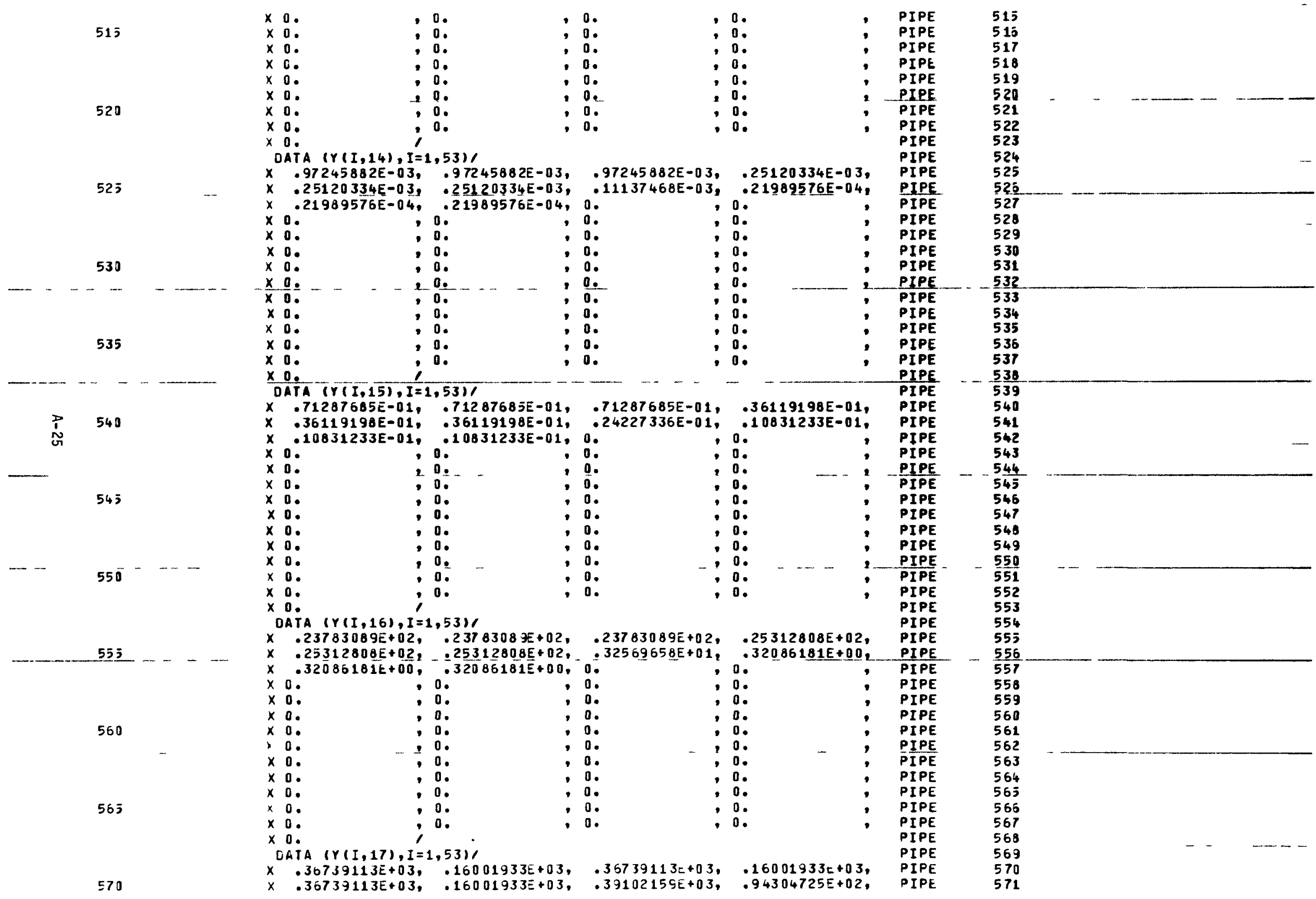


$x .33102153 E+03, .34304725 E+02, .39102159 E+03, .94304725 E+02$, $\times 50312235 E+02, \quad .36507498 E+02, \quad .43565386 E+01$,
$\times \quad .64573867 E+01$,

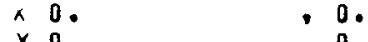

$x=0,0.0$

$x \times 0$.

$x \times$

10

$x$

$: 0$

$x=0$.

$\therefore$ :

$\times 0$

, 0 .

$\times 0$.

$\therefore 0$

- 0 .

0 .

$: 0$.

: 0.

0 .

\begin{tabular}{l}
10 \\
$: 0$. \\
\hline
\end{tabular}

0.04

DATA $(r(I, 18), I=1,53)$ )

585

$\begin{array}{ll}0 . & 0 .\end{array}$

$\begin{array}{ll}\times 0 . & : 0 . \\ \times & 0.0\end{array}$

$\times 0$.

$\times 0$.

0.

$x 0$.

: 0 .

590

595

$\times 0$.

$\begin{array}{ll}x & 0 \\ \times & 0 \\ x & 0\end{array}$

0 .

0 .

$\begin{array}{rr}x & 0 \\ \times & 0\end{array}$

$\times 0$.

- 0 .

, 0 .

: 0.

:

$: 0$.

DATA $(Y(I, 19), I=1,53)$ )

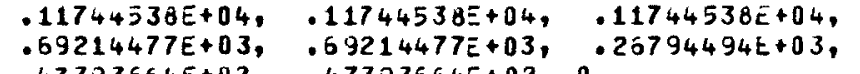

$x \quad .69214477 E+03, \quad .69214477 E+03$,
$x \quad 0.47393664 E+02, \quad .47393664 E+02$,

, 0.

, 0.

0 .

, 0 .

, 0.

, 0 .

, 0 .

, 0 .

; 0 .

, 0 .

0.

0.

0.

$\begin{array}{ll} & 0 . \\ : & 0 .\end{array}$

0.

$x \quad 0$.

$\times 0$.

$x 0$.

- 0 .

- 0 .

- 0 .

$x 0$.

$\times 0$

$\times 0$.

, 0 .

0.

$\times$
$\times 0$.

- 0 .

- 0 .

- 0 .

, 0 .

; 0 .

: 0.

- 0 .

: 0 .

- 0 .

- 0.

0.
0.

0.

0 .

- 0.

o.

$\begin{array}{ll}0 . & 0 . \\ 0 .\end{array}$

- 0 .

0

0

, 0 .

ATA $(Y(I, 20), I=1,53)$

615

620

$.12708333 E+01, .12708333 E+01, .12708333 t+01$,

$. \quad 22703333 E+01, .22708333 E+01, .66508333 E+00$,

$x .25506067 E+00, .25566667 \equiv+00$,

$x=0$

$x 0$.

$x$

$x$ o.

$\times 0$

$\times 0$

$x \quad 0$

$\begin{array}{lll}x & 0 \\ x & 0 & 0\end{array}$

625

$\times \quad 0$.

10.

0 .

0.

0.

- 0 .

- 0 .

- 0 .

, 0 .

0

0 .

$: 0$.

:

$: 0$.

$: 0$.

$: 0$.

: 0 .

: 0 .

$.69214477 E+03$, $.47393664 E+02$. 0.

0 .

, 0 .

, 0 .

0

0 .

0.

0.

PIPE

PIPE

PIPE

PIPE

PIPE

PIPE

PIPE

PIPE

PIPE

PIPE

PIPE

PIPE

PIPE

PIPE

PIPE

PIPE

PIPE

PIPE

PIPE

PIPE

PIPE

PIPE

IPE

PIPE

PIPE

PIPE

PIPE

PIPE

PIPE

PIPE

PIPE
PIPE

PIPE

PIPE

PIPE

PIPE

PIPE

PIPE

PIPE

PIPE

PIPE

PIPE

PIPE

PIPE

PIPE

PIPE

PIPE

PIPE

PIPE

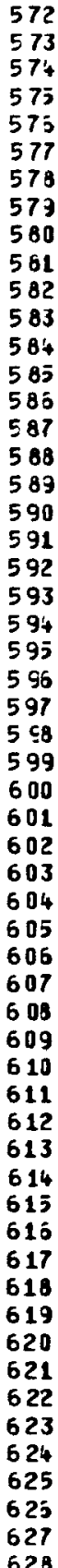


630

640

645

650

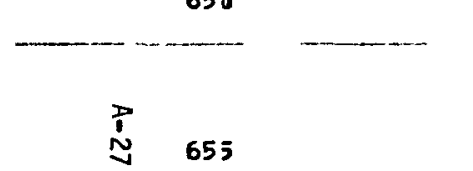

660

DATA $(Y(I, 21), I=1,53)$,

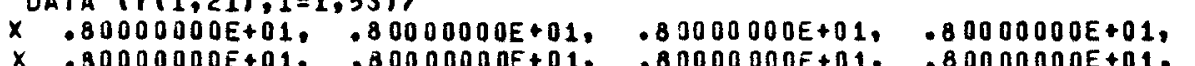
$X .30000000 E+01, \quad 8000000 E+01, \quad .80000000 E+01$, $X 80000000 E+01, .80000000 E+01,0$.

$\times 0.00$

$x$ :

$\times 10$

:

:

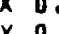

$x$

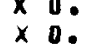

$\begin{array}{lll}x & 0 \\ \times & 0 \\ x & 0\end{array}$

$x$

$x$ o.

0.

10.

- 0 .

, D.

0

$i$

DATA IIZII, 1 ), I $=1,53)$

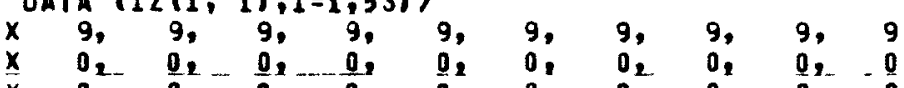

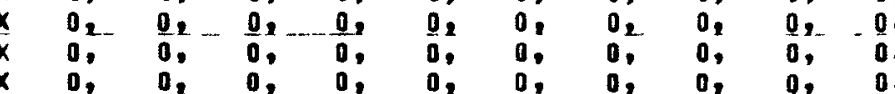

O, O, $0, \quad 0, \quad 0$

DATA (IZII, 2) $I=1,53)$

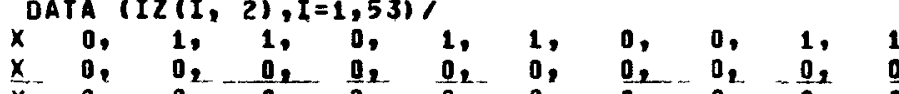

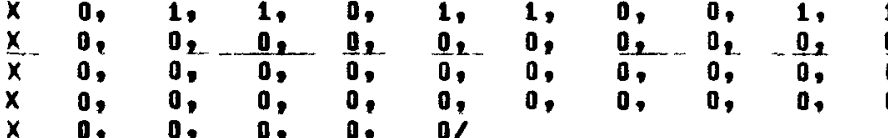

DATA IIZ(I, 3), I =1,53),

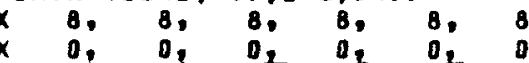

0,0,

0,0

$60 \mathrm{TO}(1,100,300), \mathrm{N}$

C CALCULATE CONSTANTS WHICH ARE INDEPENDENT OF TIME.

$1 J=I D E F L T+1$ $I=I P I P E$

GO TO $(2,2,8055,8050,8060), J$

TME $(I)=0$.

670

C UYY SET TO 1. INITIALLY ONLY TO PREVENT JIVISION BY ZERO THE FIRST C TIME THE UCJEF SUBRJUTIVE IS ENTERED IN CASE THE DEFAULT UYY (I) $=0$ 。 $X N O D=S(I)=F L O A T(N O D E S(I))$ $X[I(I)=I O(I) / 12$.

$X 02=30(1) / 12$

E7j

$X O 4=100(I)+2 * * X G A P(I)+2 \cdot * X I N S U L(I)) / 12$

$X A V=(X 01(I)+X 02)<2$

RESIS $(1, I)=A L O G(X A V / X) 1(I))=X 011(I) / 2$

$\operatorname{RESIS}(2, I)=A L O G(X 02 / X A V) * \times D 2 / 2$.

$X A V=(x O 3+$

KESIS $(3, I)=A L O G(X A Y / X 03) * X 0212$

RESIS4 = ALOG $(X 04 / X A V) * X 04 / 2$.

DOVRA $(I)=3600.1\left(P I J \vee R_{+} * X C 1\right.$ (I)

JENOII $=$ NOOES $(I)+1$
0.

Q.

o.

: 0 .

- 0 .

$: 0$,

$\because 0$.

$: 0$.

, 0 .

PIPE

PIPE $\quad 630$

PIPE $\quad 631$

$\begin{array}{ll}\text { PIPE } & 632 \\ \text { PIPE } & 633\end{array}$

PIPE - 634

PIPE

PIPE

PIPE

PIPE

PIPE

PIPE

PIPE

PIPE

PIPE

$-635$

636

637

636

640

641

642

643

644

PIPE 645

PIPE

PIPE

$-\frac{646}{647}$

648

448

649

PIPE 650

PIPE

$\begin{array}{r}651 \\ 652 \\ \hline 653\end{array}$

653

$\begin{array}{ll}\text { PIPE } & 654 \\ \text { PIPE } & 655\end{array}$

PIPE
PIPE

$\begin{array}{ll}\text { PIPE } & 656 \\ \text { PIPE } & 657\end{array}$

8, 8, 8, 8, 0, 0, PIPE

PIPE

PIPE

PIPE

PIPE

PIPE

PIPE

PIPE

PIPE

PIPE

PIPE

PIPE

PIPE

PIPE

PIPE

PIPE

PIPE

PIPE

PIPE

PIPE

PIPE

PIPE

PIPE

PIPE

PIPE

PIPE

658

659

661

662

663

664

665

665
667

667

668

669

670

672

673

674

675

677

678

679

680

681

683

683

685 
Calculat c constant heat transfer resistance factors fok pipe supface C TO AMBIENT.

$U \times X(I)=U A 3 * U A 4$

$U Y Y(I)=U A 3+U A 4$

$\operatorname{UAPA}(I)=U A(2, I) * U X X(I) /(U X X(I)+U Y Y(I) * U A(2, I))$

IF (I.NE. MAXPIP) RETUKV

PUNCHEO CAKO OUTPUT IF CALLED FJR BY IDEFLT. EY-PASSED IF IDEFLT C EQUALS 0,2 , OR 4 .

$M=I D E F L T+1$

GC TC $(d 050,8002,8050,8004,8050), 4$

8002 WRIT $=(0,8000)$

BUOO FCRMATIIH1, "PUNCHEJ CAFC OUTPUT IS AS FOLLCWS...."1/)

PIPE

PIPE $\quad 686$

PIPE

PIPE

PIPE

PIPE

PIPE

PIPE

PIPE 


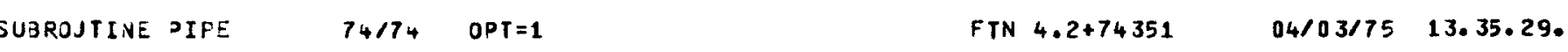

HRITE $(6,8001)$

3001 FORMAT (IX,"CONSTANTS AND INITIAL VALUES PUNCHED CARO OUTPUT.") PUNCH 8001

8004 WKITE $(0,8000)$

BOO3 FORMAT ( $1 X$, INITIAL VALUES ONLY PUNGHED CARO OUTPUT. -$)$ - PIPE PUNCH 3003

$8005008020 \mathrm{~J}=1,10$

IF (IDEFLT.NE.3) GC TO 8006

GC TO $(8020,8020,8020,8020,8020,8005,3006,8006,6020,8020), \mathrm{J}$

BODG WRITE $(0,8011) J$

B011 FCRMAT $(6 x,-$ OATA $(Z(I, \cdots, I 2, \cdots), I=1,53), \infty)$

755

PUNCH $8011, \mathrm{~J}$

WRITE $(6,0012)(Z(M, J), M=1,52)$

B012 FORMAT ( $\left.X X_{1}-X^{-\infty}, E 15.8,-,-, E 15.8,-,-, E 15.8,-, \cdots, E 15.8,-,-\right)$

PUNCH BO $12,(Z(M, J), M=1,521$

WRITE $(6,8013) \quad 2(53, J)$

8013 FORMAT $(5 X,-X=, E 15,8$
PUNCH $B 013, Z(53, J)$

PUNCH BO

$008040 \mathrm{~J}=1,21$

IF (IDEFLT.NE.3) GO TO 8032

(8040,8040,8032,8032,8040,8040,8040,8040,8040,8032,8032 8032 WRITE $(6,8033) \mathrm{J}$

B033 FORMAT (6x, "DATA ( $(I, \infty, I 2, \infty), I=1,53), \infty)$

PUNCH $8033, \mathrm{~J}$

HRITE $(6,8012) \quad(Y(M, J), M=1,52)$

PUNCH $8012,(Y(H, J), M=1,52)$

WRITE $(6,8013) \quad Y(53, J)$

PUNCH $8013, Y(53, J)$

8040 CONTINUE

IF (IDEFLT.EQ.3) 60 TO 8024

DO $6023 \mathrm{~J}=1,3$

HRITE $(6,6015) J$

B015 FORMAT $(6 x,-$ OATA $(12(I,-, 12,-), I=1,531, \cdots)$ PUNCH $8015, J$

HRITE $(6,8016)$ (IZIM,J), $M=1,48)$

8016 FORMAT $15 x, \cdots, \infty, I 4, \infty, \infty, I 4, \cdots, \cdots, I 4, \cdots, \cdots, I 4, \cdots, \cdots, I 4, \cdots, \cdots, I 4, \cdots, \infty, I 4, \cdots, \cdots, I 4$, PIPE $1, \infty, I_{4}, \infty, \infty, 14, \cdots, \infty, I_{4}, \infty, \infty, I_{4}, \cdots, 214$ PUNCH $8016,(I Z(M, J), M=1,48)$

HRITE $(6, B 017)$ (I $2(M, J), M=49,53)$

FORMAT $(5 x,-x=, I 4,-, \infty, I 4, \cdots, \cdots, I 4, \cdots, \infty, I 4, \cdots, \cdots, I 4, \infty, \infty) \quad$ PIPE

8023 CONTINUE

NOTE IHAT INITIAL FLOW RATE AND INLET COOLANT TEMP- 
WFITE $(0,6013)$ WY (53) PUNCH 3013 , WY (53)

FIT $=10.0030)$

303 U FLFMAT(5X, "OMTA (TIV(I), I =1,53), $\cdots$ )

PUNCH 8030

WFITE $(6,8012) \quad(T \times(1,1, M), M=1,52)$

PUNCH $\$ 022,(1) \times(1,1, M), Y=1,52)$

WRIT $\equiv(0,3013)$ T X $(1,1,53)$

PUNGH $8013, T \times(1,1,53)$

1050 RETUKN

C SET UF INITIAL SOOIUM AND FIPE WALL TEMPERATURES IF IDEFLT $=2$

BO5E JTOP JENO(I)

CC $8050 \mathrm{~J}=2$, JTOP

$T \times(1, J, I)=T \times(1,1, I)$

$8056 T \times(2, J, I)=T \times(1,1, I$

$T \times(2,1, I)=T \times(1,1, I)$

C SET UF INITIAL CONDITIONS IF IUEFLT $=3$ OR 4 FOR DEFAULT DIMENSIONAL C GONSTANT VALUES USED.

$8060 \times[3=100(I)+2 . * X G A P(I) / 12$ $X[4=100(I)+2 * * X G A P(I)+2 . * X I N S U L(I)) / 12$. $X A V=(X D 3+X 04) / 2$.

RESIS $4=A L O G(\times D 4 / X A V) * \times 04 / 2$

$A 3=P I * \times 04 / 3600 * 0 E L T A X(I)$

60 Tु 3

C TFANSIENT CALCULATIONS FOLLON-....-

100 CALL UCOEF(TX,WY,IPIPE)

C

C UFDATE TEMPERATURES OF CCOLANT AND PIPE WALL FOR NEXT TME

JTOP=JEVD(IPIPE)

$X X A=W Y\left(I P I P_{E}\right)+C(1, I P I P E)$

C CHLCULATE LIMITING TIYE STEPS FOR NJMERICAL STABILITY.

TAUL =WTO $(2, I P I F E) /(U A(1, I P I P E)+J A P A(I F I P E))+.99$

TAU2 $=.99 * W T C(1, I F I F E) /(10, * A 3 S(X \times A)+U A(1, I F I F E))$

DELTME = AMIN 1 (TAU1, TAU2, MAX3TP(IPIPL)

$X X S=J E L T M E / W I L 11$, IPIPE;

$X X L=U E L T M E / W T(12, I D I D E)$

$X X D=X \times A+X X 3$

$X X E=X X \dot{B} * U A(1, I F[F E)$

$X X F=1.5 * X X A+U A(1, I P I P \equiv)$

CC $230 \mathrm{~J}=1$, JTOF

C UFDATE CUOLANT ANO PIPE WALL TEMPERATUFES.

$M=\operatorname{MOJ}(J, 2)+1$

GC TJ 1202,201$), M$

C I IS LVEN....

$202 \times I 11=T \times\left(i, J, I P I P_{E}\right) *(1,-X X E)+(T \times(1, J-1, I P I P E)-T \times(1, J+1, I P I P L))$

PIFE $\quad 800$

PIPE $\quad 801$

PIPE $\quad 802$

PIPE $\quad 803$

PIPE $\quad 805$

PIPE $\quad 80$

$\begin{array}{ll}\text { PIPE } & 807 \\ \text { PIPE } & 808\end{array}$

PIPE $\quad 809$

PIPE B10

PIPE 811

PIPE 812

PIPE

PIPE 81

$\begin{array}{ll}\text { PIPE } & 815 \\ \text { PIPE } & 816\end{array}$

PIPE 817

$\begin{array}{ll}\text { PIPE } & 818 \\ \text { PIPE } & 819\end{array}$

PIPE $\quad 320$

PIPE 821

$\begin{array}{ll}\text { PIPE } & 622 \\ \text { PIPE } & 823\end{array}$

PIPE $\$ 24$

PIPE 825

PIPE

PIPE

PIPE $\quad 829$

PIFE 830

PIPE 83

PIPE $\quad 832$

PIPE 83

PIPE 635

$\begin{array}{ll}\text { PIPE } & 835 \\ \text { PIPE } & 837\end{array}$

PIPE 838

PIPE

PIPE 840

PIPE B41

PIPE 842

PIPE 843

PIPE $\quad 845$

PIPE 845

PIPE 847

$\begin{array}{ll}\text { PIPE } & 848 \\ \text { PIPE } & 849\end{array}$

PIPE $\quad 850$

PIPE B5I

PIPE $\quad 852$

PIPE 854

PIPE 855

PIPE 855 
SUZROJTINE PIFE $74 / 74$ OPT $=1 \quad$ FTN $4.2+74351 \quad 04 / 03 / 75 \quad 13.35 .29$.

$1 * x \times 0 / 2,+T \times(2, J, I P I P E) * x X E$

60 TO 203

C J IS CDD

201 IF (WYIIPIPE), GE.0.1 GO TO 204

860

C FLOW IS NEGATIVE....

IF (J.EQ.JTOP) GO TJ 203

$X T 11=T X(1, J, I P I P E)=(1,-X X B *(-1.5 * X X A+U A(1, I P I P E)\})+$

$1 \quad(.5 * T \times(1, J+2, I P I P E)-2 . * T X(1, J+1, I P I P E)) * X X D+T X(2, J, I P I P E) * X X E$

$80 ́ 5$

FLOW IS POSITIVE....

204 IF (J.EQ. 1$)$ GO Tj 203

$X T 11=T \times(1, J, I P I P E) *(1 .-X X B * X X F)+(2, * T X(1, J-1, I P I P E)-.5 * T \times(1, \mathrm{~J}-2$,

1 IPIPEI)*XXO+TX(2,J,IPIPE)*XXE

670

$1 T X(1, J, I P I P E) * X X C * U A(1, I P I P E)+T C E L L(I P I P E) * X X C * U A P A(I P I P E)$

IF (J.EQ. 1) GO TO 229

IF (J.EQ.2.AND.WY (IPIPE).GE.0.) GJ TO 228

$T X(1, J-1$, IPIPE $)=X T 1$

875

$228 T \times(2, J-1, I P I P E)=x T^{2}$

$229 \times 11=X T 11$

230 CONTINUE

IF (HY (IPIPE).LT.0.1 GO TO 231

TX $(1, J T O P, I P I P E)=X T 11$ $231 T X(2, J T O P, I P I P E)=\bar{X} T 22$

$\underset{\omega}{\stackrel{p}{\omega}}$

C UPDATE TIME OF PIPE SUBROUTIME FOR ABOVE CALCULATED TEMPERATURES.

C TME (IPIPE) $=$ THE (IPIPE) + DELTME

TME (IPIPE) $=$ THE (IPIPE)+OELTME
ICALC IIPIPE) $=$ ICALC (IPIFE)+1

ICALC (IPIPE) = ICALC (IPIFE)+

IF (NJEBUG.EQ.O) GO TO 236

C

FOALIIPIPE).NE.NCALCIIPIPE) GO TO 236

C REPORT TEMPERATURE AND FLJW OATA IF CALLED FOR BY NDEBUG AND NCALC C REPORTING FREQUENCY.

WRITE(6,9001) TME(IPIPE), IPIPE, WY(IPIPE), TAU1, TAU2, DELTHE,

1 MAXSTP(IPIPE)
9001 FORMAT (1HO, REPORT OF COOLANT AND PIPE HALL TEMPERATURES AT PIPE R PIPE

895 1OUTINE TIME,TME =", F 12.4," SECONDS FOR LEG", I4/10X,"FLOW RATE IS", PIPE $2 F 10,2, \cdots$ LB/SEC. $-110 X,-T A U 1$, TAU2, DELTME, MAXSTP VALUES ARE", 4F 12.6, / PIPE

$3 \%$ PIPE

HKITE $(6,9006)$

9006 FORMATI" 1PERATURE VALUES ARE NOT AT TIME TME AS ARE ALL OTHER VALUES $\% 10 X$ PIPE 2"THE FLOH AND INCOMING TEMPERAT JRE ARE NOT YE 2 THE FLOW ANO INCOMING TEMPERAT JRE ARE NOT YET KNO SIVEN FOR THE PRECESDING TME. WAKGA , TRO $T E(6,3002)$

FCRMATIH,

JTOP=JENO (IPIPE)

WRITE $(0,9003)(T \times(1, J, I P I P E), J=1, J T O P)$

9003 FORMAT IBF 15.2

IF (JTOP.GT.8) JTOF $=8$

WFITE $(5,3004)(T \times(2, J$, IPIPE), J $=1, J T O P)$ 1UAL POINT "/BF 15.21

PIPE $\quad 657$

$\begin{array}{ll}\text { PIPE } & 858 \\ \text { PIPE } & 859\end{array}$

PIPE $\quad 860$

PIPE 861

PIPE $\quad 862$

PIPE

PIPE

PIPE

PIPE

PIPE

PIPE

PIPE
PIPE

PIPE

PIPE

PIPE

PIPE

PIPE

PIPE

PIPE

PIPE

PIPE

PIPE

PIPE

PIPE

PIPE

PIPE

PIPE

864

865

865

867

868

869

870

671

872

873

$-\frac{874}{875}$

875
877

677

879

879

880

881

882

803

884

885

885

867

888
889

890

891

892

893

894

895

896
897

897
896

896
899

900

901

902

902

903
904

905

906

907

908

909

910

911

912

912 
IF $(J=N J(\triangle P I P E), L T \cdot B)$ 30 10 236

$J T \cup P=J=Y D$ (IPIPE)

W. IT $=(0,3005)(T \times(2, J, I P I P C), J=3, J T O P)$

306 E FOFMAT $(8 F 15.2)$

$N C A L O(I P I P E)=N C A L C(I P I P E)+N]=B U S$

920

236 LONTINUE

JTOP $=J E N D$ (IPIPE)

$X A X=5 T A R T$ (IPIFE) -START 2 (IPIPE)

$X E X=I S A V 1 A$ (IPIPE) - TSAV $2 A$ (IPIPE)

$X C X=$ IME (IPIPE) -START (IPIPE)

$X O X=S T A R T$ (IPIPE) **2-START2 (IPIPE) **2

$X E X=X B X / X A X$

$X F X=X D X / X A X$

$X G X=(T M E(I P I F E) * * 2-3 T A K T(I P I P E) * 2) / X C X$

$X H X=T M E\left(I P I P_{E}\right) * 2$

C UFDATE INTERPOLATION COEFFICIENTS.

930

CONE (IPIPE) $=(X E X-(T X(1, J T O P$, IPIPE) $-T S A V I A(I F I P E)) / X C X) /(X F X-X G X)$ $B C N E(I P I P E)=X E X-C O N E(I P I P E)$ F XFX

ACNE (IPIPE) $=T X(1, J T J P, I P I P E)-B O N=$ (IPIP. ) *TME (IPIPE) -CONE (IPIFE)* 1 XHX

$X B X=T S A V 1 B$ (IPIPE) -TSAV 23 (IPIPE)

\section{$X_{E} X=X B X / X A X$}

CTWO(IPIPE) $=(X E X-(T X(1,1, I P I P E)-T S A V 1 B(I P I P E)) / X C X) /(X F X-X G X)$

BTWO(IPIDE) $=X E X-C T W O(I F I P E) * X F X$

AT WO (IPIPE) $=I X(1,1, I P I F E)=d T H O(I P I P E)$ *TME (IPIPE)-CTWO(IPIPE) *XHX

TS AVZA (I PIPE) =TSAVIA (IPIPE)

(IPIPE) $=T S A V I B(I P I P E)$

TSAVIA (IFIFE) $=T X\left(1, J T J P, I P I D_{L}\right)$

TSAV1B (IPIPE) $=T \times(1,1, I P I P E)$

START 2 (I PIPE) $=$ START $(I P I P E)$

ST ART (IPIPE) = TME (IPIPE)

Rt TUKN

c

300 ICALC (IPIPE) $=0$

INITIALIZE INTERPOLATION FORMULA DATA WHICH AKE EQUIVALENCED TO NO C LCNGEF NEEJED INPUT DATA ANO SGM- IVITIAL VALUES.

NCALC (IPIPE) $=1$

START (IIPIPE) $=0$

JTUP=J

JTUP=J_ND (IPIPE)

TSAVIA (IPIPE) $=T X(1$, JTOP, IPIPE)

ISAVZA I PIFE $)=T \times(1, J T O P, I P I P E)$

TSAVIB (IOIFE) $=T \times(1,1, I P I P E)$

TSAV2B (IPIPE) $=T \times(1,1, I P I P E)$

AC NVE (IPIPE) $=T \times(1, J T J P, I P I P=)$

$B C N E(I \supset I P E)=0$.

CONE (IPIPE) $=0$.

AT WO(IPIPE) $=T X(1,1$, I PIPE)

BTWO (IPIPE) $=0$

CTWO(ICIPE) $=J$.

RETURN

CND

\begin{tabular}{ll} 
& \\
PIPE & $91 \%$ \\
PIPE & 915 \\
PIPE & 915 \\
PIPE & 917 \\
PIPE & 913 \\
PIPE & 919 \\
PIPE & 920 \\
PIPE & 921 \\
PIPE & 922 \\
PIPE & 923 \\
PIPE & 924 \\
PIPE & 925 \\
PIPE & 925 \\
PIPE & 927 \\
PIPE & 928 \\
PIPE & 929 \\
PIPE & 930 \\
PIPE & 931 \\
PIPE & 932 \\
PIPE & 933 \\
PIPE & 934 \\
PIPE & 935 \\
PIPE & 935 \\
PIPE & 937 \\
PIPE & 938 \\
PIPE & 933 \\
PIPE & 940 \\
PIPE & 941 \\
PIPE & 942 \\
PIPE & 943 \\
PIPE & 944 \\
PIPE & 945 \\
PIPE & 945 \\
PIPE & 947 \\
PIPE & 948 \\
PIPE & 949 \\
PIPE & 950 \\
PIPE & 951 \\
PIPE & 952 \\
PIPE & 953 \\
PIPE & 954 \\
PIPE & 955 \\
PIPE & 956 \\
PIPE & 957 \\
PIPE & 958 \\
PIPE & 959 \\
PIPE & 960 \\
PIPE & 961 \\
PIPE & 962 \\
PIPE & 963 \\
PIPE & 964 \\
PIPE & 965 \\
PIPE & 965 \\
PIPE & 967 \\
PIPE & 968 \\
PIPE & \\
\hline
\end{tabular}


SUBRUUTINE JEOLF $\quad 74 / 74 \quad$ OPT=1 FTN $4.2+74351 \quad 04 / 03 / 75 \quad 13.35 .55$.

SUBROUTINE UCOEF (TX, HX, I)

C SUJROUTINE OET RMIMES OHYSICAL PROPERTIES UCOEF C SUSROUTINE DETLRMINES OHYSICAL PROPERTIES AND HEAT TRANSFEF COEFFIC- UCOEF

$5 \quad C$ REFER TO PIPE SUBROUTIVE FOR DEFINITION OF SYMBOLS.

COMMON/PIPE1/ TO (53),KINSUL (53), LNTH (53), MAXSTP(53),00 (53), TCELL $(53)$, TINSUL $(53)$, TSUKF
COMHON/PIPE2/JEND $(53)$, JTYP $(53)$, NODES $(53)$

10

1

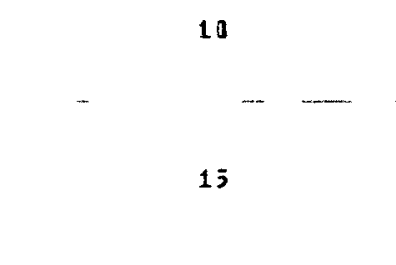

, DOVRA (53), RESIS $(3,53)$, ,WTC $(2,53)$, WTPIPE $(53)$, XD $1(53)$, XNODES $(53)$

DIMEYSION KM(2), TX(2, 9,53), WX(53)

$c$ REAL NUNO,KM,KINSUL, MAXSTP

TPARI IS AVERAGE TEMPERATURE OF SODIUM IN THE FIPE LEG

TBARZ IS AVERAGE TEMPERATJRE OP PIPE WALL IN THE PIPE LEG. C.

20

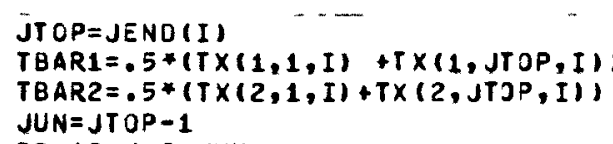

$10 T$ TBAR2 $=T B A R 2+T \times(2, J, I)$

TBAR1 $=$ TBAR1 $/ \times$ NOOESII)

TBAR2 $=$ TBAR2 $\times$ XNODESIII

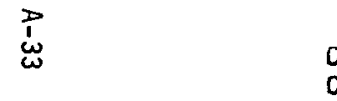

C $C$

CALCULATE PHYSICAL PROPERTIES AYO PARAMETERS WHICH ARE A FUNCTION OF

RHO1 (I) $=59.566-7.950 E-3 * T$ BAR1-.2872E-6*TBAR1**2+.06035E-9*TBAR1**3 VIS $1=10 . * * 11.0203+397.17 /($ TBAR1+459.688) -.4925*ALOG10 (TBAR1+

1 453.68811

$K M(1)=54.306-1.878 E-2 * T B A R 1+2.0914 E-6 * T B A R 1 * * 2$ $C(1, I)=.34574-.79226 E-4 * T$ BAR1+.34086E-7*TBAR1**2 $K M(2)=3.087+.0043 * 1 B A 22$

$C(2, I)=.1175+.00001875 * T B A R 2$

WTC $(1, I)=$ VOLNA $(I) * R H O 1(I) * C(1, I I)$

40 WTC $(2, I)=H T P I P E(I) * C(2, I)$

C CALCULATE SODIUM FILM COEFFICIENT.

RENO=DOVRA (I)*ABS (AX(I))/VISI PFNO $=C(1, I) * V I S 1 / K Y(1)$ PHIS $=$ PHIF (RENO, 0.$)$ IF (PHIS-PRNO) $40,41,41$

40 PSIS $=1$. - PHIS/PRNO GC TO 42

41 PSIS $=0$

42 PENO=RENO*PRNO NUNO $=5.0+.025 *(P S I S * F=N 0) * * .0$ $H I=N U N O^{*} K H(1) / X D 1(I)$

UCOEF

UCOEF

$U C O E F$

UCOEF

UGOEF

UCOEF

UCOEF

UCOEF

UCEF

UCOEF

UCOEF

UCOEF

UCOEF

UCOEF

UCOEF

UCOEF

COEF

UCOEF

UCOEF

UCOEF

UCOEF

UCOEF

UCOEF

UCOEF

COEF

UCOEF

UCOEF

UCOEF

UCOEF

UCOEF

UCOEF

UCOEF

UCOEF

UCOEF

UCOEF

UCOEF

UCOEF

UCOEF

UCOEF

UCOEF

UCOEF

UCEF

UCOEF

UCOEF

UCOEF

UCOE

UCOEF

UCOEF

UCOEF

UCOEF

UCOEF

UCOEF

UCOEF

UCOEF

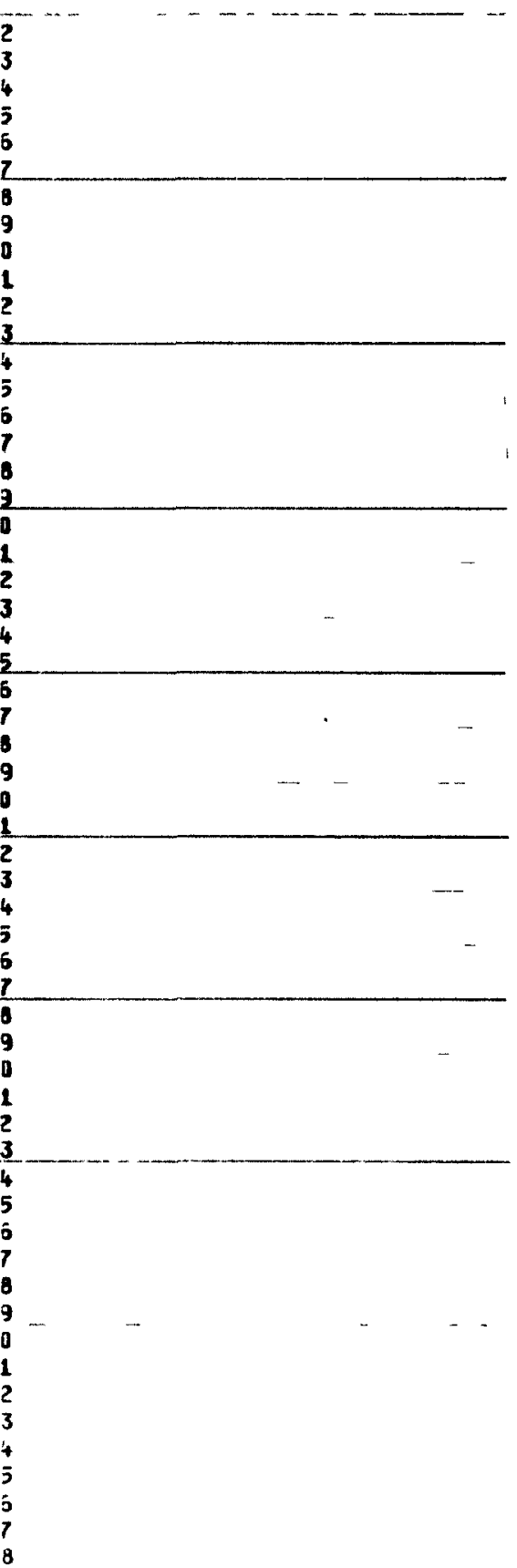


13. 35.55.

$U F(2, I)=1.1(x E S I S\{2, I\} / K M(2)+R E S I S(3, I) / K I\}, S U L(I)) * A(2, I)$ $\operatorname{UAFA}(I)=U A(2, I)+U X X(I) /(U X X(I)+\operatorname{UYY}(I)+U A(2, I))$ KETUKN

UCUEF

UCOEF

UCOEF

USCEF 
UC-79 Basic (204)

UC-79i (20)

ERDA-RL (2)
A. G. Fremling
R. M. Poteat

FFTF-PO (1)

R. L. Ferguson

$\underline{A R D}$ (2)

Dr. L. C. Mackey

W. H. Alliston

HEDL (20)

T. R. Beaver

L. D. Gustafson

J. D. Lodge

H. G. Johnson (6)

R. E. Peterson

R. J. Slember

D. D. Stepnewski

C. D. Swanson

Publications Services (2)

Central Records and Files (5)

* Distributed by HEDL 